\author{
Gregory Ramos Pitta
}

$\mathrm{O}$ balanço de carbono em paisagens tropicais antropizadas

Carbon balance in human-modified tropical landscapes

São Paulo 


\author{
Gregory Ramos Pitta
}

\title{
O balanço de carbono em paisagens tropicais antropizadas
}

\section{Carbon balance in human-modified tropical landscapes}

Dissertação apresentada ao Instituto de Biociências da Universidade de São Paulo, para a obtenção de título de Mestre em Ecologia, na área de Ecossistemas Terrestres e Aquáticos.

Orientador: Renato Augusto Ferreira de Lima

Co-orientador: Paulo Inácio de Knegt López de Prado

São Paulo 


\section{Ficha Catalográfica}

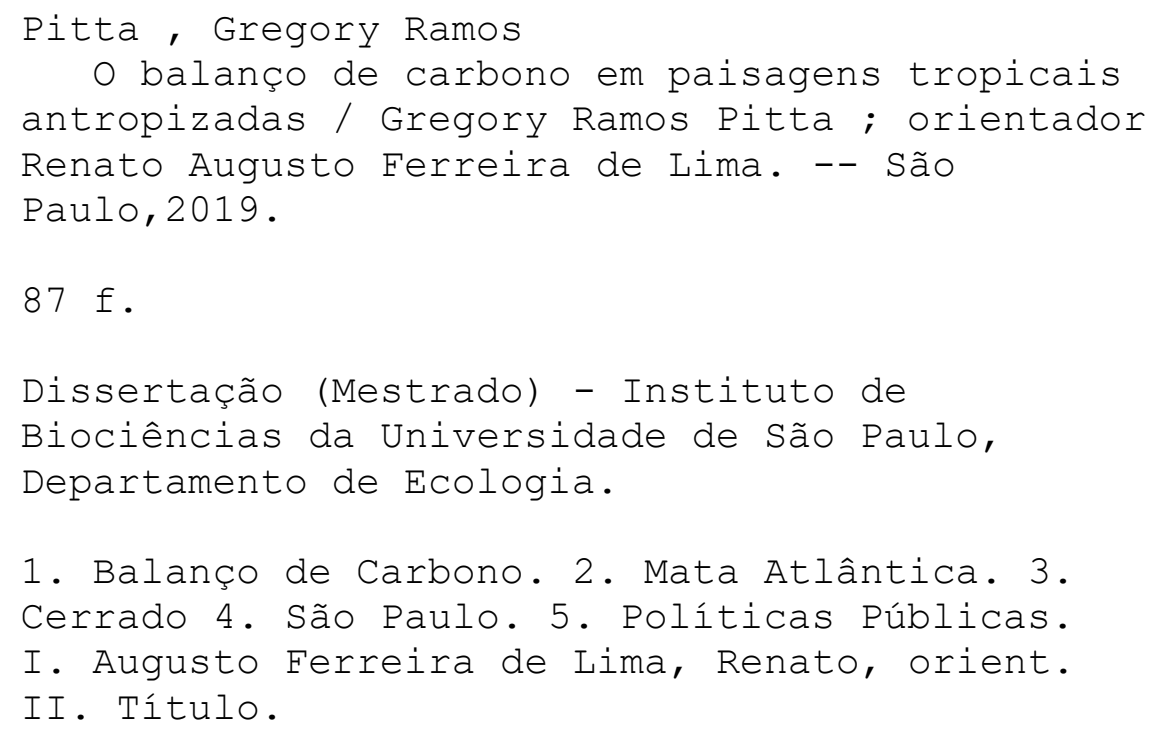

Comissão Julgadora:

Prof. Dr. Renato Augusto Ferreira de Lima 


\section{Agradecimentos}

"O presente trabalho foi realizado com apoio da Coordenação de Aperfeiçoamento de Pessoal de Nível Superior - Brasil (CAPES) - Código de Financiamento 001”

Burocracias à parte, gostaria de agradecer a todos que tomaram café, chás, águas e afins comigo nesses últimos dois anos. Meus agradecimentos, no entanto, são mais do que proporcionais. Alguns cafés foram pontuais e valeram muito, outros foram diários, semanais, alguns por só um mês, apenas um esbarrão na copa, mas por cada um desses momentos eu agradeço, pois você estava lá por mim. Esses momentos, por mais que tenham sido banais, são os que guardo com mais carinho.

Às pessoas diretamente envolvidas na execução desse trabalho:

Ao meu orientador Renato Lima que teve a paciência e disponibilidade infinitas para lidar com minhas limitações, que forneceu conselhos e experiência para mais do que o meio acadêmico. Por ser mais que um orientador, um verdadeiro amigo.

Ao meu co-orientador Paulo Inácio, pelas reuniões semanais e pelo bom humor, palavras de motivação e observações pontuais que mudaram radicalmente a direção do trabalho mais de uma vez.

A Milton Ribeiro e Luiz Magnago que me confundiram com enxurradas de ideias em cada uma das reuniões de comitê de acompanhamento. Mas que com cada confusão, me levaram a ter novas reflexões e foram essenciais na construção desse trabalho.

À Vera Lima que sempre esteve disponível na parte administrativa, cuidando da máquina burocrática que é a USP. Seu conhecimento, agilidade e destreza nos processos fez a diferença incontáveis vezes. 


\section{Índice}

\begin{tabular}{lr}
\hline Introdução Geral & 1 \\
Capítulo Único & 3 \\
Abstract & 3 \\
Introduction & 4 \\
Methods & 5 \\
Results & 12 \\
Discussion & 23 \\
Acknowledgements & 27 \\
Discussão Geral e Conclusões & 28 \\
Resumo & 30 \\
Abstract & 31 \\
Referências Bibliográficas & 32 \\
$\quad$ Introdução & 32 \\
$\quad$ Capítulo único & 33 \\
$\quad$ Discussão Geral & 38 \\
Anexos e Apêndices & 40
\end{tabular}

Appendix 1: Tree community surveys and above ground biomass reference points.

Appendix 2: Basal area, Above Ground Biomass and Carbon relationships. 44

Appendix 3: Co-variables for AGB modeling 49

Climate Co-variables $\quad 49$

Soil 49

$\begin{array}{ll}\text { Soil Co-variables } & 49\end{array}$

Terrain Co-variables $\quad 50$

$\begin{array}{ll}\text { Vegetation Co-variables } & 50\end{array}$

Processing and selection of explanatory variables included in the model $\quad 50$

Linear mixed-effect models $\quad 51$

Appendix 4: Interpolation of AGB in a pre-colonial scenario 53

Appendix 5: Municipal data table $\quad 58$

Appendix 6: List of studies containing forest inventories $\quad 71$

Appendix 7: List of R packages used $\quad 85$ 


\section{Introdução Geral}

Desde a Rio92 (CORDANI et al., 1997) ao acordo de Paris na COP-24 (UNFCCC, 2018), passando pelos marcos dos protocolos REDD e REDD+ (PHELPS et al., 2010), a comunidade científica, civil e tomadores de decisão se debruçam sobre o tema que interliga a ecosfera, economia e sociedade: lidar com a emissão de gases de efeito estufa na atmosfera e minimizar mudanças climáticas. O carbono é a moeda corrente ao quantificarmos emissões, estoques e impactos humanos, e realizar um balanço de carbono em paisagens tropicais é um desafio e uma necessidade. Focamos aqui no balanço para o carbono estocado na vegetação nativa, uma vez que essa vegetação abriga os maiores estoques acessíveis de carbono terrestre do planeta (FAHEY et al., 2009).

Nos trópicos em particular, as florestas costumam conter elevados estoques de biomassa, e consequentemente, de carbono (FEARNSIDE, 2000; POTAPOV et al., 2017). Tratando-se de estoques de carbono florestais, sabemos que quando a floresta é derrubada, o carbono estocado acima e abaixo do solo em folhas, galhos troncos e raízes é gradualmente liberado na atmosfera. Como consequência, o desmatamento passa uma das principais fontes de emissão de de carbono na atmosfera (VAN der WERF et al., 2009). Portanto, evitar a supressão, fragmentação e degradação florestal adquire papel essencial nas metas de contenção das mudanças climáticas (GULLISON et al., 2007).

Estimar os estoques de carbono contidos na vegetação representa em si uma tarefa complexa (GLOOR et al., 2012). Essa tarefa necessita de dados de campo e alguma ferramenta de extrapolação, seja por modelagem, por sensoriamento remoto, ou combinação dessas técnicas (SCOLFORO et al., 2015). Para algumas regiões do planeta, os esforços de mensuração dos estoques de carbono chegam tarde. No Brasil, por exemplo, restam em torno de $11 \%$ a $16 \%$ de cobertura vegetal na Mata Atlântica (RIBEIRO et al., 2009), e pouco menos de 54\% no Cerrado (STRASSBURG et al., 2017). E se as tendências de aumento de desmatamento (INPE, 2017) se realizarem, podemos esperar um cenário parecido para a Floresta Amazônica nas próximas décadas, que já as taxas de desmatamento aumentaram em 29\% no período entre 2012 e 2016 (FEARNSIDE, 2017). 
Neste estudo, combinamos dados de inventários florestais (LIMA et al., 2015) para modelar biomassa em função de variáveis ambientais e de estrutura da paisagem. A partir desse modelo, projetamos um cenário pré colonial, em que pressupomos pouca ou nenhuma influência antrópica nas formações florestais do estado de São Paulo antes da colonização européia (MELATTI, 2007). Assumimos ainda que os dados oriundos dos remanescentes florestais em estágio avançado de sucessão são boas proxies dos estoques de biomassa pré colonial. Esse cenário foi então usado como base para nossa estimativa de carbono atual e também para a estimativa de potencial de recuperação de biomassa no estado com a adequação ao Novo Código Florestal Brasileiro (BRASIL, 2012), levantamos, além do cenário de atendimento aos requisitos da lei, um cenário alternativo e ideal em que recuperamos a degradação dos fragmentos de vegetação existentes. Buscamos, no entanto, estabelecer mais do que estimativas particulares do balanço de carbono para São Paulo. Buscamos pôr em perspectiva, a situação de uma paisagem tropical antropizada, em que a vegetação remanescente está reduzida a ilhas (LAURANCE et al., 2008), que abrange dois biomas hiper-diversos (SCOLFORO et al., 2016) e se repete em outros estados do Brasil, assim como em outras regiões tropicais ao redor do mundo.

Apresento essa dissertação em um capítulo único, que acredito ser suficiente para contar a história de forma sucinta: de onde partimos, onde estamos e onde podemos chegar em termos de estoques de carbono no estado de São Paulo, Brasil. Finalmente, discuto as limitações dessa estratégia, a coerência das estimativas dos estoques de carbono com os esforços disponíveis na literatura e, finalmente, as implicações para a conservação e recuperação dos estoques de carbono. 


\title{
Capítulo Único
}

\section{Carbon balance in human-modified tropical landscapes}

\begin{abstract}
Carbon pools around the globe are vanishing due to habitat conversion and degradation, making it essential the estimation of local carbon budgets. The research aimed to estimate the carbon balance of the natural vegetation of a tropical anthropized landscape. We estimate the amount of pre-existing tree biomass above the soil (pre-colonial scenario), how much was lost by human action (deforestation and fragmentation) and how much carbon could be recovered with the compliance to the New Brazilian Forest Code (NCFB). This balance is represented for the state of São Paulo, in its different stages (e.g. carbon inventory map for the original vegetation cover), and is based on field data to associate tonnage values with the estimated inventories. We estimated a pre-colonial above ground biomass (AGB) stock for São Paulo of 4.62 Gigatonnes, of which $87.3 \%$ (3.85 Gt) were lost. These losses were attributed to $90 \%(3.46 \mathrm{Gt})$ to deforestation, and $10 \%(0.39 \mathrm{Gt})$ to the effects of fragmentation. The legal vegetation deficits stipulated by the NCFB translate into a potential recovery of $0.11 \mathrm{Gt}$ of AGB. If we were to reduce degradation in forest fragments as well, then the potential AGB recovery would triple $(0.37 \mathrm{Gt})$. Our approached allowed the identification of current biomass hotspots and of regions with the greatest potential for carbon recovery. Finally, we discussed the viability of using compensation mechanisms to mitigate restoration costs. For our study area, 0.96 to 2.79 billion US\$ would be required to restore the legal deficit of vegetation, an amount that is feasible as long as carbon markets are willing to pay a minimum of 17.5 US\$ for ton of fixed carbon.
\end{abstract}

\section{Key-words}

1. Carbon balance 2. Atlantic Forest 3. Cerrado 4. São Paulo 5. Public policy 


\section{Introduction}

Forest carbon stocks are particularly abundant in the tropics (GULLISON et al., 2007), and much work has been put in estimating the status of current stocks (HUGHTON, 2005; ENGLUND et al., 2017), which is a particularly difficult task given a series of uncertainties associated with methodology and precision of carbon estimates (MITCHARD et al., 2013). Despite of these difficulties, it represents a paramount task, since forest carbon storage is one of the most accessible and dynamic pools of carbon on earth (FAHEY et al., 2009). Thus, its estimation opens the possibility for developing a highly efficient strategy of carbon sequestration (CHAZDON et al., 2016), contender of solid plan for counteracting climate change (IPCCC, 2018).

If we look at the forest carbon balance in any highly anthropized tropical landscapes - we make use of the São Paulo state in Brazil as a starting point here human development associated with the evolution and dynamicity of its legal framework (MUELLER, 2016; CPI, 2016, 2018) led to a great loss of natural vegetation cover. In São Paulo, this sustained habitat conversion resulted in the very little amount of remaining natural vegetation seen today (RIBEIRO et al., 2009; STRASSBURG et al., 2017). In addition, the remaining habitats often correspond to isolated islands of disturbed vegetation (LAURANCE, 2008), which are affected by the surrounding landscape and fragmentation processes (MESQUITA et al., 1999). Conserving the remaining natural vegetation is key to avoid extra emissions of carbon into the atmosphere, and restoration is thus an effective way to sink carbon from atmosphere, while enhancing ecosystem services and species preservation (REZENDE et al., 2018).

Efforts to estimate carbon balances generally concentrate in relative short term emissions (past 10 to 20 years) resulting from deforestation (HANSEN et al., 2013; PÜTZ, et al., 2014; TYUKAVINA et al., 2015). This approach does not take into account that the remaining vegetation is the result of a mix of deforestation and fragmentation processes. On the other hand, in eastern Brazil these processes started more than 500 years ago, when European colonization began (MORELLATO \& HADDAD, 2000), and today those processes can be considered as having leveled off in the region (SOS-MA, 2018). If we can estimate what was the magnitude of the original carbon stocks that pre-date the first satellite images and advanced LIDAR 
techniques (ASNER \& MASCARO, 2014), we may understand how much we can do and expect in the coming years, both in terms of carbon emissions and sequestration from the atmosphere.

The New Brazilian Forest Code (NCFB) (BRASIL, 2012) opened new possibilities such as ex situ compensation (CRAs) (SOARES-FILHO et al., 2016) and payments for ecosystem services (PES) (RUGGIERO et al., 2018). The NCFB also defines minimum standards for natural vegetation, both in Legal Reserves (RL), and Permanent Preservation Areas (APP). Moreover, this new law strengthens the Rural Environmental Registry (CAR), a geo-referenced database of the boundaries, protected areas, and native vegetation occurrence in private rural properties. Brazil has also launched its EN+REDD, reinforcing its commitment to the reduction of deforestation and forest degradation (MMA, 2018). Therefore, we currently have at our disposal the tools needed to assess the current forest stocks define regeneration potential for carbon sequestration and to start thinking what is next (CPI, 2018).

Here we quantify the above ground carbon balance in the highly-modified tropical landscapes of the state of São Paulo, southeastern Brazil. With centuries of history of human impacts, this region combines high levels of habitat conversion and fragmentation with one of the most well-established economies and environmental legislations in the tropics. More specifically, we calculated the carbon balance by estimating pre-colonization carbon stocks, and then by subtracting the losses related to native vegetation loss and fragmentation processes. Besides the estimation of the current carbon stocks, we also quantify the state carbon potential recovery, based on local legislation requirements. Finally, we provide the regions with high priority to conserve carbon stocks (i.e. carbon hot-spots) and the regions with the highest carbon potential for ecological restoration.

\section{Methods}

Our study area was the state of São Paulo, southeastern Brazil, which has a total area of 28.4 million ha, 45.5 million inhabitants and over 257 billion US\$ of GDP in 2017 (IBGE, 2018). It is one of the most well-studied states of Brazil, resulting in extensive scientific databases available (LIMA et al., 2015; FREITAS et al., 2017a). Climate is stratified from the coast to the continental interior with more precipitation climates tending to be oceanic $(\mathrm{Cfb})$ and tropical rainforest (Af) transitioning to humid subtropical (Cfa) and dryer tropical savanna (Aw), according to 
Koppen's classification (ALVARES et al., 2013). Precipitation decreases from the coast to the mainland, and temperature averages ranges from $10{ }^{\circ} \mathrm{C}$ on July to $24^{\circ} \mathrm{C}$ in January (ALVARES et al., 2013). Elevation varies from $0 \mathrm{~m}$ at the coastal line to $2,798 \mathrm{~m}$ at the highest point, but still remain under reasonable latitudinal restriction (OLIVEIRA-FILHO \& FONTES, 2000). São Paulo includes almost 16 million ha $(15 \%)$ of total original area of the Atlantic Forest domain (AF), and 7.5 million ha (4\%) of the total original area of Cerrado, the Brazilian Savanna (IBGE, 2009).

We describe the the carbon balance of São Paulo, in terms of above ground biomass (AGB). Our operational biomass variable was stand basal area which is the most commonly estimate provided in our database of inventories. Based on the inventories that had both basal area $\left(\mathrm{m}^{2} / \mathrm{ha}\right)$ and AGB per se $(\mathrm{Mg} / \mathrm{ha})$, we built an equation to get AGB from basal area and vice-versa. Basal area is a good proxy for carbon estimations (SLIK et al., 2010, BALDERAS TORRES \& LOVETT, 2012), since both basal area and AGB are functions of tree diameter. Here, we found that basal area had a explanation power higher than $84 \%$ of the variation in AGB (Appendix 02).

The carbon balance considered in this study was composed by the following factors:

$$
\text { Current AGB }=\text { Pre-colonial AGB }- \text { Losses of AGB, }
$$

where losses can be broken in:

$$
\text { Losses of } \mathrm{AGB}=\text { Deforestation } \mathrm{AGB}+\text { Fragmentation AGB. }
$$

Besides the estimation of the current AGB stocks, we also considered the long term potential of carbon recovery, given by:

$$
\text { Potential AGB }=\text { Current AGB + FR* (Legal debt AGB })+ \text { Recovered AGB, }
$$

where FR is the average loss of carbon by fragmentation estimated for the study area, which is given by:

$$
\text { FR = Fragmentation AGB/(Pre-colonial AGB - Deforestation AGB). }
$$


Below, we present the steps used to obtain each of the factors of (1) and (3) that comprise the carbon balance. For simplicity, all factors were obtained in Gigatonnes which correspond to $10 \mathrm{e} 15$ grams. All analysis were performed under R environment version 3.5 (R CORE TEAM, 2018), a full list of packages used is listed on Appendix 7.

\section{Pre-colonial AGB}

The estimate of the pre-colonial AGB was based on published forest biomass data obtained from the Neotropical Tree Communities database (TreeCo http://labtrop.ib.usp.br/doku.php?id=projetos:treeco:start). Starting from TreeCo, we first filtered all inventories including biomass estimates conducted in the Atlantic Forest and Cerrado domains. We then performed an additional bibliographic search to retrieve any new and missing inventories in TreeCo, using the same protocols presented by Lima et al., (2015). To standardize data compilation from each inventory (data collection methods, forest information, locality, etc.) we manually checked all forest inventories with coordinates that felt inside the study area or within a $25 \mathrm{Km}$ buffer around the political limits of the state of São Paulo. We ended with 331 (details on Appendix 1) forest inventories (Table 1), that had an estimate of above-ground vegetation biomass (AGB) and their coordinates and forest descriptors verified. 
Table 1: Descriptive statistics of the forest inventories compiled for São Paulo state, Brazil, along with their vegetation type, average above-ground biomass and total sampling efforts ( $\mathrm{N}$ : number of individuals sampled and Effort: total area sampled).

\begin{tabular}{|c|c|c|c|c|}
\hline Biome & Vegetation type (Samples) & $\begin{array}{r}\text { Mean } \\
\text { AGB } \\
\text { (Mg/ha) }\end{array}$ & Total N & $\begin{array}{c}\text { Sum of } \\
\text { Effort (ha) }\end{array}$ \\
\hline Atlantic Forest & Alluvial Forest (16) & 242.35 & 24971 & 6.97 \\
\hline Atlantic Forest & Ombrophilous Dense Forest (126) & 232.05 & 165146 & 123.02 \\
\hline Atlantic Forest & Ombrophilous Mixed Forest (8) & 361.40 & 6343 & 3.5 \\
\hline Atlantic Forest & Pioneer Marine Forest (31) & 159.65 & 41547 & 20.62 \\
\hline Atlantic Forest & Semideciduous Seasonal Forest (116) & 161.13 & 139224 & 101.87 \\
\hline Savanna & Savanna Forest (Cerradão - 22) & 142.29 & 75899 & 25.44 \\
\hline Savanna & Open Savanna (Cerrado - 12) & 63.59 & 52619 & 11.47 \\
\hline TOTALS & 331 & 194.63 & 505753 & 292.88 \\
\hline
\end{tabular}

For each inventory, we obtained different abiotic and biotic co-variables related to energy, water availability, terrain structure, soil quality, forest conditions, and major landscape metrics calculated for $4 \times 4 \mathrm{~km}$ landscapes (full list of variables, can be found at Appendix 3). We performed a variable selection procedure in an attempt to select the those co-variables that were the least correlated and that did not present collinearity between each other (CRABTREE, et al., 2009). We tested the normality of co-variables (log-transforming them whenever needed) and the effects of possible interactions between co-variables. We only tested meaningful interactions that could, within reason, have biological function. Finally, we used a framework based on linear mixed-effects regression models (BATES et al., 2015) to relate biomass estimates for each survey with co-variables (i.e. fixed-effects), while using survey methods, sampling effort and forest domains as random effects (BONAN, 1995; LIMA et al., 2015). After the selection of the best random and fixed-effects model structure, we optimized the following model:

(5) $\quad$ AGB $\sim$ Temperature + Humidity + Solar Radiation * Forest Disturbance Level + Fragment Size * Landscape Aggregation Index (at 4km) + Fragment Shape Index + (1| Vegetation Type)

In this model, Forest Disturbance Level is an ordered and weighted ponderation from heavy, high, medium and low forest disturbance levels. Fragment 
size is the normalized log-transformed area of the forest fragment. The Aggregation Index derived from the proportion of forest in a $4 \mathrm{~km}$ square landscape around the forest inventory (LIMA et al., 2015). The Fragment Shape Index given by the perimeter area relationship of the forest fragment where the inventory was conducted.

Next, we overlaid a hexagonal grid (BIRCH \& BEECHAM, 2007) to the study area and extracted the same explanatory co-variables of (5) to each hexagon (mean values at a spatial resolution of 2,500 ha). To simulate a pre-colonial scenario, we assumed that the whole study area had no major human-related interventions in vegetation conditions and landscape structure. Indigenous populations have been inhabiting the region for the past 8000 prior to european colonization (FIGUTI, 1993), those are still relatively small and very pontual interventions (MELATTI, 2007). In practice, we set all human-related co-variables (i.e. landscape metrics and forest disturbance level) to the best values found on our sample of forest inventories (Figure 1). Although there may have been climate changes in the past 500 years, we assumed that this changes were neglectable, so climate variables were left untouched.

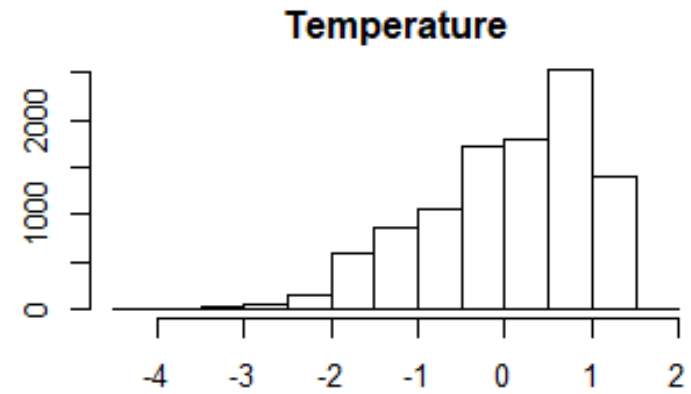

Radiation

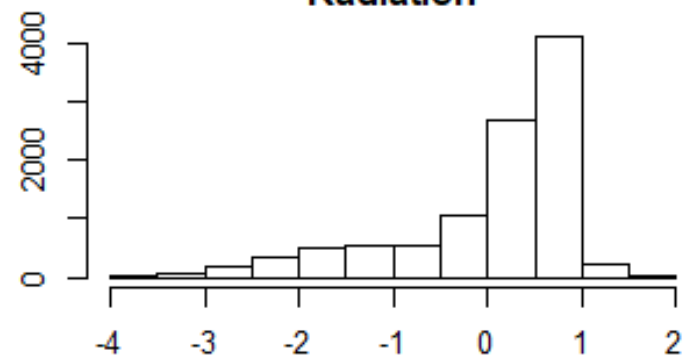

Humidity

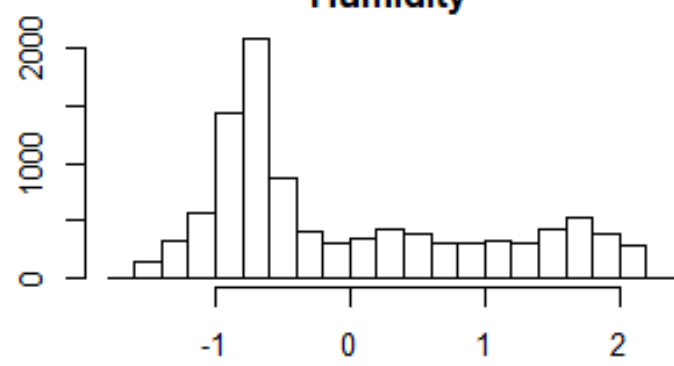

Pre-colonial fixed values

Forest Disturbance Level $=1.347$

Fragment Size $=1.78$

Aggregation Index (at $4 \mathrm{~km})=100$

Fragment Shape Index $=-2.461$

Figure 1: Frequency distributions of the co-variables used on our AGB model in the overlaid hexagonal grid (total of 10,482 cells). All co-variables have been normalized. On the lower right corner are the best values from our TreeCo forest inventory sample, that we attribute to a pre-colonial scenario.

We extrapolated AGB values obtained using equation (5) over the grid with three different methodologies: (i) Linear Mixed Effects Model, with group random 
effects, and spatial correlation between biomass observations, (BATES et al., 2015), (ii) a Geographically Weighted Regression Model (BIVAND \& YU, 2017), and (iii) Auto Kriging (HIEMSTRA et al., 2008; GRÄLER et al., 2016). Thus, we obtained three similar spatial representations of AGB distribution prior to heavy human interventions. The three methodologies were very similar in terms of the total biomass estimated and in their ranges (Appendix 4). For not having to choose one methodology over another (considering SCOLFORO et al., 2015; HARRIS et al., 2010), we opted to present the average of these three methodologies as the final estimates of above ground biomass.

\section{Current AGB}

To obtain current carbon we need to estimate losses related to deforestation, to attain this we masked the pre-colonial carbon estimates with the 2017 natural vegetation remnants from the classification provided by Mabiomas 3.0, classes 1 to 5 corresponding natural remnants of forests, savannas and mangroves (MAPBIOMAS, 2018). Fragmentation effects on carbon stocks were calculated on two steps. First, we considered edge-effects as a linear decreasing intensity of carbon loss from the edge of the forest fragments up to $120 \mathrm{~m}$ (DE-PAULA et al., 2011; CHAPLIN-KRAMER, et al., 2015). Next, we incorporated other fragmentation effects that can permeate to the core of the fragments and also are responsible for additional carbon loss (CHAPLIN-KRAMER, et al., 2015; TYUKAVINA, et al., 2015), such as selective logging, fire (NEPSTAD et al., 1999), large tree mortality (LAURANCE et al., 2000). To incorporate those effects we made use of the size of the fragment core (fragment area excluding edges up to $120 \mathrm{~m}$ ) and long term estimates of the carbon loss (PÜTZ et al., 2014). The first 5-10 years are usually known as the time needed for trees communities to pay biomass debts due edge creation in tropical forests (LAURANCE et al., 1998; PÜTZ et al., 2014), thus we assume that the forest fragments were isolated long enough to have leveled off their carbon losses. 


\section{Potential AGB}

Based on current legislation requirements (BRASIL, 2012) and on available databases of private rural properties (SPAROVEK et al., 2015; FREITAS et al., 2017a; GUIDOTTI et al., 2017) we calculated the legal deficits of forest area cover for the state of São Paulo. These calculations considered the Legal Reserve (RL) and Permanent Preservation Areas (APP) areas around rivers and water springs on rural properties. To attribute values of carbon per hectare we used the cell-specific precolonial AGB in onder to estimate how much carbon can be restored in RL and APP. We assumed that restoration projects are generally lower than 50 ha (SMA-SP, 2018) in total implantation area, which roughly corresponds to the mean fragment size of the São Paulo state remnants (RIBEIRO et al., 2015). Therefore, we used the average percentage of carbon loss from fragmentation in the study area (FR from equation 4) to correct the estimated value of AGB that could be stored in restored RLs and APPs.

We evaluated two potential long term scenarios of carbon stocks for the state of São Paulo: (i) a legal scenario, where all debts of forest area are restored in accordance to the legal compliance (RL and APP are both restored and are subject the same fragmentation effects from current forest fragments); (ii) an ideal scenario, where both RL and APP are fully restored and active measures (DIXON, et al., 1993; ALBRECHT \& KANDJI 2003) are taken increase the carbon storage potential of restored RL and APPs areas as well as existing forest fragments (CHAZDON et al., 2016). In other words, these ideal measures should be capable of reducing edgeeffects and the deterioration of the quality of the core forest (i.e. reversion of withinforest disturbance processes). Thus, this scenario represents a strategy that by increasing only the forest area required by law and by managing the future forest area to obtain carbon storages closer to the pre-colonial estimates. In this scenario, fragmentation effects are still present but are lessened (MURCIA, 1995; LAURANCE et al., 1997). 


\section{Results}

The first step of the São Paulo carbon balance was to estimate the amount of AGB prior to european colonization. The linear mixed effect model with best fit to our biomass data explained $56 \%$ of the variation in forest biomass (conditional $R^{2}$ sensu NAKAGAWA, et al., 2013) (Table 2) and estimated a total of 4.62 Gigatonnes [SE +- 0.19] (10e15g) of above ground biomass for our pre-colonial scenario (i.e. no deforestation or fragmentation effects). Most of this biomass was concentrated along the mountainous regions in the state coast (up to $150 \mathrm{~km}$ inland) (Figure 1A), which correspond to the part of the state which is less seasonal in precipitation and thus mainly covered by lowland to high-altitude rainforests. On the other hand, the regions with lower biomass corresponded to more seasonal areas covered by savannas or on the transition between savannas and seasonal forests. AGB estimates per grid cell average $191 \mathrm{Mg} / \mathrm{ha}$ [SE +-7.97].

Table 2: Parameter estimates of the linear mixed-effects model with best fit to AGB data, used here to estimate the pre-colonial scenario AGB for the state of São Paulo.

\begin{tabular}{|c|c|c|c|}
\hline Parameter & Estimate & Std. Error & $\operatorname{Pr}(>|\mathbf{t}|)$ \\
\hline Intercept & 102.2236 & $(24.26)$ & 0.00 \\
\hline Temperature & -1.1474 & $(0.66)$ & 0.08 \\
\hline Humidity & 3.2961 & $(1.19)$ & 0.01 \\
\hline Radiation & 0.8047 & $(0.59)$ & 0.17 \\
\hline Forest Succession & 5.2032 & $(0.62)$ & 0.00 \\
\hline Fragment Size & 34.8976 & $(15.72)$ & 0.03 \\
\hline Aggregation Index (at $4 \mathrm{~km}$ ) & -0.7592 & $(0.25)$ & 0.00 \\
\hline Fragment Shape Index & 1.6715 & -0.57 & 0.00 \\
\hline Fragment Size: Aggregation Index (at 4km) & -0.3432 & -0.16 & 0.03 \\
\hline Radiation: Forest Succession & -1.2879 & -0.52 & 0.01 \\
\hline
\end{tabular}

The second step of the carbon balance was to calculate the amount AGB lost until present. Based on the 2017 vegetation cover and excluding areas of agriculture and silviculture, we found that only $16.7 \%$ of the original pre-colonial aboveground biomass remains $(0.77 \mathrm{Gt})$ (Figure 1B). This estimate is smaller than to the total natural vegetation cover remaining in the state of São Paulo (21.3\% in area). The AGB losses were mostly due to vegetation cover loss $(3.46 \mathrm{Gt}$, or about $89.87 \%$ of the total AGB losses). The remaining losses were attributed to edge-effects and to the 
deterioration of core natural vegetation quality (i.e. disturbances), accounting for 0.39 Gt (10.12\% of the total AGB losses) (Figure 2). If we discount deforestation from the pre-colonial estimates (i.e. calculating FR in equation 4), then the fragmentation is responsible for losses of $34 \%$ of the carbon in the remaining vegetation fragments in 2017. Which concentrates on the more mountainous region around state parks: Serra do Mar, Carlos Botelho, Ilha bela, Intervales and Alto Ribeira. Hence, the current carbon balance for the state of São Paulo can be expressed as:

(5) Current AGB = Pre-colonial AGB - ( Deforestation AGB + Fragmentation AGB )

$$
0.77 \mathrm{Gt}=4.62 \mathrm{Gt}-(3.46 \mathrm{Gt}+0.39 \mathrm{Gt})
$$



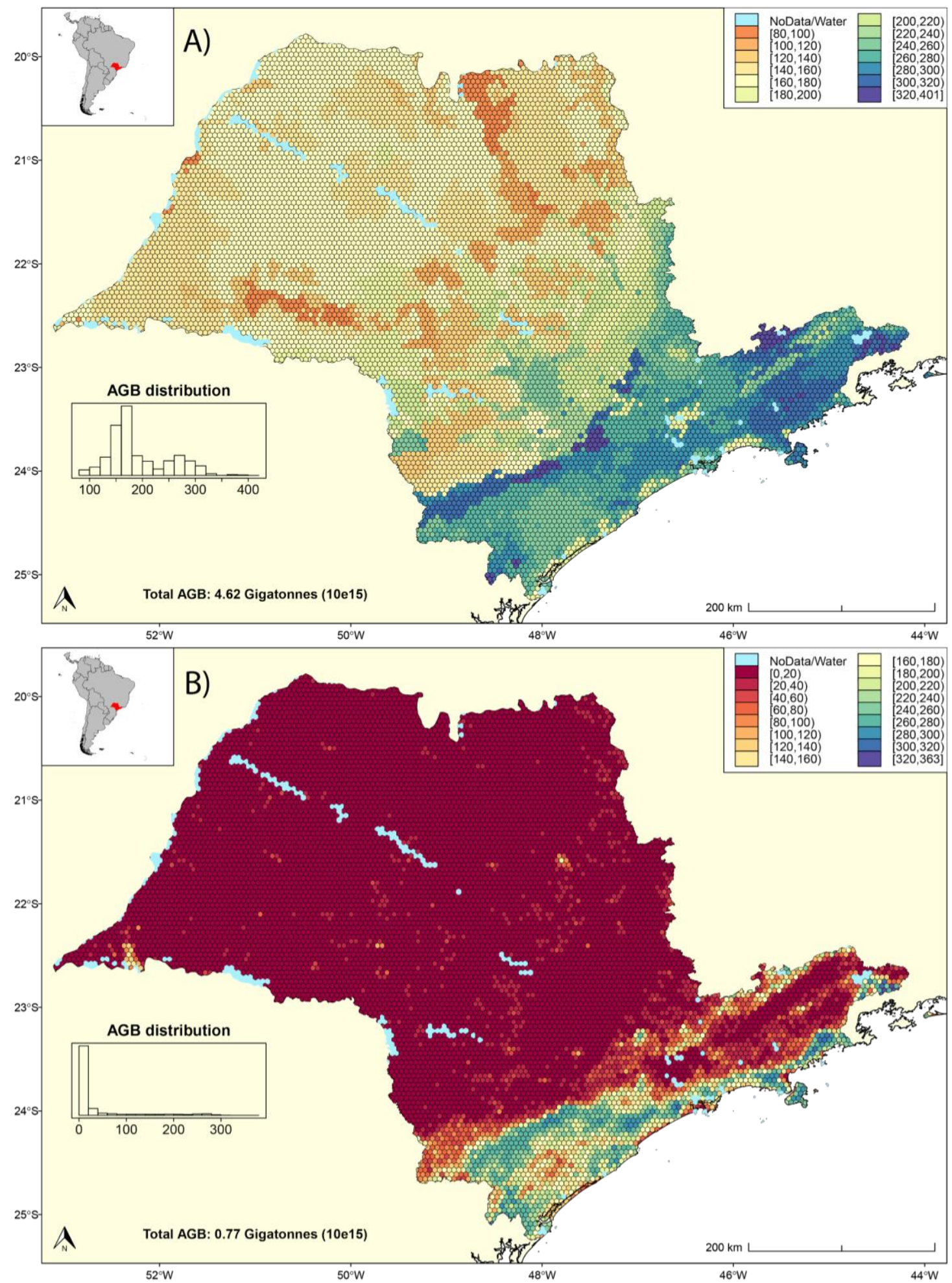

Figure 1: Estimates of the (A) pre-colonial and (B) remaining AGB for the state of São Paulo, Brazil. There are 10482 hexagonal cells and 260 hexagons missing estimations. 

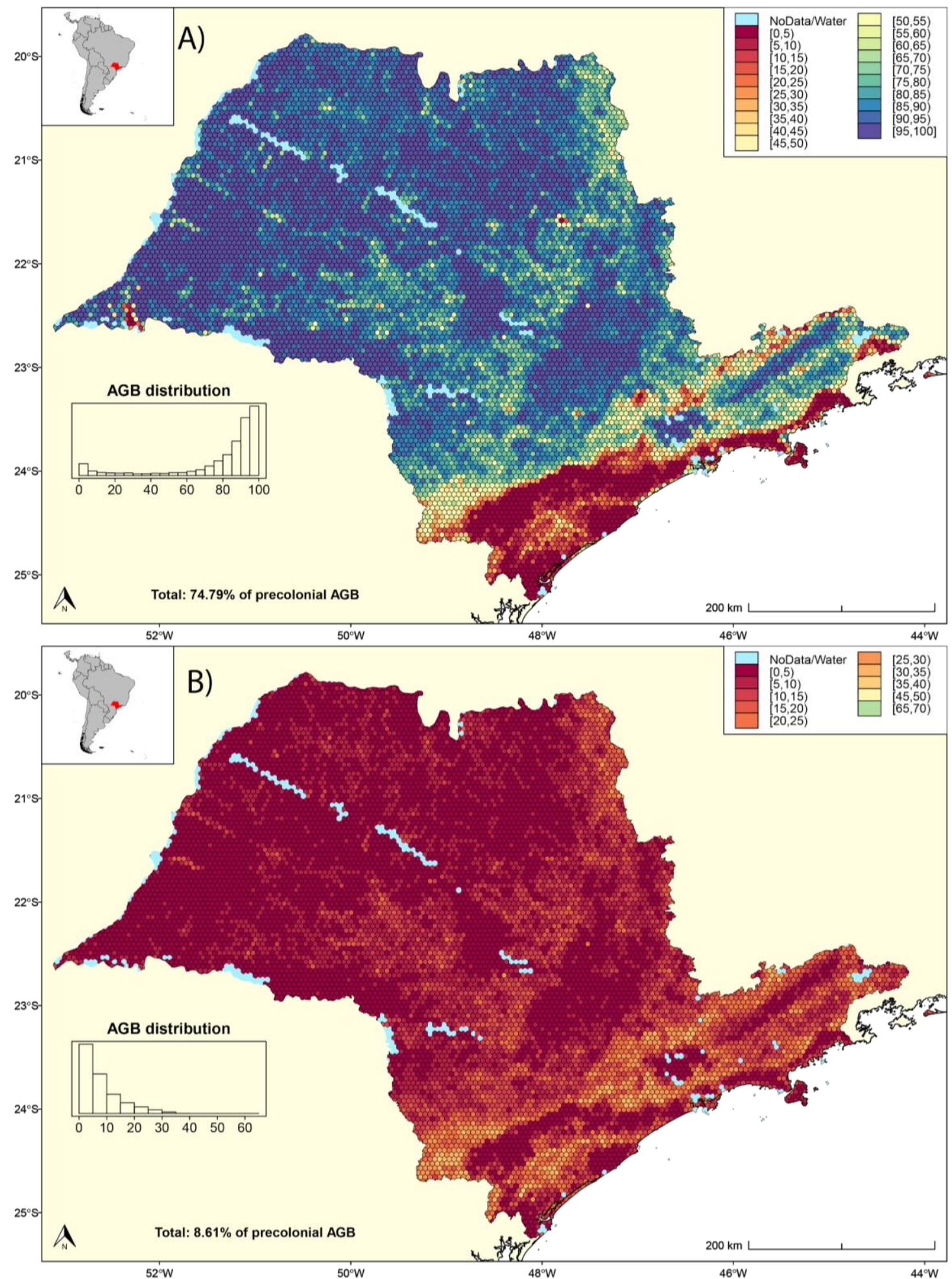

Figure 2: Estimates of AGB losses by type of effect: (A) habitat conversion and (B) forest fragmentation and degradation. In this map, colder tones indicate greater percentage of loss in $\mathrm{Mg} / \mathrm{ha}$ in respect to the pre-colonial reference values. Fragmentation losses in B are inherently low due the extent of deforestation in A. Both maps combined result in the total AGB loss until 2017 (83.4\% or $3.46 \mathrm{Gt})$. 
We found no study providing pre-colonial estimates of AGB for São Paulo state, so we could not compare or validate our results with those from other researchers. However, we cross-checked our pre-colonial estimations and current estimates of AGB for São Paulo with other estimates available in the literature (AVITABILE, et al., 2015; SANTORO et al., 2015; ENGLUND et al., 2017), which ranged between $0.95-1.13$ Gt. Our estimates without fragmentation effects fall in the same range, especially regarding the study of Englund et al. (2017) (Figure 03), and the R-squared of the relationship between their estimates of current carbon stocks ranged from $91 \%$ to $68 \%$.
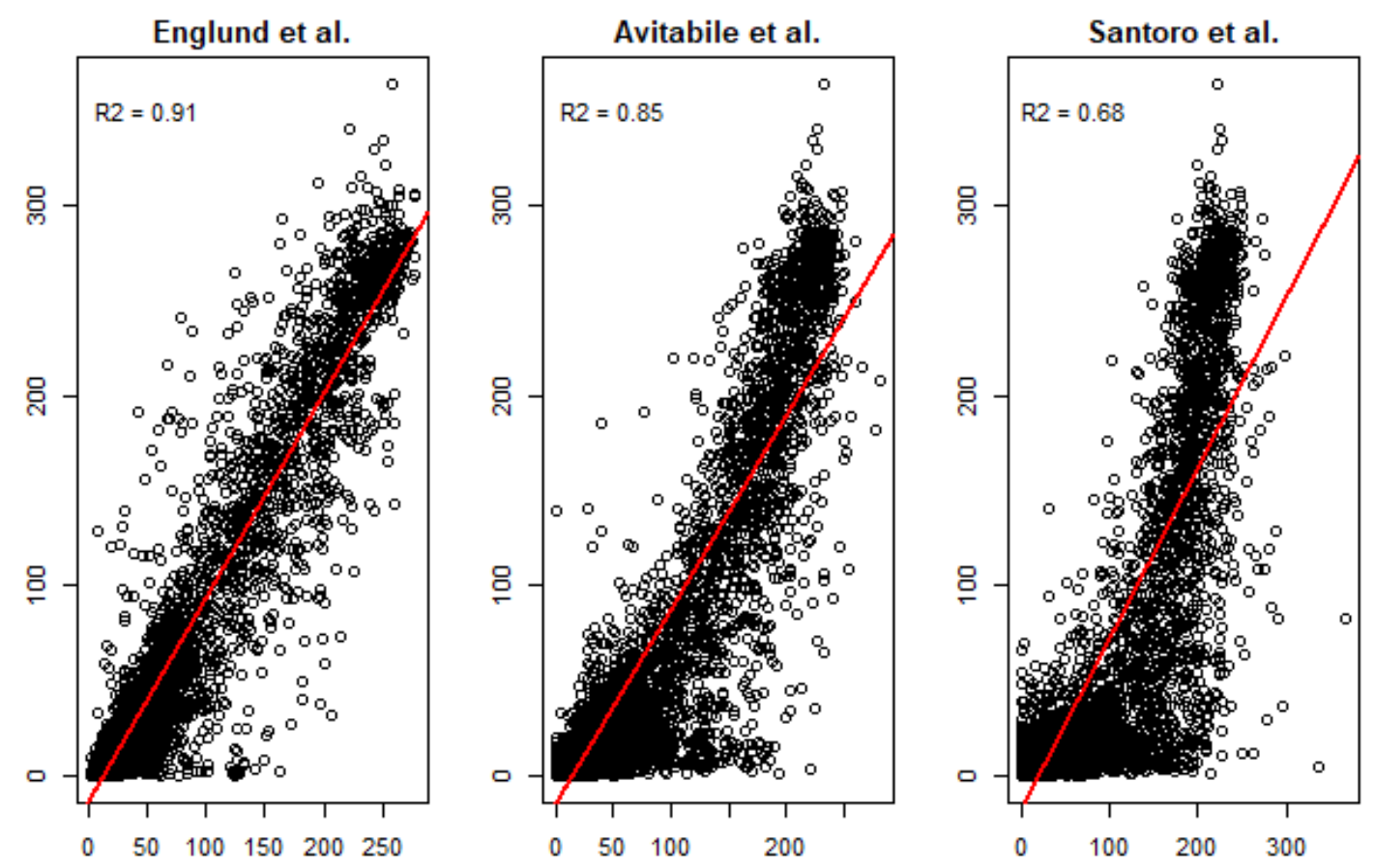

Figure 3: Comparison between the current AGB stocks obtained in this study (x-axes) with the most recent literature AGB estimates for São Paulo (y-axes). Simple dispersion plots where each circle is one of the cells in Figure 1A. The results of the linear regression lines are given in red along with the amount of variance explained by the model (R2). All values are given in $\mathrm{Mg}$ per ha.

We then estimated what could be the long term carbon balance under two different scenarios of AGB recovery: a legal compliance and an ideal one. The first scenario considers that all the area that should be restored due to legislation constraints would be fully restored (i.e. de facto legislation according to Freitas et al., 2017a). Under this scenario, we estimated a total of $0.17 \mathrm{Gt}$ of total deficit (Legal Reserve: 0.05 Gt; Permanent Preservation Areas: 0.12 Gt). These estimates assume that the restoration of these areas will be able to recover $100 \%$ of the pre-colonial AGB, which is not likely. If we take into account that in the long term that this areas 
will be under fragmentation effects once they are restored, we can thus use the average of $34 \%$ of fragmentation-induced losses (FR) we estimated for the remaining forest fragments in the state of São Paulo to get a more conservative estimate of AGB recovery potential (Figures $4 \mathrm{~A}, 5 \mathrm{~A})$ :

$$
\begin{gathered}
\text { Potential AGB }=\text { Current AGB }+ \text { FR* }(\text { Legal debt AGB }) \\
0.88 \mathrm{Gt}=0.77 \mathrm{Gt}+(1-0.342) *(0.17 \mathrm{Gt})
\end{gathered}
$$

Therefore, under the legal compliance scenario we could expect a total increase over current stocks of $14.66 \%$.

Considering the ideal scenario, where active restoration measures would also be put into place to mitigate the effects of the fragmentation and disturbance over the remaining forest fragments (LAURANCE, et al., 2011; KUPFER, et al., 2006), we could further add $0.225 \mathrm{Gt}$ of carbon at forest edges and cores. In this scenario fragmentation effects are modelled to be halved in the $120 \mathrm{~m}$ of edges and absent of the core of forest fragments. In this implementation the fragmentation-induced losses (FR) becomes $14.9 \%$. This means that we could potentially increase up to one half of the current carbon (Figures 4B 5B). In other words our potential AGB recovery in the optimistic scenario is:

$$
\begin{gathered}
\text { Potential AGB }=\text { Current AGB }+ \text { FR* }(\text { Legal debt AGB })+\text { Recovered AGB } \\
1.14 \mathrm{Gt}=0.77 \mathrm{Gt}+(1-0.149) *(0.17 \mathrm{Gt})+0.225 \mathrm{Gt}
\end{gathered}
$$

In this scenario, the expected increase in AGB would be three times higher than in the legal compliance scenario, reaching up to $48.27 \%$ over current carbon stocks. In both scenarios, seen in Figure 5, we have the regions that would have the greatest marginal gains in carbon stocks, which we refer as the hotspots of carbon potential. 

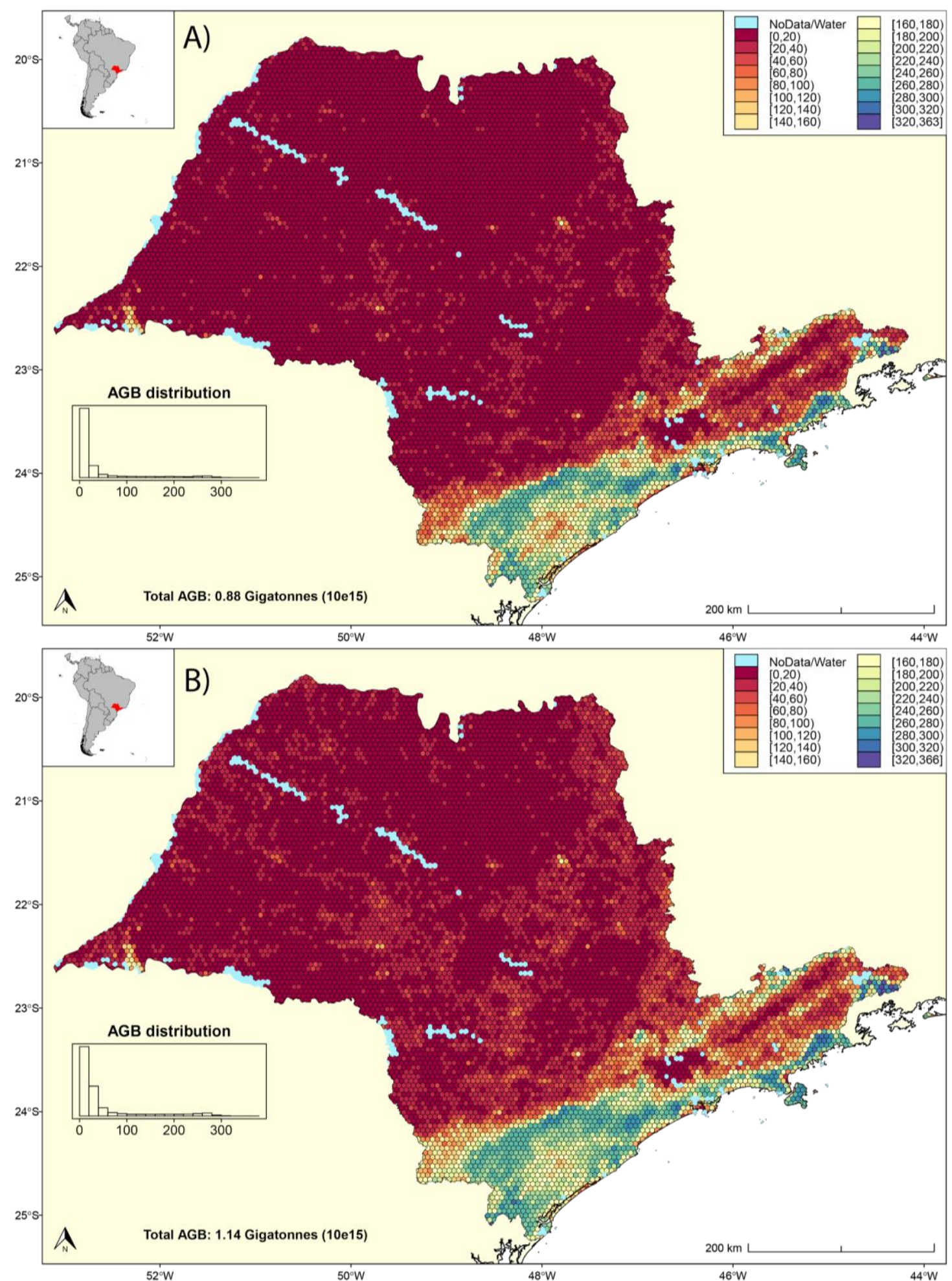

Figure 4: Projected scenarios of potential AGB recovery: (A) The legal compliance scenario where recovery potential includes only legal obligation of RL and APP areas.; and (B) the ideal scenario, where recovery potential includes RL, APP and active measures to revert fragmentation processes. Stocks in $\mathrm{Mg} / \mathrm{ha}$, figures in the same scale. 

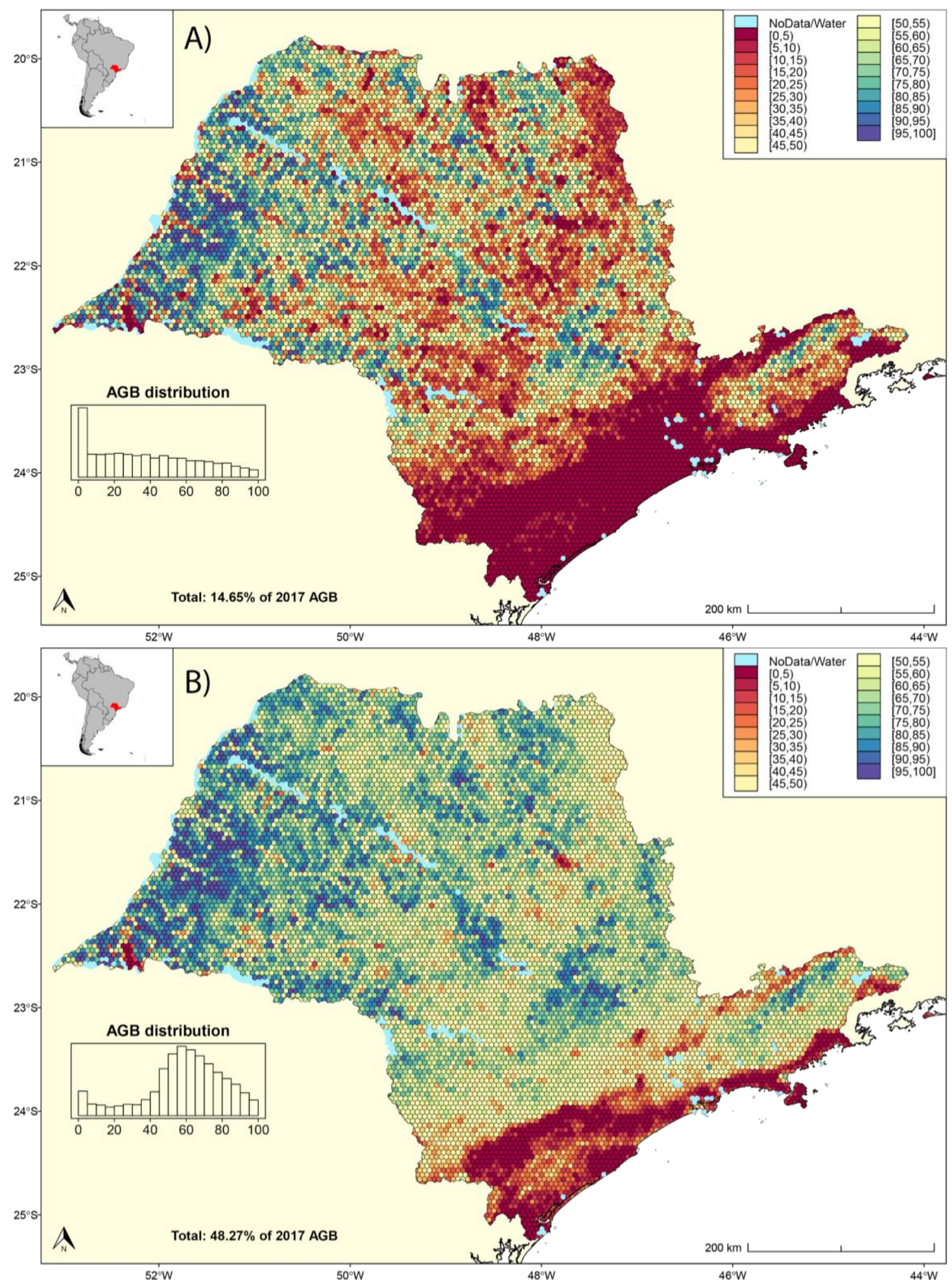

Figure 5: Projected scenarios of the full potential of recovery of the AGB stocks in São Paulo state, represented here in percentage of increase over 2017 carbon stocks. (A) legal compliance scenario and (B) ideal, active effort scenario. 
Finally, to help the visualization of our results in more practical manners, we present them aggregated by municipality or administrative units of management (UGRHIs) (Figures 6 and 7). We are able to name the municipalities with highest legal forest area debt and their respective carbon potential, which are not the same municipalities that would have the greatest marginal increase in its carbon stocks by restoration (Table 3). Clustering the data by UGRIs, the west of the state is clearly the area with the highest potential for biomass increase, but today it retains only about 0.1 Gt of florestal carbon. Equally if we look at the lowest potential of recovery the coastal units store around $0.43 \mathrm{Gt}$ of carbon.

Table 3: Ranked municipalities by area deficit and percentual increase in carbon stocks by complying to the NCFB.

\begin{tabular}{rrrrrr}
\hline \multicolumn{2}{c}{$\begin{array}{l}\text { Municipality with highest area } \\
\text { Rank }\end{array}$} & \multicolumn{2}{c}{$\begin{array}{l}\text { Carbon } \\
\text { Potential (Mg) }\end{array}$} & \multicolumn{2}{c}{$\begin{array}{l}\text { Municipality highest carbon } \\
\text { potential \% - (Mg) }\end{array}$} \\
\hline 1 & Teodoro Sampaio & 107222 & 1111643 & Santo Expedito & 63571 \\
2 & Guararapes & 8490 & 123678 & Flora Rica & 139255 \\
3 & Santo Antônio da Alegria & 8056 & 824891 & Ribeirão dos Índios & 126674 \\
4 & Morro Agudo & 7814 & 729432 & Junqueirópolis & 492682 \\
5 & Andradina & 7227 & 773476 & Pacaembu & 304241 \\
6 & Rancharia & 6775 & 626505 & Alfredo Marconde & 106171 \\
7 & Martinópolis & 6609 & 634696 & Severí-nia & 73279 \\
8 & Castilho & 6583 & 688505 & Emilianópolis & 114891 \\
9 & Euclides da Cunha Pta. & 6527 & 665710 & Santa Mercedes & 137463 \\
10 & Pereira Barreto & 6478 & 756706 & Irapuru & 169448 \\
\hline
\end{tabular}



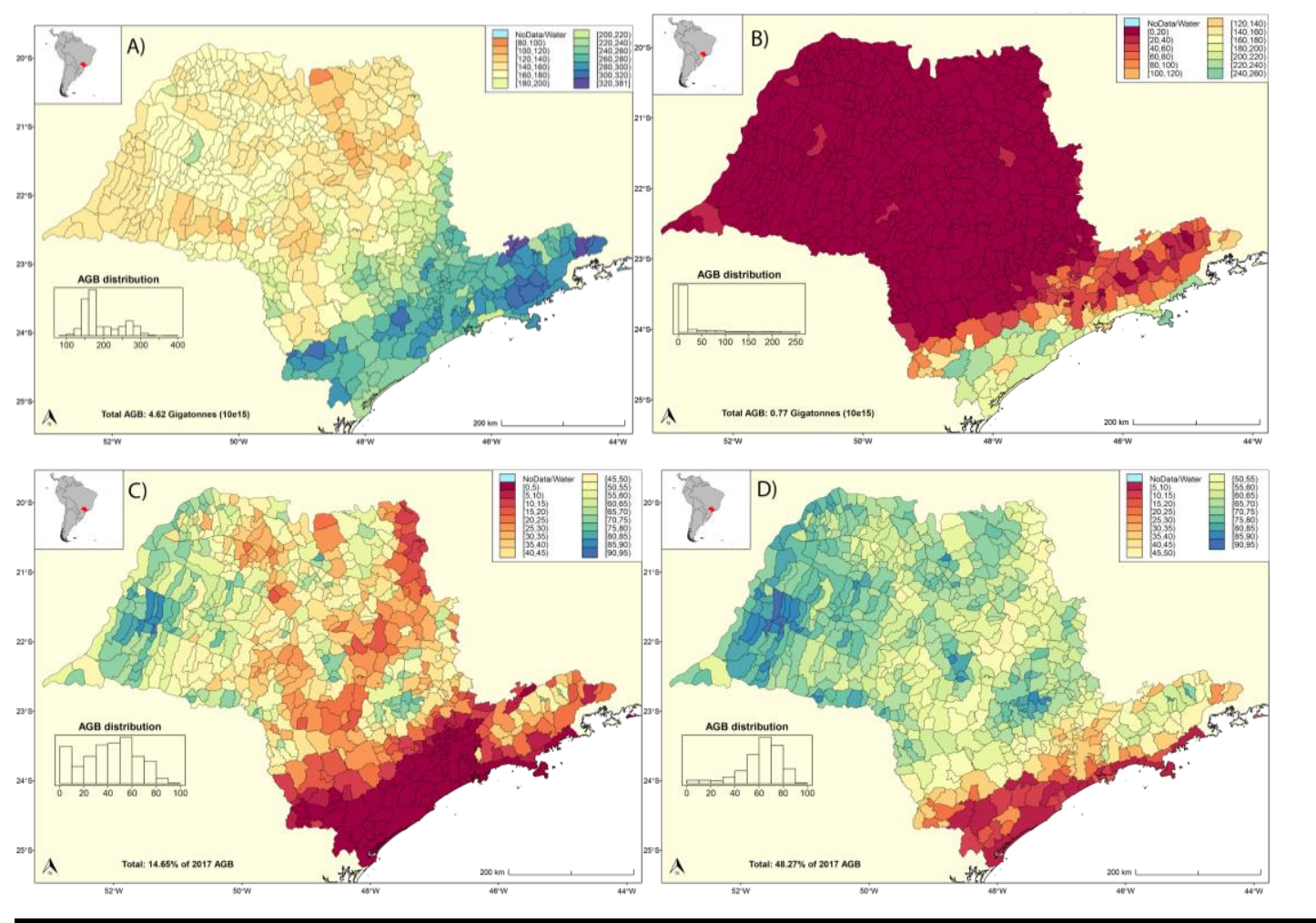

\begin{tabular}{|c|c|c|c|}
\hline Rank & $\begin{array}{c}\text { Pre-colonial Highest AGB } \\
\text { (Mg/ha) }\end{array}$ & $\begin{array}{l}2017 \text { Highest AGB } \\
\text { (Mg/ha) }\end{array}$ & $\begin{array}{c}\text { Highest Potential \% } \\
\text { increase over 2017 AGB. (Both } \\
\text { scenarios) }\end{array}$ \\
\hline 1 & São Bento do Sapucaí 380.68 & Ilhabela 250.39 & Santo Expedito $91.1 \sim 93.6$ \\
\hline 2 & Campo Limpo Paulista 363.70 & Pedro de Toledo 247.15 & Flora Rica $87.3 \sim 91.1$ \\
\hline 3 & Santo Antônio do Pinhal 339.69 & Iporanga 241.37 & Ribeirão dos Índios $86.4 \sim 90.8$ \\
\hline 4 & São José do Barreiro 325.58 & Ubatuba 237.50 & Junqueirópolis $86.0 \sim 90.3$ \\
\hline 5 & Bananal 314.69 & Tapiraí 225.97 & Pacaembu $85.7 \sim 89.9$ \\
\hline 6 & Natividade da Serra 312.08 & Eldorado 221.82 & Alfredo Marconde $84.1 \sim 89.0$ \\
\hline 7 & São Luiz do Paraitinga 310.92 & Miracatu 217.68 & Severínia $83.9 \sim 89.2$ \\
\hline 8 & Redenção da Serra 309.66 & São Sebastião 216.98 & Emilianópolis $83.4 \sim 88.8$ \\
\hline 9 & Paraibuna 308.66 & Barra do Turvo 213.37 & Santa Mercedes $83.3 \sim 88.3$ \\
\hline 10 & Piedade 305.02 & Itariri 211.89 & Irapuru $83.1 \sim 88.2$ \\
\hline
\end{tabular}

Figure 6: Estimates of the carbon balance for São Paulo aggregated by municipalities. (A) Pre-colonial AGB; (B) Remaining AGB in 2017; (C) Potential of recovery in the legal compliance and (D) ideal, scenarios. Table presents the top 10 Municipalities according to the upper graphs. Potential percentual increase according to legal compliance (lower value) and ideal (higher value) scenarios. 


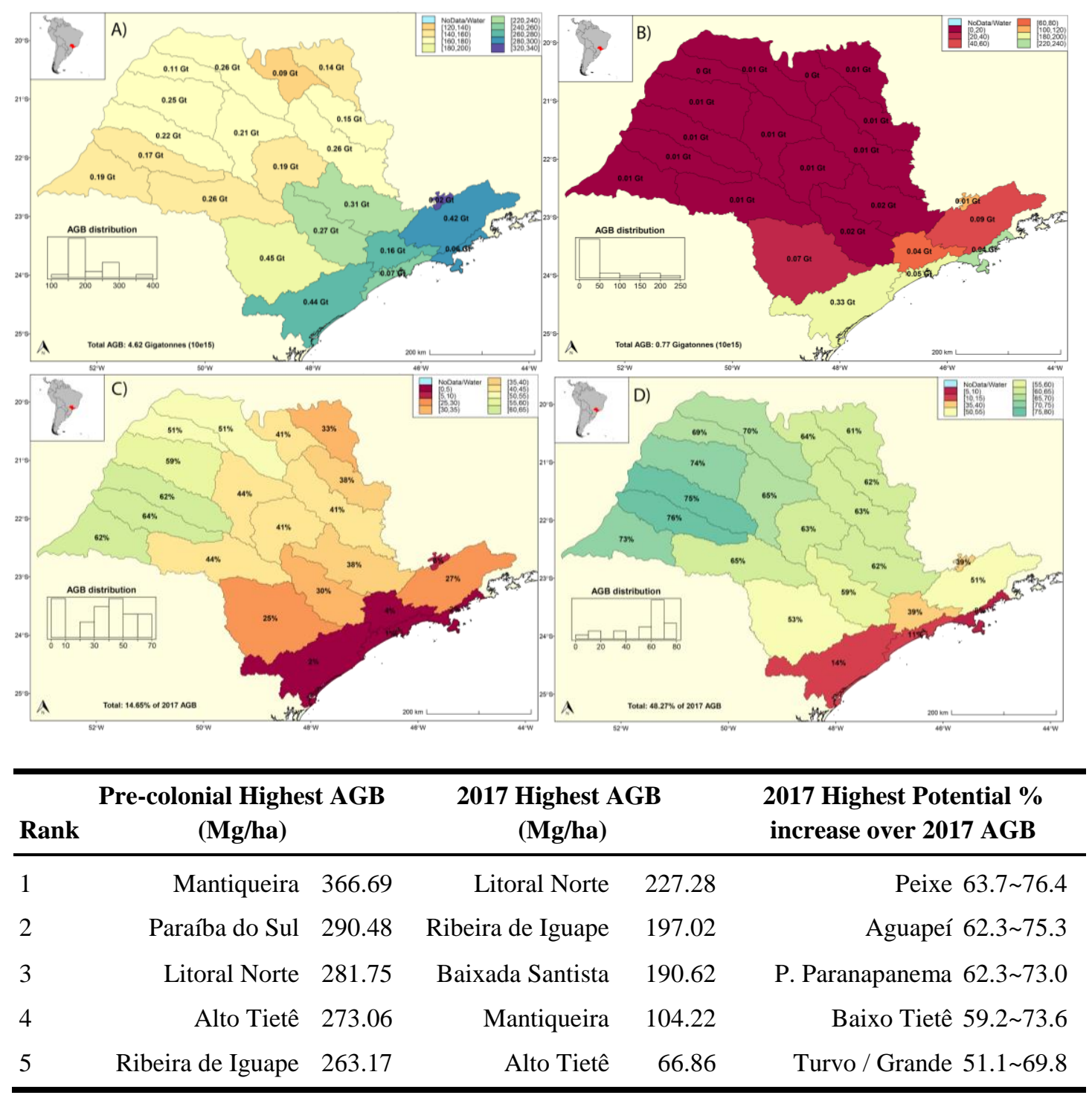

Figure 7: Estimates of the carbon balance for São Paulo aggregated by main river basins (i.e. UGHRI). (A) Pre-colonial AGB; (B) Remaining AGB in 2017; Potential AGB recovery under (C) the legal compliance and (D) ideal scenarios. Table presents the top 5 UGHRIs according to the upper graphs. Potential percentual increase according to legal compliance (lower value) and ideal (higher value) scenarios. 


\section{Discussion}

Estimating carbon stocks and its potential of recovery is a important but complex task (GLOOR et al., 2012), especially because 70\% of terrestrial ecosystems are disturbed by man (LUYSSAERT, et al., 2008). Hence, assessments of carbon storage anywhere else than in remotes area of the Amazon, Sub-Saharan Africa, or Southeast Asia (SAATCHI, et al., 2011) must take into account human-induced carbon losses. Here we provide such assessment and, as far as we known, this is the first time anyone estimates the carbon storage prior to human intervention in a tropical anthropized landscape. Our approach provides a spatially explicit carbon carrying capacity that can be used as benchmark for calculating current carbon stocks and to set site-specific references for carbon restoration. Another implication is the inherent lower standard deviations generated by the modelling, than other spatial interpolators currently used (ENGLUND, et al., 2017; AVITABILE, et al., 2015) that allows for a greater precision than ever before attained in spatial carbon modelling. On that account, our approach could be readily used for other human-modified regions of the world, as long as there is well-curated forest inventories available.

However, estimating carbon stocks from centuries ago most likely have its limitations. For the Atlantic Forest, the available knowledge on forest structure does not go past beyond 70 years (LIMA, et al., 2015). If old-growth forests currently available in São Paulo are not good proxies of forests 500 years ago, our pre-colonial estimates may be biased. For instance, large, hard-wooded tree species (e.g. Aspidosperma polyneuron, Cedrela fissilis, Handroanthus spp.) have a long history of selective logging particularly in seasonal forests on the west part of the state. In our sample, average AGB for seasonal forests were conspicuously low in comparison to other forest types (Table 1). Therefore, it is possible that our seasonal forest inventories may not have had enough time to recover and thus they may underestimate their carbon storage potential. This suggestion may be especially true because high-fragmentation levels, typical of this part of São Paulo state, are known to hinder the establishment/persistence of big trees (LAURANCE et al., 2000). It should be noted, however, that if this bias do exist in our sample, it means that our pre-colonial carbon estimate (4.62 Gt) is actually a conservative one.

As with niche modeling (TOWNSEND, 2001), our approach indicates what should be the carbon stock where there is no data available. Thus, this should be seen 
a baseline that can be used in carbon assessments and restoration planning. For São Paulo state, we found that current carbon estimates decurred from this baseline values were comparable to other published AGB estimates (ENGLUND et al., 2017). The main differences between ours $(0.77 \mathrm{Gt})$ and their estimates $(1.05 \mathrm{Gt})$, is probably due to the fact that we specifically did not include silviculture or agriculture carbon and we did include fragmentation effects in our current estimates. In addition, our approach allows to break the sources of carbon loss into deforestation and types of fragmentation effects (edge-effects and core degradation). For example, model adjustments can and provide or test breakpoints where those effects become relevant (D'ALBERTAS et al., 2018). Thus reinforcing that our approach can be used for multiple purposes regarding carbon estimates.

Regarding our results on the current carbon stocks for São Paulo, the most striking outcome was quite clear: we have lost almost all vegetation cover, and with that almost all carbon stock. This footprint is not new and is expected from the deforestation rates described elsewhere (RIBEIRO, et al., 2009). The impressive 3.85 Gt AGB loss registered, however, is a novelty and quantifies the magnitude of human impacts. This quantity can be used to estimate the contribution of carbon emissions to climate change (MATTHEWS, et al., 2009). To understand the magnitude of the above ground carbon loss for the São Paulo state, yearly the entire country of Brazil releases about $0.43 \mathrm{Gt}$ of carbon (MCTIC, 2017). The total loss of vegetation carbon in São Paulo account for about four and a half years of current emissions of the entire country. This comparison further emphasizes the need for preservation of the remaining current vegetation carbon stocks.

Another compelling result is to know that today we have, proportionally, more natural vegetation standing than stored carbon for São Paulo state, a result that could be true for other tropical regions. The difference between the remaining natural vegetation cover (21.3\%) and the current carbon stocks (16.7\%) can be explained by the combination of: (i) fragmentation effects and (ii) the intrinsic spatial variability our pre-colonial scenario. If there were no fragmentation effects the standing forest conditions would be much closer to the undisturbed scenario and thus forest area and carbon stocks would be more proportional. In addition, the pattern of deforestation specific to São Paulo resulted in the concentration of the remaining carbon in a single region: the mountainous coastal forests (which originally had the highest concentration to begin with). Both these effects interact, and if deforestation had been 
uniform throughout our study area, then the expected carbon stocks should be even smaller, around $14 \%$ of the original. Therefore, the observed higher than expected carbon stocks ultimately are the consequence of the clumpiness of the remaining fragments in the pre-colonial hotspots of carbon.

The magnitude of carbon loss due to the fragmentation effects (FR) found in this study (34\%) is very close to the findings of Laurance et al., (1998) for the amazon forest fragments, where at $100 \mathrm{~m}$ of edges fragmentation loss of carbon rates were around $36 \%$. We know that more than $80 \%$ of remaining fragments of the Atlantic Forest have less than 50 ha (RIBEIRO et al., 2009) and thus where most of the fragmentation effects occur. Those forest fragments are subject to the highest total carbon loss, and are responsible for $72.21 \%$ of the carbon losses by fragmentation. On the other hand, it may be argued that the Cerrado domain is not subjected to the same fragmentation effects as a the Atlantic Forest domains. However, there are very few studies on Cerrado domain edges (COELHO, 2017), making it difficult to parameterize edge-effects in this type of vegetation, if they exist at all. Thus, our assumption of using percentual losses has inherent less impact in the Cerrado domain.

By providing estimates of current carbon stocks and carbon recovery potential, our approach allows to identify long term hotspots of carbon sequestration. For São Paulo, independently of the recovery scenario, these hotspots are mainly located in intensive sugarcane systems in the west of the state, and in the Paraiba valley region that has a long history related to coffee plantations. These areas were identified as hotspots because they have the greatest natural area deficits and/or they hold the highest marginal potential of carbon storage increase. Thus, our approach can be readily used for planning future restoration actions aiming at maximizing carbon sequestration (Appendix 05).

Based on our different scenarios of potential AGB recovery, we can also monetize the carbon net gain. By assuming the european allowance cost of 5 to 25 US\$ as proxy for value of an stored ton of carbon in 2018 (BUSSINES-INSIDER, 2019) and a biomass to carbon conversion rate of 0.5 (HOUGHTON et al., 2001), then the carbon potential for the State of São Paulo would value between 0.28 and 1.38 billion US\$ only in our legal compliance scenario. If we consider the ideal scenario, these values would increase to $0.925-4.63$ billion US\$. In this latter case carbon credit gains triple over the legal compliance scenario. Therefore, our approach 
allows not only to value carbon gains but also to assess separately the of carbon or credit gains based on different restoration strategies or goals for a given locality.

These results naturally lead to the following question: Can carbon credits alone pay for restoration costs? The AGB recovery of $0.11 \mathrm{Gt}$ under the legal compliance scenario would represent a total 958,117 ha of restored lands. Considering restoration costs of tropical vegetation ranging from 1000-3000 US\$ per ha (RODRIGUES et al., 2009), total costs would range from 0.96 to 2.79 billion US\$ for the legal compliance scenario. Under the ideal scenario however, the total recovery potential is $0.37 \mathrm{Gt}$, but costs are harder to estimate. If we consider only costs of fencing the remaining forest fragments, we would need to fence over 550 thousand $\mathrm{km}$ of fragment edges in São Paulo. Considering the average cost of fencing at 2000 US\$ per km (SOARES-FILHO et al., 2016), we would add a cost of approximately 1.1 billion US\$. Thus, our estimates for the ideal scenario would reach total costs of 2.06 to 3.89 billion US\$.

So, in terms of funding restoration costs using carbon market mechanisms, our results suggest that the legal compliance and ideal scenarios would be economically viable if markets are willing to pay at least 11.15 (ideal) and 17.5 (legal) US\$ for fixed carbon ton. The ideal scenario can be further more attractive if we consider other fencing alternatives (e.g. green fences of Mimosa caesalpiniaefolia) that should be cheaper (10 US\$ for $\mathrm{km}$ ) providing ecosystem services, buffering for forest fragments and example of mitigation of edge effects (BRANCALION et al., 2012; RUGGIERO et al., 2018). Hence, besides providing spatially explicit carbon reference values and the contribution of fragmentation induced carbon loss, our approach can also supply projections economic feasibility of different strategies for carbon restoration. 


\section{Acknowledgements}

This study was financed in part by the Coordenação de Aperfeiçoamento de Pessoal de Nível Superior - Brasil (CAPES) - Finance Code 001. Data compilation used in this research, available from the TreeCo database, was mainly supported by the grant 2013/08722-5, São Paulo Research Foundation (FAPESP). We also thank the institute of Biosciences of the University of São Paulo, for the infrastructure and administrative support. We would like to kindly thank the thousands of researchers that made this work possible by direct and indirect contributing to the state of the art science we have today. 


\section{Discussão Geral e Conclusões}

Neste trabalho estabelecemos o balanço de carbono para o estado de São Paulo, uma paisagem tropical altamente modificada pelo ser humano, com elevadas atividades agrícolas e demandas conflitantes pelo uso da terra e pela conservação (ADAMS et al., 2007). Nesta paisagem, onde a supressão de vegetação nativa ocorre há pelo menos cinco séculos (MORELLATO \& HADDAD, 2000), é crucial estabelecer parâmetros de referência para os estoques de carbono na vegetação em uma dada localidade (BIRCH et al., 2010). Uma vez estabelecidos estes parâmetros, pudemos revisar as estimativas dos estoques atuais de carbono e evidenciar a situação crítica desse serviço ambiental. Finalmente, destacamos regiões com potencial para recuperação (i.e. hotspots de recuperação de carbono), juntamente com os potenciais de custos de restauração e uma breve análise de sua viabilidade econômica.

A modelagem de carbono utilizada neste estudo se mostrou um método relativamente simples, que gerou resultados mais precisos (i.e. menores intervalos de confiança) em relação às estimativas até então disponíveis (ENGLUND et al., 2017), que foram feitas majoritariamente por sensoriamento remoto da cobertura vegetal (HANSEN et al., 2013). A aquisição de informações oriundas de sensores remotos ainda é necessária no método utilizado aqui, mas associada apenas à variáveis como temperatura e umidade, que estão atualmente disponíveis com graus de precisão elevados (ALVARES et al., 2013). Em particular, obter um mapa de cobertura vegetal nativa remanescente (MAPBIOMAS, 2018) é essencial para a boa execução desse método. A compilação e auditoria de dados de biomassa florestal publicados foi o fator limitante e que demandou um grande tempo para sua compilação (LIMA et al., 2015). Eventualmente espera-se que bancos de inventários florestais com informações de biomassa se tornem mais comuns e prontamente disponíveis, facilitando a réplica do procedimento para demais localidades ao redor do globo.

Tendo em vista essas considerações, com os dados de inventários florestais disponíveis hoje seria possível prontamente produzir mapas similares para outras localidades. No contexto nacional, o TreeCo seria capaz de fornecer dados de biomassa com boa cobertura para reproduzir 
esse estudo para Minas Gerais, Santa Catarina e Rio de Janeiro. Para Minas Gerais, essa metodologia poderia inclusive ser comparada com o estudo de Scolforo et al., (2015). No contexto global, seriam necessários dados especializados de remanescentes florestais atuais. Alguns candidatos que já possuem numerosos inventários florestais tropicais já disponíveis são o Peru, Guinea Equatorial, Gabão, Uganda e boa parte do sudeste Asiático (AVITABILE et al., 2015).

Em um sentido mais amplo, os objetivos deste trabalho foram: (i) produzir resultados práticos, contextualizados e de fácil entendimento para o público geral; (ii) capacitar o aluno para produção científica e, ao mesmo tempo, (iii) instrumentalizá-lo como técnicas e conceitos que possam ser úteis também para o seu futuro como profissional no mercado de trabalho. Acredito que dentro das limitações de 24 meses, esses objetivos foram alcançados. Certamente existem pontos que poderiam ser trabalhados para aprimorar esse estudo caso houvesse mais tempo disponível, como a explicitação espacial dos custos de oportunidade para recomposição de estoques de carbono, locais com menor eficiência e maior potencialidade de regeneração espontânea (i.e. restauração passiva). Estas possibilidades parecem óbvias uma vez ditas, mas são considerações que apenas se mostram ao longo do processo já em andamento, com a troca de experiências com demais pesquisadores. Mas, acredito que o trabalho oferece uma contribuição substancial para o campo científico, técnicas e estimação de carbono, para tomada de decisão pública e para, acima de tudo, instigar no leitor um imaginário de um futuro mais verde. 


\section{Resumo}

Esta pesquisa consistiu em estimar o balanço de carbono da vegetação nativa de uma paisagem antropizada, ou seja, calcular a quantidade de biomassa arbórea acima do solo (AGB) preexistente (cenário pré-colonial), o quanto foi perdido pela ação humana (desmatamento e fragmentação) e que quantidade de carbono poderia ser recuperada com a adequação ao Novo Código Florestal Brasileiro (NCFB). Os fatores desse balanço são apresentados cartograficamente, e foram obtidos baseado em dados de campo para associar valores de tonelagem aos estoques estimados. A AGB précolonial estimada foi de 4.62 Gigatoneladas, dos quais $87.3 \%$ (3.85 Gt) foram perdidos até 2017. Essas perdas foram atribuídas em $90 \%$ (3.46 Gt) ao desmatamento, e $10 \%$ (0.39 Gt) à efeitos decorrentes da fragmentação. Os déficits em Reserva Legal e Áreas de Preservação Permanente estipulados pelo NCFB se traduzem em um potencial de recuperação de 0.11 Gt de AGB para São Paulo. Se reduzíssemos os efeitos da fragmentação esse potencial triplicaria $(0.37 \mathrm{Gt})$. Os hotspots de biomassa atuais estão restritos às florestas costeiras (Ribeira do Iguape, Baixada Santista e Litoral Norte) e que as regiões com maior potencial de recuperação de carbono com a adequação ao NCFB são o Vale do Paraíba, Aguapeí e Pontal do Paranapanema. Finalmente, discutimos a eficácia dos mecanismos de compensação: seriam necessários 0.96 a 2.79 bilhões de US\$ para restaurar o déficit legal de vegetação, possível apenas se os mercados estiverem dispostos a pagar pelo menos 17.5 US\$ por tonelada de carbono fixado na vegetação.

Palavras chave: Balanço de Carbono, Mata Atlântica, Cerrado, São Paulo, Políticas Públicas 


\section{Abstract}

The research aimed to estimate the carbon balance of natural vegetation in a tropical anthropized landscape. That is, to calculate the amount of pre-existing tree biomass above the soil (pre-colonial scenario), how much was lost by human action (deforestation and fragmentation) and how much carbon could be recovered with the adaptation to the New Brazilian Forest Code (NCFB). This balance is represented cartographically for the state of São Paulo, in its different stages (e.g. carbon inventory map for the original vegetation cover), and is based on field data to associate tonnage values with the estimated inventories. The estimated pre-colonial AGB for São Paulo was 4.62 Gigatonnes, of which $87.3 \%$ (3.85 Gt) were lost. These losses can be attributed to $90 \%(3.46 \mathrm{Gt})$ to deforestation, and $10 \%(0.39 \mathrm{Gt})$ to the effects of fragmentation. The vegetation deficits in Legal Reserve and Areas of Permanent Preservation stipulated by the NCFB translate into a potential recovery of $0.11 \mathrm{Gt}$ of AGB. If we were to reduce degradation in forest fragments this potential AGB recovery would raise to 0.37 Gt. It was observed that current biomass hotspots are restricted to coastal forests (Ribeira do Iguape, Baixada Santista and Litoral Norte) and that the regions with the greatest potential for carbon recovery with adaptation to the NCFB are the Vale do Paraíba, Aguapeí and Pontal of Paranapanema. Finally, we discussed the effectiveness of compensation mechanisms, it would require 0.96 to 2.79 billion US\$ to restore the legal deficit of vegetation, feasible as long as carbon markets are willing to pay 17.5 US\$ for ton of fixed Carbon.

Key-words: Carbon Balance, São Paulo, Atlantic Forest, Cerrado, Public Policy 


\section{Referências Bibliográficas}

\section{Introdução}

BRASIL (2012) Lei n. 12,651 Lei da Proteção da Vegetação Nativa. Brasília, DF, 25 de mai. de 2012.

Cordani, U. G., Marcovitch, J., \& Salati, E. (1997). Avaliação das ações brasileiras após a Rio-92. Estudos Avançados, 11(29), 399-408.

Fearnside, P. M. (2000). Global warming and tropical land-use change: greenhouse gas emissions from biomass burning, decomposition and soils in forest conversion, shifting cultivation and secondary vegetation. Climatic change, 46(1-2), 115-158.

Fearnside, P. M. (2017). Business as usual: a resurgence of deforestation in the Brazilian Amazon. Yale Environ, 360.

Fahey, T. J., Woodbury, P. B., Battles, J. J., Goodale, C. L., Hamburg, S. P., Ollinger, S. V., \& Woodall, C. W. (2009). Forest carbon storage: ecology, management, and policy. Frontiers in Ecology and the Environment, 8(5), 245-252

Gloor, M., Gatti, L., Brienen, R., Feldpausch, T. R., Phillips, O. L., Miller, J., ... \& Houghton, R. A. (2012). The carbon balance of South America: a review of the status, decadal trends and main determinants. Biogeosciences, 9(12), 54075430.

Gullison, R. E., Frumhoff, P. C., Canadell, J. G., Field, C. B., Nepstad, D. C., Hayhoe, K., ... \& Nobre, C. (2007). Tropical forests and climate policy. Science, 316(5827), 985-986.

INPE- Instituto Nacional de Pesquisas Espaciais. (2018, May 14). Taxas de desmatamento na Amazônia em 2017. Retrieved January 12, 2019, from http://www.obt.inpe.br/OBT/noticias/inpe-registra-6-947-km2-dedesmatamento-na-amazonia-em-2017

Laurance, W. F. (2008). Theory meets reality: how habitat fragmentation research has transcended island biogeographic theory. Biological conservation, 141(7), 1731-1744.

Lima, R. A., Mori, D. P., Pitta, G., Melito, M. O., Bello, C., Magnago, L. F., ... \& Prado, P. I. (2015). How much do we know about the endangered Atlantic Forest? Reviewing nearly 70 years of information on tree community surveys. Biodiversity and conservation, 24(9), 2135-2148.

Melatti, J. C. (2007). Índios do Brasil. Edusp. pp 44-47

Phelps, J., Webb, E. L., \& Agrawal, A. (2010). Does REDD+ threaten to recentralize forest governance?. Science, 328(5976), 312-313.

Potapov, P., Hansen, M. C., Laestadius, L., Turubanova, S., Yaroshenko, A., Thies, C., ... \& Esipova, E. (2017). The last frontiers of wilderness: Tracking loss of intact forest landscapes from 2000 to 2013. Science Advances, 3(1), e1600821..

Ribeiro, M. C., Metzger, J. P., Martensen, A. C., Ponzoni, F. J., \& Hirota, M. M. (2009). The Brazilian Atlantic Forest: How much is left, and how is the remaining forest distributed? Implications for conservation. Biological conservation, 142(6), 1141-1153.

Scolforo, H. F., Scolforo, J. R. S., Mello, C. R., Mello, J. M., \& Ferraz Filho, A. C. (2015). Spatial distribution of aboveground carbon stock of the arboreal 
vegetation in Brazilian biomes of savanna, Atlantic Forest and semi-arid woodland. PloS one, 10(6), e0128781.

Scolforo, H. F., Scolforo, J. R. S., de Mello, J. M., de Mello, C. R., \& Morais, V. A. (2016). Spatial interpolators for improving the mapping of carbon stock of the arboreal vegetation in Brazilian biomes of Atlantic forest and Savanna. Forest Ecology and Management, 376, 24-35.

Strassburg, B. B., Brooks, T., Feltran-Barbieri, R., Iribarrem, A., Crouzeilles, R., Loyola, R., ... \& Soares-Filho, B. (2017). Moment of truth for the Cerrado hotspot. Nature Ecology \& Evolution, 1(4), 0099

UNFCCC. Conference of the Parties (COP) (2018) Draft report of the Conference of the Parties on its twenty-fourth session. Katowice Climate Change Conference - December 2018. Available at: https://unfccc.int/documents/184486 Accessed 24/12/18

Van der Werf, G. R., Morton, D. C., DeFries, R. S., Olivier, J. G. J., Kasibhatla, P. S., Jackson, R. B., ... \& Randerson, J. T. (2009). CO2 emissions from forest loss. Nature Geoscience 2: 737-738.

\section{Capítulo único}

Albrecht, A., \& Kandji, S. T. (2003). Carbon sequestration in tropical agroforestry systems. Agriculture, ecosystems \& environment, 99(1-3), 15-27.

Alvares, C. A., Stape, J. L., Sentelhas, P. C., \& de Moraes Gonçalves, J. L. (2013). Modeling monthly mean air temperature for Brazil. Theoretical and Applied Climatology, 113(3-4), 407-427.

Asner, G. P., \& Mascaro, J. (2014). Mapping tropical forest carbon: Calibrating plot estimates to a simple LiDAR metric. Remote Sensing of Environment, 140, 614-624.

Avitabile, V., Herold, M., Heuvelink, G. B. M., Lewis, S. L., Phillips, O. L., Asner, G. P., Armston, J., Ashton, P. S., Banin, L. et al., (2015). An integrated pantropical biomass map using multiple reference datasets. Global Change Biology, 22, pp. 1406-1420.

Balderas Torres, A., \& Lovett, J. C. (2012). Using basal area to estimate aboveground carbon stocks in forests: La Primavera Biosphere's Reserve, Mexico. Forestry, 86(2), 267-281

Gräler, B., Pebesma, E., and Heuvelink, G. (2016). Spatio-Temporal Interpolation using gstat. The R Journal 8(1), 204-218

Bates, D., Maechler M., Bolker, Ben., Walker, S. (2015). Fitting Linear MixedEffects Models Using lme4. Journal of Statistical Software, 67(1), 1-48 doi:10.18637/jss.v067.i01.

Birch, C. P., Oom, S. P.,, J. A. (2007). Rectangular and hexagonal grids used for observation, experiment and simulation in ecology. Ecological modelling, 206(3-4), 347-359.

Bivand R. \& Danlin Yu (2017). spgwr: Geographically Weighted Regression. R package version 0.6-32. Available at https://CRAN.Rproject.org/package $=$ spgwr

Bonan, G. B. (1995). Land-atmosphere interactions for climate system models: coupling biophysical, biogeochemical, and ecosystem dynamical processes. Remote Sensing of Environment, 51(1), 57-73.

Brancalion, P. H. S., Viani, R. A., Strassburg, B. B. N., \& Rodrigues, R. R. (2012). Finding the money for tropical forest restoration. Unasylva, 63(1), 239 
BRASIL (2012) Lei n. 12,651 Lei da Proteção da Vegetação Nativa. Brasília, DF, 25 de mai. de 2012.

Business-Insider. (2019). CO2 European Emission Allowances PRICE Today | CO2 European Emission Allowances Spot Price Chart | Markets Insider. Retrieved January 07, 2019, from

https://markets.businessinsider.com/commodities/co2-emissionsrechte

Chaplin-Kramer, R., Ramler, I., Sharp, R., Haddad, N. M., Gerber, J. S., West, P. C., ... \& Mueller, C. (2015). Degradation in carbon stocks near tropical forest edges. Nature communications, 6, 10158.

Chazdon, R. L., Broadbent, E. N., Rozendaal, D. M., Bongers, F., Zambrano, A. M. A., Aide, T. M., ... \& Craven, D. (2016). Carbon sequestration potential of second-growth forest regeneration in the Latin American tropics. Science Advances, 2(5), e1501639

Coelho, A. J. P. (2017) Efeito da fragmentação nas diversidades taxonômica e filogenética do Cerrado stricto sensu. 56 f. Dissertação (Mestrado em Botânica) - Universidade Federal de Viçosa, Viçosa. Available at http://www.locus.ufv.br/handle/123456789/11877?show=full

CPI - Climate Policy Initiative \& Costa, R.D. (2016) Insecure Land Rights in Brazil, Consequences for Rural Areas and Challenges for Improvement. Available at https://climatepolicyinitiative.org/wp-

content/uploads/2016/08/Insecure_Land_Rights_in_Brazil_CPI.pdf Accessed on $01 / 01 / 19$

CPI Climate Policy Initiative (2018). Insights: The Brazilian Forest Code finally can be implemented. What's next? INPUT: Agroicone Rio de Janeiro (Brazil) Available a thttps://climatepolicyinitiative.org/wpcontent/uploads/2018/03/CPI_Agroicone_Insights_Forest_Code__Whats_Next.pdf Accessed 01/01/19

Crabtree, R., Potter, C., Mullen, R., Sheldon, J., Huang, S., Harmsen, J., ... \& Jean, C. (2009). A modeling and spatio-temporal analysis framework for monitoring environmental change using NPP as an ecosystem indicator. Remote Sensing of Environment, 113(7), 1486-1496.

d'Albertas, F., Costa, K., Romitelli, I., Barbosa, J. M., Vieira, S. A., \& Metzger, J. P. (2018). Lack of evidence of edge age and additive edge effects on carbon stocks in a tropical forest. Forest Ecology and Management, 407, 57-65.

Dixon, R. K., Winjum, J. K., \& Schroeder, P. E. (1993). Conservation and sequestration of carbon: the potential of forest and agroforest management practices. Global Environmental Change, 3(2), 159-173

Englund, O., Sparovek, G., Berndes, G., Freitas, F., Ometto, J. P., Oliveira, P. V. D. C. E., ... \& Lapola, D. (2017). A new high-resolution nationwide aboveground carbon map for Brazil. Geo: Geography and Environment, 4(2), e00045.

Fahey, T. J., Woodbury, P. B., Battles, J. J., Goodale, C. L., Hamburg, S. P., Ollinger, S. V., \& Woodall, C. W. (2009). Forest carbon storage: ecology, management, and policy. Frontiers in Ecology and the Environment, 8(5), 245-252

Figuti, L. (1993). O homem pré-histórico, o molusco e o sambaqui: considerações sobre a subsistência dos povos sambaquieiros. Revista do Museu de Arqueologia e Etnologia, (3), 67-80.

Freitas, F.L.M. De, Sparovek, G., Mörtberg, U., Silveira, S., Klug, I., Berndes, G., (2017a). Offsetting legal deficits of native vegetation among Brazilian landholders: Effects on nature protection and socioeconomic development. Land use policy 68, 189-199. 
Freitas, F.L.M., Englund, O., Sparovek, G., Berndes, G., Guidotti, V., Pinto, L.F.G., Mörtberg, U., (2017b). Who owns the Brazilian carbon? Global Change Biology, 1-14.

Gloor, M., Gatti, L., Brienen, R., Feldpausch, T. R., Phillips, O. L., Miller, J., ... \& Houghton, R. A. (2012). The carbon balance of South America: a review of the status, decadal trends and main determinants. Biogeosciences, 9(12), 54075430.

Guidotti, V., Freitas, F.L.M. De, Sparovek, G., Hamamura, C., Cerignoni, F., Pinto, L.F.G. (2017). Números detalhados do novo código florestal e suas implicações para os PRAs. Sustentabilidade em debate. Imaflora: Piracicaba, 10p. (2).

Gullison, R. E., Frumhoff, P. C., Canadell, J. G., Field, C. B., Nepstad, D. C., Hayhoe, K., ... \& Nobre, C. (2007). Tropical forests and climate policy. Science, 316(5827), 985-986.

Hansen, M. C., Potapov, P. V., Moore, R., Hancher, M., Turubanova, S. A. A., Tyukavina, A., ... \& Kommareddy, A. (2013). High-resolution global maps of 21st-century forest cover change. Science, 342(6160), 850-853.

Harris, P., Fotheringham, A. S., Crespo, R., \& Charlton, M. (2010). The use of geographically weighted regression for spatial prediction: an evaluation of models using simulated data sets. Mathematical Geosciences, 42(6), 657-680.

Hiemstra, P.H., Pebesma, E.J., Twenhofel, C.J.W. and G.B.M. Heuvelink, (2008). Real-time automatic interpolation of ambient gamma dose rates from the Dutch Radioactivity Monitoring Network. Computers \& Geosciences, accepted for publication.

Houghton, R. A., Lawrence, K. T., Hackler, J. L., \& Brown, S. (2001). The spatial distribution of forest biomass in the Brazilian Amazon: a comparison of estimates. Global Change Biology, 7(7), 731-746.

Houghton, R. A. (2005). Aboveground forest biomass and the global carbon balance. Global Change Biology, 11(6), 945-958.

IBGE - Instituto Brasileiro de Geografia e Estatística (2009) Biomas do Brasil Available at : https://biblioteca.ibge.gov.br/visualizacao/livros/liv47603_cap4_pt8.pd $\mathrm{f}$

IBGE - Instituto Brasileiro de Geografia e Estatística (2018) Estimativa da População Available at :

ftp://ftp.ibge.gov.br/Estimativas_de_Populacao/Estimativas_2018/esti mativa_dou_2018_20181019.pdf

IPCC - Intergovernmental Panel on Climate Change. (2018, October 05). Global Warming of $1.5{ }^{\circ} \mathrm{C}$. Retrieved January 12, 2019, Available at : https://report.ipcc.ch/sr15/index.html

Kupfer, J. A., Malanson, G. P., \& Franklin, S. B. (2006). Not seeing the ocean for the islands: the mediating influence of matrix-based processes on forest fragmentation effects. Global ecology and biogeography, 15(1), 8-20

Laurance, W. F., Laurance, S. G., Ferreira, L. V., Rankin-de Merona, J. M., Gascon, C., \& Lovejoy, T. E. (1997). Biomass collapse in Amazonian forest fragments. Science, 278(5340), 1117-1118.

Laurance, W. F., Ferreira, L. V., Rankin-de Merona, J. M., \& Laurance, S. G. (1998). Rain forest fragmentation and the dynamics of Amazonian tree communities. Ecology, 79(6), 2032-2040 
Laurance, W. F., Delamônica, P., Laurance, S. G., Vasconcelos, H. L., \& Lovejoy, T. E. (2000). Conservation: rainforest fragmentation kills big trees. Nature, 404(6780), 836.

Laurance, W. F. (2008). Theory meets reality: how habitat fragmentation research has transcended island biogeographic theory. Biological conservation, 141(7), 1731-1744.

Laurance, W. F., Camargo, J. L., Luizão, R. C., Laurance, S. G., Pimm, S. L., Bruna, E. M., ... \& Van Houtan, K. S. (2011). The fate of Amazonian forest fragments: a 32-year investigation. Biological conservation, 144(1), 56-67.

Lima, R. A., Mori, D. P., Pitta, G., Melito, M. O., Bello, C., Magnago, L. F., ... \& Prado, P. I. (2015). How much do we know about the endangered Atlantic Forest? Reviewing nearly 70 years of information on tree community surveys. Biodiversity and conservation, 24(9), 2135-2148.

Luyssaert, S., Schulze, E. D., Börner, A., Knohl, A., Hessenmöller, D., Law, B. E., ... \& Grace, J. (2008). Old-growth forests as global carbon sinks. Nature, 455(7210), 213.

MCTIC - Ministério da Ciência Tecnologia Inovações e Comunicações (2017) Estimativas anuais de emissões de gases de efeito estufa no Brasil. Esplanada dos Ministérios Bloco E, Brasília.

Matthews, H. D., Gillett, N. P., Stott, P. A., \& Zickfeld, K. (2009). The proportionality of global warming to cumulative carbon emissions. Nature, 459(7248), 829.

Mesquita, R. C., Delamônica, P., \& Laurance, W. F. (1999). Effect of surrounding vegetation on edge-related tree mortality in Amazonian forest fragments. Biological Conservation, 91(2-3), 129-134.

Melatti, J. C. (2007). Índios do Brasil. Edusp. pp 44-47

Mitchard, E. T., Saatchi, S. S., Baccini, A., Asner, G. P., Goetz, S. J., Harris, N. L., \& Brown, S. (2013). Uncertainty in the spatial distribution of tropical forest biomass: a comparison of pan-tropical maps. Carbon balance and management, 8(1), 10.

Morellato, L. P. C., \& Haddad, C. F. (2000). Introduction: The Brazilian Atlantic Forest 1. Biotropica, 32(4b), 786-792.

Mueller, B. (2016). Key issues for property rights in Brazil: Implications for the Forest Code. Núcleo de Avaliação de Poltticas Climáticas.(ed Initiative CP). PUC-Rio.

Murcia, C. (1995). Edge effects in fragmented forests: implications for conservation. Trends in ecology \& evolution, 10(2), 58-62.

MMA - Ministério do Meio Ambiente do Brasil (2018) REDD+ Brasil Available at: http://redd.mma.gov.br/images/central-demidia/pdf/publicacoes/notainformativa2018_captacaodescentralizacao.pdf Accessed 01/01/19

Nakagawa, S., \& Schielzeth, H. (2013). A general and simple method for obtaining R2 from generalized linear mixed-effects models. Methods in Ecology and Evolution, 4(2), 133-142.

Nepstad, D. C., Verssimo, A., Alencar, A., Nobre, C., Lima, E., Lefebvre, P., ... \& Cochrane, M. (1999). Large-scale impoverishment of Amazonian forests by logging and fire. Nature, 398(6727), 505.

Oliveira-Filho, A. T., \& Fontes, M. A. L. (2000). Patterns of floristic differentiation among Atlantic Forests in Southeastern Brazil and the influence of climate 1. Biotropica, 32(4b), 793-810. 
de-Paula, M. D., Costa, C. P. A., \& Tabarelli, M. (2011). Carbon storage in a fragmented landscape of Atlantic forest: the role played by edge-affected habitats and emergent trees. Tropical Conservation Science, 4(3), 349-358.

MapBiomas Project (2018) - Collection 3 of Brazilian Land Cover \& Use Map Series, Available at:

https://code.earthengine.google.com/?accept_repo=users/mapbiomas/u ser-toolkit Accessed: 01/01/19

Pütz, S., Groeneveld, J., Henle, K., Knogge, C., Martensen, A. C., Metz, M., ... \& Huth, A. (2014). Long-term carbon loss in fragmented Neotropical forests. Nature Communications, 5, 5037.

Rezende, C. L., Scarano, F. R., Assad, E. D., Joly, C. A., Metzger, J. P., Strassburg, B. B. N., ... \& Mittermeier, R. A. (2018). From hotspot to hopespot: An opportunity for the Brazilian Atlantic Forest. Perspectives in ecology and conservation, 16(4), 208-214.

R Core Team (2018). R: A language and environment for statistical computing. $R$ Foundation for Statistical Computing, Vienna, Austria. URL https://www.R-project.org/.

Ribeiro, M. C., Metzger, J. P., Martensen, A. C., Ponzoni, F. J., \& Hirota, M. M. (2009). The Brazilian Atlantic Forest: How much is left, and how is the remaining forest distributed? Implications for conservation. Biological conservation, 142(6), 1141-1153

Ruggiero, P. G., Metzger, J. P., Tambosi, L. R., \& Nichols, E. (2019). Payment for ecosystem services programs in the Brazilian Atlantic Forest: Effective but not enough. Land Use Policy, 82, 283-291

Saatchi, S. S., Harris, N. L., Brown, S., Lefsky, M., Mitchard, E. T., Salas, W., ... \& Petrova, S. (2011). Benchmark map of forest carbon stocks in tropical regions across three continents. Proceedings of the National Academy of Sciences, 108(24), 9899-9904.

Santoro, M., Beaudoin, A., Beer, C., Cartus, O., Fransson, J.E.S., Hall, R.J., Pathe, C., Schmullius, C., Schepaschenko, D., Shvidenko, A., Thurner, M. and Wegmüller, U., (2015). Forest growing stock volume of the northern hemisphere: Spatially explicit estimates for 2010 derived from Envisat ASAR. Remote Sensing of Environment, 168, pp. 316-334.

Slik, J. W. F., Aiba, S. I., Brearley, F. Q., Cannon, C. H., Forshed, O., Kitayama, K., ... \& Poulsen, A. D. (2010). Environmental correlates of tree biomass, basal area, wood specific gravity and stem density gradients in Borneo's tropical forests. Global Ecology and Biogeography, 19(1), 50-60.

SMA-SP Secretaria do Meio Ambiente de São Paulo (2018). Prateleira de Projetos. Retrieved January 5, 2019, from https://www.ambiente.sp.gov.br/programanascentes/prateleira-de-projetos/

Sparovek, G., Barretto, A. G. D. O. P., Matsumoto, M., \& Berndes, G. (2015). Effects of governance on availability of land for agriculture and conservation in Brazil. Environmental science \& technology, 49(17), 10285-10293.

Soares-Filho, B., Rajão, R., Merry, F., Rodrigues, H., Davis, J., Lima, L., ... \& Santiago, L. (2016). Brazil's market for trading forest certificates. PLoS One, 11(4), e015231

SOS-MA - SOS Mata Atlântica. (2018). Atlas dos remanescentes florestais da mata atlântica período 2016-2017. Retrieved January 13, 2019, from https://www.sosma.org.br/link/Atlas_Mata_Atlantica_20162017_relatorio_tecnico_2018_final.pdf 
Strassburg, B. B., Brooks, T., Feltran-Barbieri, R., Iribarrem, A., Crouzeilles, R., Loyola, R., ... \& Soares-Filho, B. (2017). Moment of truth for the Cerrado hotspot. Nature Ecology \& Evolution, 1(4), 0099

TreeCo. (2018, October 08). Neotropical Tree Communities database. Retrieved January 13, 2019, from http://labtrop.ib.usp.br/doku.php?id=projetos:treeco:start

Townsend, A. P. (2001). Predicting SPECIES' Geographic Distributions Based on Ecological Niche Modeling. The Condor, 103(3), 599-605.

Tyukavina, A., Baccini, A., Hansen, M. C., Potapov, P. V., Stehman, S. V., Houghton, R. A., ... \& Goetz, S. J. (2015). Aboveground carbon loss in natural and managed tropical forests from 2000 to 2012. Environmental Research Letters, 10(7), 074002.

\section{Discussão Geral}

Adams, C., da Motta, R. S., Ortiz, R. A., Reid, J., Aznar, C. E., \& de Almeida Sinisgalli, P. A. (2008). The use of contingent valuation for evaluating protected areas in the developing world: Economic valuation of Morro do Diabo State Park, Atlantic Rainforest, São Paulo State (Brazil). Ecological Economics, 66(2-3), 359-370.

Alvares, C. A., Stape, J. L., Sentelhas, P. C., \& de Moraes Gonçalves, J. L. (2013). Modeling monthly mean air temperature for Brazil. Theoretical and Applied Climatology, 113(3-4), 407-427.

Avitabile, V., Herold, M., Heuvelink, G. B. M., Lewis, S. L., Phillips, O. L., Asner, G. P., Armston, J., Ashton, P. S., Banin, L. et al., (2015). An integrated pantropical biomass map using multiple reference datasets. Global Change Biology, 22, pp. 1406-1420.

Birch, J. C., Newton, A. C., Aquino, C. A., Cantarello, E., Echeverría, C., Kitzberger, T., ... \& Garavito, N. T. (2010). Cost-effectiveness of dryland forest restoration evaluated by spatial analysis of ecosystem services. Proceedings of the National Academy of Sciences, 201003369.

Englund, O., Sparovek, G., Berndes, G., Freitas, F., Ometto, J. P., Oliveira, P. V. D. C. E., ... \& Lapola, D. (2017). A new high-resolution nationwide aboveground carbon map for Brazil. Geo: Geography and Environment, 4(2), e00045.

Hansen, M. C., Potapov, P. V., Moore, R., Hancher, M., Turubanova, S. A. A., Tyukavina, A., ... \& Kommareddy, A. (2013). High-resolution global maps of 21st-century forest cover change. Science, 342(6160), 850-853.

Lima, R. A., Mori, D. P., Pitta, G., Melito, M. O., Bello, C., Magnago, L. F., ... \& Prado, P. I. (2015). How much do we know about the endangered Atlantic Forest? Reviewing nearly 70 years of information on tree community surveys. Biodiversity and conservation, 24(9), 2135-2148.

MapBiomas Project (2018) - Collection 3 of Brazilian Land Cover \& Use Map Series, Available

at:

https://code.earthengine.google.com/?accept_repo=users/mapbiomas/u ser-toolkit Accessed: 01/01/19

Morellato, L. P. C., \& Haddad, C. F. (2000). Introduction: The Brazilian Atlantic Forest 1. Biotropica, 32(4b), 786-792.

Scolforo, H. F., Scolforo, J. R. S., Mello, C. R., Mello, J. M., \& Ferraz Filho, A. C. (2015). Spatial distribution of aboveground carbon stock of the arboreal 
vegetation in Brazilian biomes of savanna, Atlantic Forest and semi-arid woodland. PloS one, 10(6), e 0128781.

TreeCo. (2018, October 08). Neotropical Tree Communities database. Retrieved January 13, 2019, Available at :

http://labtrop.ib.usp.br/doku.php?id=projetos:treeco:start 


\section{Anexos e Apêndices}

\section{Appendix 1: Tree community surveys and above ground biomass reference points.}

The TreeCo database is an ongoing effort to compile and organize vegetation surveys for the Atlantic Forest (LIMA et al., 2015) and other extra-Amazonian domains of Brazil. Starting with TreeCo we conducted complimentary a search for inventories of natural formations including basal area, above ground biomass, or carbon done in the Atlantic Forest and Cerrado domain in several online reference databases (BTDCAPES, Google Scholar, Web of Knowledge, SCIELO, SCOPUS, SPRINGERLINK, SCIDIR) adding all studies published until April 2017.

We selected only those inventories containing any type of tree biomass estimates (basal area, above ground biomass and/or carbon). Inventory basal area is a good proxy of the forest above ground biomass (SLIK et al., 2010, BALDERAS TORRES \& LOVETT, 2012), and is used throughout the analysis as the measure of biomass. Fifteen studies that only contained measurements of biomass or carbon had theirs values converted to basal area according to methods on Appendix 2. All forest surveys selected had their coordinates manually checked with google-earth suite to check it falls inside the reported forest fragment (Figure A1.1).

Our natural vegetation dataset contains 331 entries, which represented a total of 505,753 trees, covering 292.88 hectares. The total basal area recorded was $9,749.25$ square meters. The forest types most sampled were Ombrophilous $(38.07 \%$ of the entries) and Semi-Deciduous (35.05\%) and the class with few surveys is the Cerrado stricto sensu (3.63\%) and Mixed Ombrophilous (2.42\%).

From each natural vegetation inventory retrieved during the search, we extracted qualitative and quantitative information and added them into the TreeCo database. We included all Atlantic Forest and Cerrado subtype formations listed by forest inventory authors, making small adjustments to standardize nomenclature. We limited our search to forest inventories done from 1990 onwards unless when the forest inventory was conducted inside conservation unities (at least $65 \mathrm{ha}$ ), assuming that the landscapes containing this forests tend to be more stable over time in terms of its forest cover. This led to the inclusion of surveys with the oldest forest inventory data acquired in 1979. 


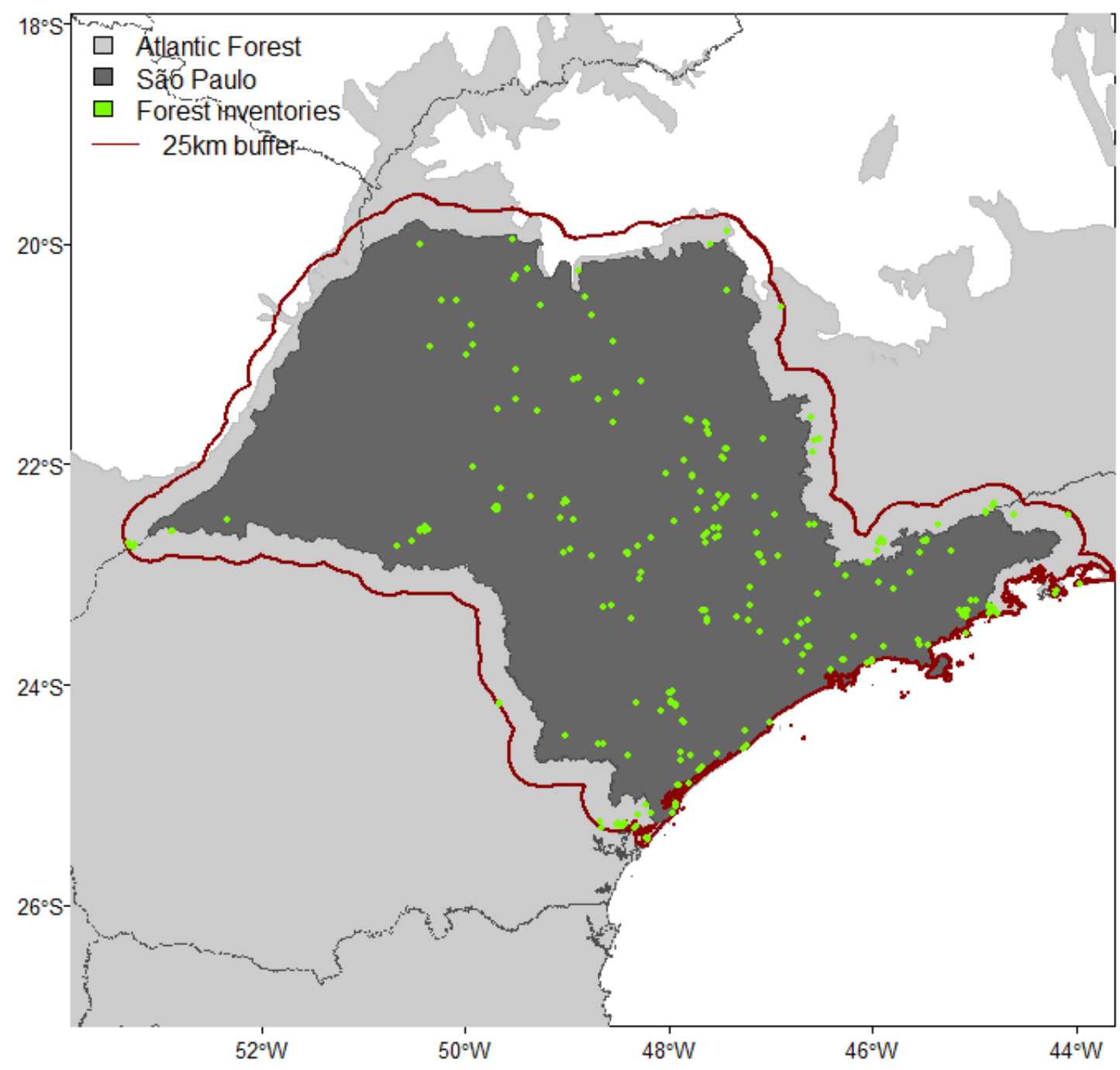

Figure A1.1: Location of the study area and the distribution of the forest inventories. The shaded grey corresponds to the Atlantic Forest limits, darker area represents the São Paulo state, each green dot represents one survey, and the red line is a $25 \mathrm{~km}$ buffer of forest survey inclusion around the state.

The inventories used in the analysis use different criteria to include individuals in their sampling. Most of the used a minimum diameter at breast height (DBH) as their inclusion criterion, but other surveys used diameter at ground height (DGH) or a minimum height $(\mathrm{H})$. To simplify the analysis, we first grouped the original dbh cutoff criteria into some major dbh classes 3 (2.8-3.2), 5 (4.8-5.0) and 10 centimeters. Then, we obtained an equivalent value of dbh for those surveys using criteria such as diameter at ground height or a minimum height criterions, using the following equations:
(A1.1)
$\mathrm{DGH}=0.7814+1.269 * \mathrm{DBH}$,
(A1.2)
$\mathrm{DBH}=1.656 \mathrm{e}-01+1.087 \mathrm{e}-02 * \mathrm{H}$. 
This allometric relationships were obtained from data collected by Lima (2013) which contained measurements of DBH, DGH and H. The conversion between DBH and DGH presented above is in line with the conversion obtained using the equation of Gehring et al. (2008), but we decided to use ours equation because it was obtained from data collected in a stretch of Atlantic Forest of São Paulo state.

We classified all surveys according to four categorical classes of forest disturbance (i.e. heavy, high, medium and low disturbance levels), based on the information given by authors on the forest age and forest disturbance history intensity and timing of human disturbances within the fragment, such as logging, fire, livestock grazing, etc. This is a very general classification with lots of variation in forest structure and diversity within classes, but we were unable to refine it further due to a lack of more detailed information of site disturbance histories in most inventories. If authors did not provide information on the forest disturbances and/or stand age, the relative abundance of typical light-demanding Neotropical genera (e.g. Baccharis, Cecropia, Celtis, Piptocarpha, Trema, Urera and Vernonanthura) were used in a final attempt to classify forests according to their disturbance level.

We recorded total sampled area and sampling arrangement (i.e. contiguous or systematically/randomly distributed), assuming that randomly and systematically distributed sample units are equivalent for the estimation of forest biomass and richness (COCHRAN, 1977). Finally, we carefully cross checked references and data values to avoid inclusion of duplicated entries (i.e. different studies using the same data). 


\section{References}

Balderas Torres, A., \& Lovett, J. C. (2012). Using basal area to estimate aboveground carbon stocks in forests: La Primavera Biosphere's Reserve, Mexico. Forestry, 86(2), 267-281

Cochran, W. G., (1977) Sampling techniques. John Wiley \& Sons, New York, Thrid edition.

Gehring, C., Park, S., \& Denich, M. (2008). Close relationship between diameters at $30 \mathrm{~cm}$ height and at breast height (DBH). Acta Amazonica, 38(1), 71-76.

Lima, R. A. F., Prado, P. I., Martini, A. M. Z., Fonseca, L. J., Gandolfi, S., \& Rodrigues, R. R. (2013). Improving methods in gap ecology: revisiting size and shape distributions using a model selection approach. Journal of Vegetation Science, 24(3), 484-495.

Lima, R. A. F, Mori, D. P., Pitta, G., Melito, M. O., Bello, C., Magnago, L. F., ... \& Prado, P. I. (2015). How much do we know about the endangered Atlantic Forest? Reviewing nearly 70 years of information on tree community surveys. Biodiversity and conservation, 24(9), 2135-2148.

Slik, J. W. F., Aiba, S. I., Brearley, F. Q., Cannon, C. H., Forshed, O., Kitayama, K., ... \& Poulsen, A. D. (2010).Environmental correlates of tree biomass, basal area, wood specific gravity andstem density gradients in Borneo's tropical forests. Global Ecology and Biogeography, 19(1), 50-60. 


\section{Appendix 2: Basal area, Above Ground Biomass and Carbon relationships.}

Studies reporting forest biomass estimates often use distinct methodologies. The most common forest biomass estimate is basal area (cross-sectional area of tree stems), which is obtained based on the DBH measurements of individuals inside a given area. Above ground biomass (AGB) and carbon (AGC) are more precise estimates of forest biomass, because they often take into account not only tree DBH but also tree height and species wood specific gravity. Estimates of AGB are generally obtained based on allometric equations, many of them being developed for specific types of forests or parts of the world. The surveys used in this study presented 13 different allometric equations, although many other were found in the TreeCo database (Table A2.1).

Table A2.1: List of allometric equations reported in the forest inventories, $\mathrm{H}$ denotes Height of the tree, DBH, diameter at breast height, WSG wood specific gravity. After the equation autho $(*)$ indicates that the formula was used in a São Paulo forest inventory and in this study.

\begin{tabular}{|c|c|}
\hline Allometric Equation & uthor (Model) \\
\hline $\exp \left(-2.289+2.649 * \log (\mathrm{DBH})-0.021 *(\log (\mathrm{DBH}))^{\wedge} 2\right)$ & Brown_1997 \\
\hline $\exp \left(-3.676+0.951 *\left(\log \left(\left(\mathrm{DBH}^{\wedge} 2\right) * \mathrm{H}\right)\right)\right)$ & Burger_\&_Delitti_2008 \\
\hline $\exp ((-3.068)+2.522 * \log (\mathrm{DBH}))$ & Burger_\&_Delitti_2008(b) \\
\hline $\exp \left(-2.187+0.916 * \log \left(\mathrm{WSG}^{*}\left(\mathrm{DBH}^{\wedge} 2\right)^{*} \mathrm{H}\right)\right)$ & Chave_et_al_2005(DryH) \\
\hline WSG*exp $\left(-1.449+2.148 * \log (\mathrm{DBH})+0.207 *\left(\log (\mathrm{DBH})^{\wedge} 2\right)-0.0281 *\left(\log (\mathrm{DBH})^{\wedge} 3\right)\right)$ & Chave_et_al_2005(Moist) \\
\hline $\exp \left(-2.977+\log \left(\mathrm{WSG}^{*}\left(\mathrm{DBH}^{\wedge} 2\right)^{*} \mathrm{H}\right)\right)$ & Chave_et_al_2005(MoistH) \\
\hline $\exp \left(-2.557+0.940 * \log \left(\mathrm{WSG}^{*}\left(\mathrm{DBH}^{\wedge} 2\right)^{*} \mathrm{H}\right)\right)$ & Chave_et_al_2005(WetH) \\
\hline $0.0673 *\left(\mathrm{WSG}^{*}\left(\mathrm{DBH}^{\wedge} 2\right)^{*} \mathrm{H}\right)^{\wedge}(0.976)$ & Chave_et_al_2014(4) \\
\hline $\exp \left(-4.15190+1.06068 * \log \left(\left(\mathrm{DBH}^{\wedge} 2\right)^{*} \mathrm{H}\right)\right)$ & Melo_\&_Mantovani_1994 \\
\hline $\exp (-10.9520199234+2.0898526615 * \log (\mathrm{DBH})+0.8096162241 * \log (\mathrm{H})) /(0.4839)$ & Scolforo_et_al_2008(FES) \\
\hline $\exp (-11.319842099+2.1415723631 * \log (\mathrm{DBH})+0.8134282561 * \log (\mathrm{H})) /(0.4833)$ & Scolforo_et_al_2008(FOM) \\
\hline $21.297-(6.953 * \mathrm{DBH})+\left(0.74 *\left(\mathrm{DBH}^{\wedge} 2\right)\right)$ & Tiepolo_et_al_2002 \\
\hline $0.6 * \exp (-2.694+2.038 * \log (\mathrm{DBH})+0.902 * \log (\mathrm{H}))$ & Velasco_\&_Higuchi_2007 \\
\hline
\end{tabular}

After compiling the AGB formulas, we used individual tree data from 43 plots from Brazil to estimate the relationships between different allometric equations to 
estimate AGB. Tree species listings were crossed with a database of wood specific gravity (WSG) (CHAVE et al., 2009; ZANNE et al., 2009) and assigned WSG for each species. If a species had no WSG available, it was assigned the average of the genus (BAKER et al., 2004; CHAVE et al. 2006). If at this taxonomic level still no WSG recorded, then the family average was assigned. If still any of those steps did not provide a wsg value, the average of the total sample was assigned $(0.6555 \mathrm{~g} / \mathrm{cm} 3)$.

The TreeCo database also includes raw data from around 167 thousand trees measured in 43 permanent plots in Brazil (TreeCo, 2018). We used data regarding tree diameter at breast height $(\mathrm{DBH})$, tree height $(\mathrm{H})$ and wood specific gravity (WSG), trees with missing height measurement or on-field height guess had estimations of height provided by an allometric relationship of dbh and height (Figure 2). Three concurring models were tested to describe (Power model, Weibull model and Chapman-Richards model SCARANELLO et al., 2012) along with equation 6a from Chave et al. 2014 which uses a coordinate grid of environmental stress to define such Height and DBH relationship). Using the Akaike information criterion the winning representation was the power model relationship below:

Height $\sim \mathrm{a} * \mathrm{DBH}^{\wedge} \mathrm{b}$

$\begin{array}{lllll}\text { Parameters: } & \text { Estimate } & \text { Std. Error } & \mathbf{t} \text { value } & \operatorname{Pr}(>|\mathbf{t}|) \\ \text { a } & 2.614573 & 0.010210 & 256.1 & <2 \mathrm{e}-16 * * * \\ \text { b } & 0.476434 & 0.001454 & 327.6 & <2 \mathrm{e}-16 * * *\end{array}$



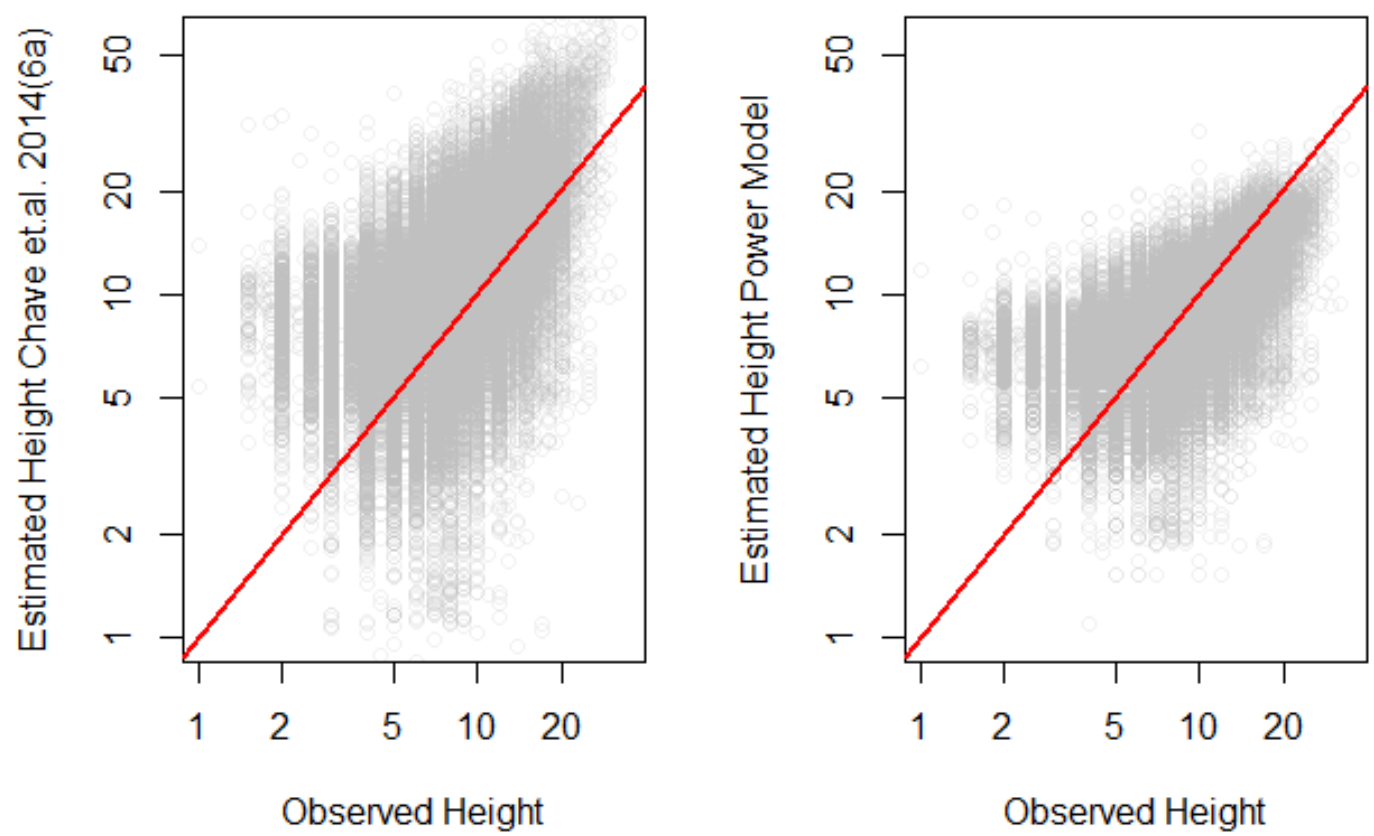

Figure A2.1: Visual interpretation of our power model (b) reveals less dispersion along the 1:1 line than the estimation using Chave et. al. 2014 (a). Grey dots are individual trees, red line is the mean prediction of the estimated relationship.

For each plot we estimated the relationship of all allometric equations (Table 2) with the allometric equation proposed by Chave et.al. (2014) - see formula 7. We used a simple linear model to describe the relationship between each pair of allometric equation. We tested two types of linear regression, one weighted by the total sampling effort of each survey (in ha) and its logarithmic transformation. Neither weighting efforts returned a better fit. Figure A2.3 depicts all the relationships between allometric equations. 

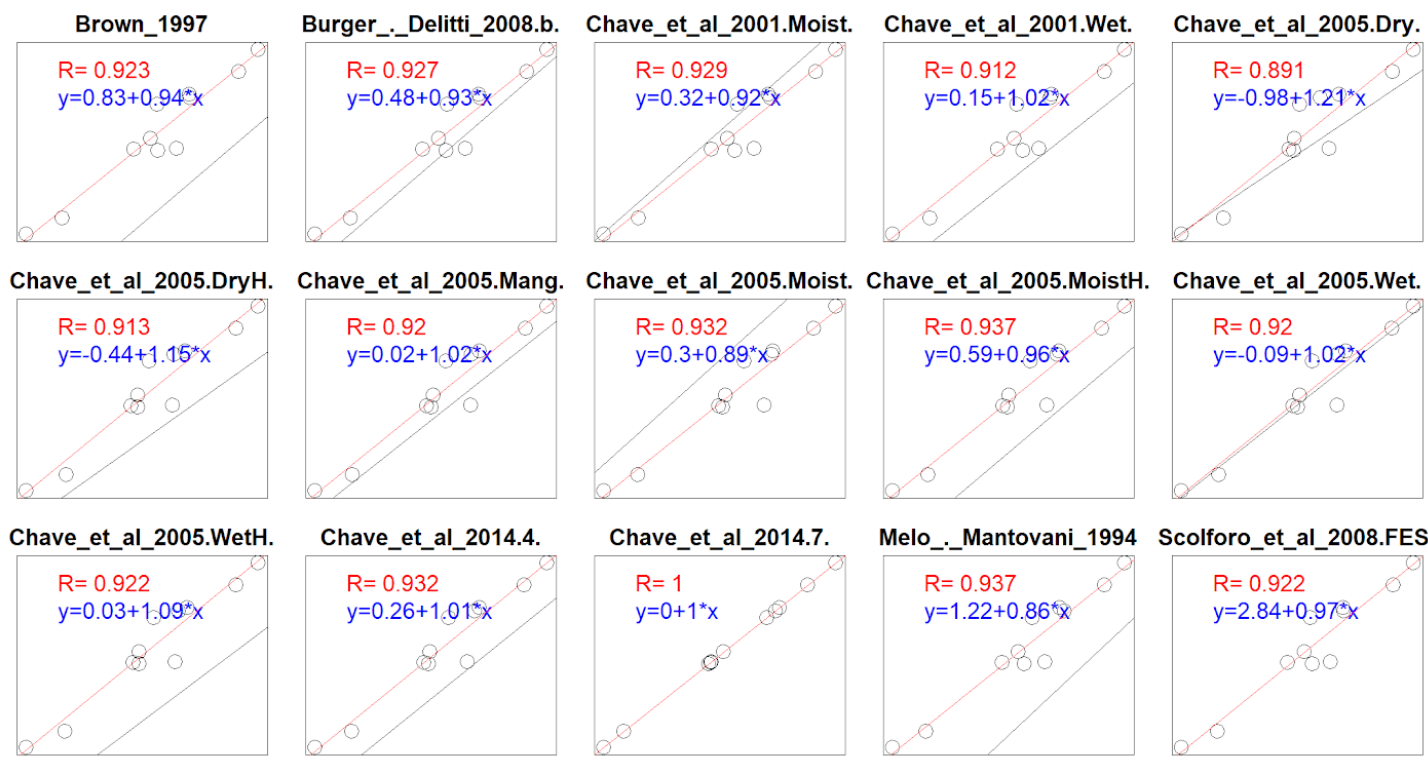

Chave_et_al_2014.4.

Chave_et_al_2014.7.

Melo_-_Mantovani_1994 Scolforo_et_al_2008.FES. $\mathrm{R}=0.932$ $y=0.26+1.01 * x$

$\mathrm{R}=1$

$y=0+1^{*} x$

$\mathrm{R}=0.937$

$y=1.22+0.86^{*} \times$

$\mathrm{R}=0.922$

$y=2.84+0.97^{*} x$

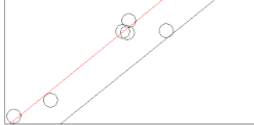

Scolforo_et_al_2008.FOM.

Tiepolo_et_al_2002
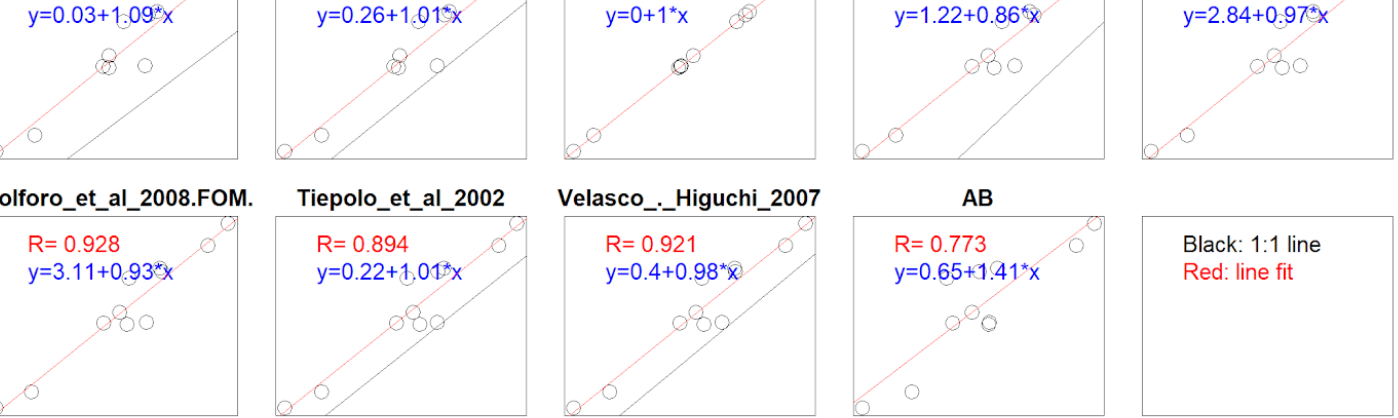

Velasco_._Higuchi_2007

$\mathrm{AB}$
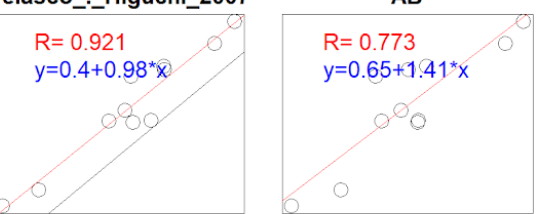

Black: $1: 1$ line Red: line fit

Figure A2.2: Linear relationships with between allometric equations and Chave et.al. 2014 formula (7). Y is the natural logarithmic of the the Chave's formula value for aboveground biomass and $\mathrm{X}$ is the natural logarithmic of the aboveground biomass of each allometric equation. We present the resulting parameters of the regression (in blue), the associated R square of the relationship (in red), 1:1 line and fit lines are also displayed in each graph (grey line). 


\section{References}

Baker, T. R., Phillips, O. L., Malhi, Y., Almeida, S., Arroyo, L., Di Fiore, A., ... \& Lewis, S. L. (2004). Variation in wood density determines spatial patterns in Amazonian forest biomass. Global Change Biology, 10(5), 545-562.

Brown, S. (1997). Estimating biomass and biomass change of tropical forests: a primer (Vol. 134). Food \& Agriculture Org..

Burger, D. M., \& Delitti, W. B. C. (2008). Allometric models for estimating the phytomass of a secondary Atlantic Forest area of southeastern Brazil. Biota Neotropica, 8(4), 0-0.

Chave J, Coomes DA, Jansen S, Lewis SL, Swenson NG, Zanne AE (2009) Towards a worldwide wood economics spectrum. Ecology Letters 12(4): 351-366.

Chave, J., Andalo, C., Brown, S., Cairns, M. A., Chambers, J. Q., Eamus, D., ... \& Lescure, J. P. (2005). Tree allometry and improved estimation of carbon stocks and balance in tropical forests. Oecologia, 145(1), 87-99

Chave, J., Muller-Landau, H. C., Baker, T. R., Easdale, T. A., Steege, H. T., \& Webb, C. O. (2006). Regional and phylogenetic variation of wood density across 2456 neotropical tree species. Ecological applications, 16(6), 2356-2367

Chave, J., Réjou-Méchain, M., Búrquez, A., Chidumayo, E., Colgan, M. S., Delitti, W. B., ... \& Henry, M. (2014). Improved allometric models to estimate the aboveground biomass of tropical trees. Global change biology, 20(10), 31773190.

Melo, M.M.R.F. \& Mantovani, W. 1994. Composição florística e estrutura de trecho de Mata Atlântica de encosta, na Ilha do Cardoso (Cananéia, SP, Brasil). Boletim do Instituto de Botânica 9:107-158.

Scaranello, M. A. D. S., Alves, L. F., Vieira, S. A., Camargo, P. B. D., Joly, C. A., \& Martinelli, L. A. (2012). Height-diameter relationships of tropical Atlantic moist forest trees in southeastern Brazil. Scientia Agricola, 69(1), 26-37.

Scolforo, J. R. (2008). Inventário florestal de Minas Gerais: equações de volume, peso de matéria seca e carbono para diferentes fisionomias da flora nativa. Editora UFLA.

Tiepolo, G., Calmon, M., \& Feretti, A. R. (2002, November). Measuring and monitoring carbon stocks at the Guaraqueçaba climate action project, Paraná, Brazil. In Proceedings of the International Symposium on Forest Carbon Sequestration and Monitoring (pp. 11-15). Taipei: Taiwan Forestry Research Institute.

Velasco, G. D. N. \& Higuchi N. (2009) Estimativa de seqüestro de carbono em mata ciliar: projeto POMAR, São Paulo (SP) Ambiência Guarapuava, PR v.5 n.1 p.135 -141

Zanne AE, Lopez-Gonzalez G, Coomes DA, Ilic J, Jansen S, Lewis SL, Miller RB, Swenson NG, Wiemann MC, Chave J (2009) Data from: Towards a worldwide wood economics spectrum. Dryad Digital Repository. https://doi.org/10.5061/dryad.234 


\section{Appendix 3: Co-variables for AGB modeling}

For our pre-colonial carbon estimation we evaluated several co-variables capable to help explaining the observed carbon stocks in the forest inventories. We evaluated these variables for their normality and correlation within other co-variables, and selected those least correlated. Some variables were obtained from the original publication, while others, such as climatic, soil, landscape and ecological data, were obtained from georeferenced datasets.

\section{Climate Co-variables}

We extracted air temperature, annual rainfall and monthly precipitation, all with $100 \mathrm{~m}$ of resolution (ALVARES et al., 2013). From monthly precipitation we computed rainfall seasonality (sensu WALSH \& LAWLER, 1981). We also extracted the climatic water deficit at resolution of 5000 m (CHAVE et al. 2014), and the 19 Bioclimatic variables from WorldClim at resolution of $1000 \mathrm{~m}$; (HIJMANS et al. 2005). Data extraction was done in $\mathrm{R}$ (R Core Team, 2018) using package raster (HIJMANS, 2017).

\section{$\underline{\text { Soil }}$}

To estimate our pre-colonial carbon stocks we needed a map of the vegetation types prior to human intervention. To this end we used the 2009 vegetation map from Brazil elaborated by the Brazilian Institute of Geography and Statistics (IBGE, 2009), which includes a preterit vegetation classification, that delimits the reported limits of ecotones. We also made use of the the soil maps produced by IBGE, and adjusted the naming scheme to match the forest surveys.

\section{$\underline{\text { Soil Co-variables }}$}

Forest surveys soil reports provided by the authors were checked against soil maps at state level (DOS SANTOS et al., 2011). Soil information was manually checked and classified, giving priority to the classification provided by the authors of the original publication. Each survey had its soil type defined at the best resolution possible, following the IBGE and Rossi (2017) classification. We generated an index of soil suitability for plant growth Where to obtain the soil suitability for plant 
growth, we had assess to used a database of nearly 6000 soil profiles from Brazil (MUNIZ et al., 2011). After classifying each profile using the same soil classification from Rossi 2017, profiles were ordered in terms of its suitability for plant growth according to: depth, fertility, drainage, and aluminium toxicity (PEREIRA \& LOMBARDE NETO, 2004). For each of these soil attributes were ranked from 0 (very inapt for plant growth) to 4 (very apt for plant growth). Therefore, the soil aptitude variable used in this study is a compound index varying from 0 (very inapt) to 16 (very apt).

\section{$\underline{\text { Terrain Co-variables }}$}

We gathered NASA Shuttle Radar Topography Mission data sets from year 2000 with the resolution of 1 arc degree. Georeferenced to WGS84 and grouped the geo-tifs into $4 \times 4$ arc degree files. Along the height we calculated the slope with GDAL-QGIS "slope" function ranging from 0 to 90 degrees. Aspect of the terrain, with GDAL-QGIS "aspect" function, attributing North to 1 and 359 and south to 180 in a 360 scale, and 0 to pixels without aspect.

\section{$\underline{\text { Vegetation Co-variables }}$}

\section{$\underline{\text { Fragment size }}$}

Fragment size is a good proxy for habitat availability for species and a proxy of the proportion of the fragment susceptible to landscape effects transitioning to fragment core areas (Putz, et al., 2014). Fragment size was extracted from the original publications and checked with Google Earth Pro (@) Google Inc.). The smallest vegetation fragment had only $0.55 \mathrm{ha}$ and the larger fragments (>50.000 ha) were rare.

\section{Processing and selection of explanatory variables included in the model}

Forest disturbance level was the only categorical explanatory variable we had, but since categories are ordered we attributed arbitrary values for each category. These values were: 15 for very heavy, 40 for high, 70 for medium and 100 for low disturbance levels. We standardized all explanatory variables prior to analysis (i.e. (observed - mean)/standard deviation), so that all variables had a similar range of variation, making their estimated effects comparable.

The selection of explanatory variables was based on their performance on previous similar studies (unpublished data, R.A.F. LIMA) and on the absence of 
strong correlation or collinearity with other explanatory variables. We selected as candidate variables humidity and mean annual temperature, as they are basic climatic variables, and measure seasonality. While we tested other landscape metrics (such as perimeter area relationships, fractal mandelbrot index), the metric with least collinearity was the aggregation index, which provides a simple measure of patch aggregation (MCGARIGAL et al., 2012). In this index values close to one represent high aggregation, while higher values represent greater disaggregation. The regression model containing all the pre-selected candidate environmental and human-related variables was tested for collinearity and all condition indices were considered quite low (BELSLEY, 1991).

\section{$\underline{\text { Linear mixed-effect models }}$}

We performed a model selection procedure to find the best fixed and random effects structure to explain the variation of biomass in our study area. Candidate models had different combinations of abiotic and biotic co-variables and interactiosn between them. To avoid problems with the interpretation of individual coefficients, only those interactions with a clear biological meaning, were included such as the interactions of solar incidence with Forest Disturbance Level. The model with best fit to data contained only one random effect (i.e. vegetation type) that improved overall model fit. Model selection was based on the Akaike information criterion (AIC) and AIC values greater than 2 between models were considered as an indicative of difference in models fit (HU, 2007). We tested the significance of the chosen model based on the comparison of a "null" model containing only random effects (no fixed effects), using Chi-squared statistics. We also obtained the conditional (pseudo) $R^{2}$, which may be seen as the variance explained by the full model (fixed + random effects NAKAGAWA \& SCHIELZETH 2013). 


\section{References}

Alvares, C. A., Stape, J. L., Sentelhas, P. C., \& de Moraes Gonçalves, J. L. (2013). Modeling monthly mean air temperature for Brazil. Theoretical and Applied Climatology, 113(3-4), 407-427.

Belsley, D.A., (1991) A Guide to using the collinearity diagnostics. Comput. Sci. Econ. Manag. 4, 33-50 .

Chave, J., Réjou-Méchain, M., Búrquez, A., Chidumayo, E., Colgan, M. S., Delitti, W. B., ... \& Henry, M. (2014). Improved allometric models to estimate the aboveground biomass of tropical trees. Global change biology, 20(10), 31773190.

dos Santos, H. G., Carvalho Junior, W. D., Dart, R. D. O., Áglio, M. L. D., de Sousa, J. S., Pares, J. G., ... \& de Oliveira, A. P. (2011). O novo mapa de solos do Brasil: legenda atualizada. Embrapa Solos-Documentos (INFOTECA-E).

Google Inc (2018 - Google Earth Pro Available at: https://www.google.com/earth/versions/\#download-pro

Hijmans, R. J., (2017). raster: Geographic Data Analysis and Modeling. R package version 2.6-7. Available at: https://CRAN.R-project.org/package=raster

Hijmans, R. J., Cameron, S. E., Parra, J. L., Jones, P. G., \& Jarvis, A. (2005). Very high resolution interpolated climate surfaces for global land areas. International journal of climatology, 25(15), 1965-1978.

$\mathrm{Hu}$, S. (2007). Akaike information criterion. Center for Research. Scientific Computation, 93.

IBGE - Instituto Brasileiro de Geografia e Estatística (2009) Biomas do Brasil Available at : https://biblioteca.ibge.gov.br/visualizacao/livros/liv47603_cap4_pt8.pdf

McGarigal, K., Cushman, S., Ene, E., (2012) FRAGSTATS v4: Spatial Pattern Analysis Program for Categorical and Continuous Maps. Comput. Softw. Progr. Prod.

Muniz, M., Curi, N., Sparovek, G., de Carvalho Filho, A., Godinho Silva, S. H., (2011) Principles, Application and Assessment in Soil Science, B. E. O. Gungor, Ed. (InTech, Rijeka, Croatia, 2011), pp. 309-332.

NASA. (2019, January 14). Shuttle Radar Topography Mission. Retrieved January 14, 2019, from https://www2.jpl.nasa.gov/srtm/cbanddataproducts.html

Pereira, L. C., Lombarde Neto F., (2004) Avaliação da aptidão agrícola das terras: proposta metodológica. Embrapa Meio Ambiente. Documentos, 43, Jaguariúna, vol. 43.

Pütz, S., Groeneveld, J., Henle, K., Knogge, C., Martensen, A. C., Metz, M., ... \& Huth, A. (2014). Long-term carbon loss in fragmented Neotropical forests. Nature Communications, 5, 5037.

Rossi, M. (2017). Mapa pedológico do Estado de São Paulo: revisado e ampliado. São Paulo: Instituto Florestal, 2017. V.1. 118p.

S. Nakagawa, H. Schielzeth, A general and simple method for obtaining R2 from generalized linear mixed-effects models. Methods Ecol. Evol. 4, 133-142 (2013).

Walsh, R. P. D., Lawler, D. M. (1981) Rainfall Seasonality: Description, Spatial Patterns and Change Through Time. Weather. 36, 201-208 


\section{Appendix 4: Interpolation of AGB in a pre-colonial scenario}

For our extrapolation of above ground biomass stocks prior colonization we applied a $25 \mathrm{~km}$ buffer around the São Paulo state, and overlaid an hexagonal grid (BIRCH et al., 2010). Whenever a hexagon felt partially inside the study area its center was moved inside the study area (Figure A5.1.).

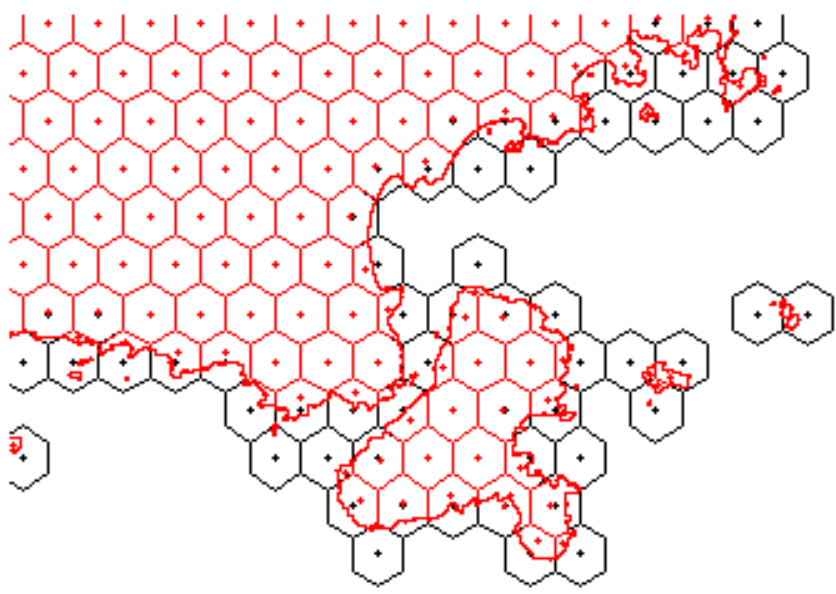

Figure A5.1: Detail at coastal and island region of São Paulo, red lines represent the interior of continental margins and black hexagons the result of a simple overlay of the hexagonal grid. The snapping of hexagons to the continental margin to keep proportional area.

This hexagonal grid at a 2.500ha was used for the spatial extraction of the covariables used on the extrapolation of our linear mixed effects model (1 in methods section) and building of the pre-colonial scenario. The spatial representation of the covariables use displayed on Figure A5.2: 

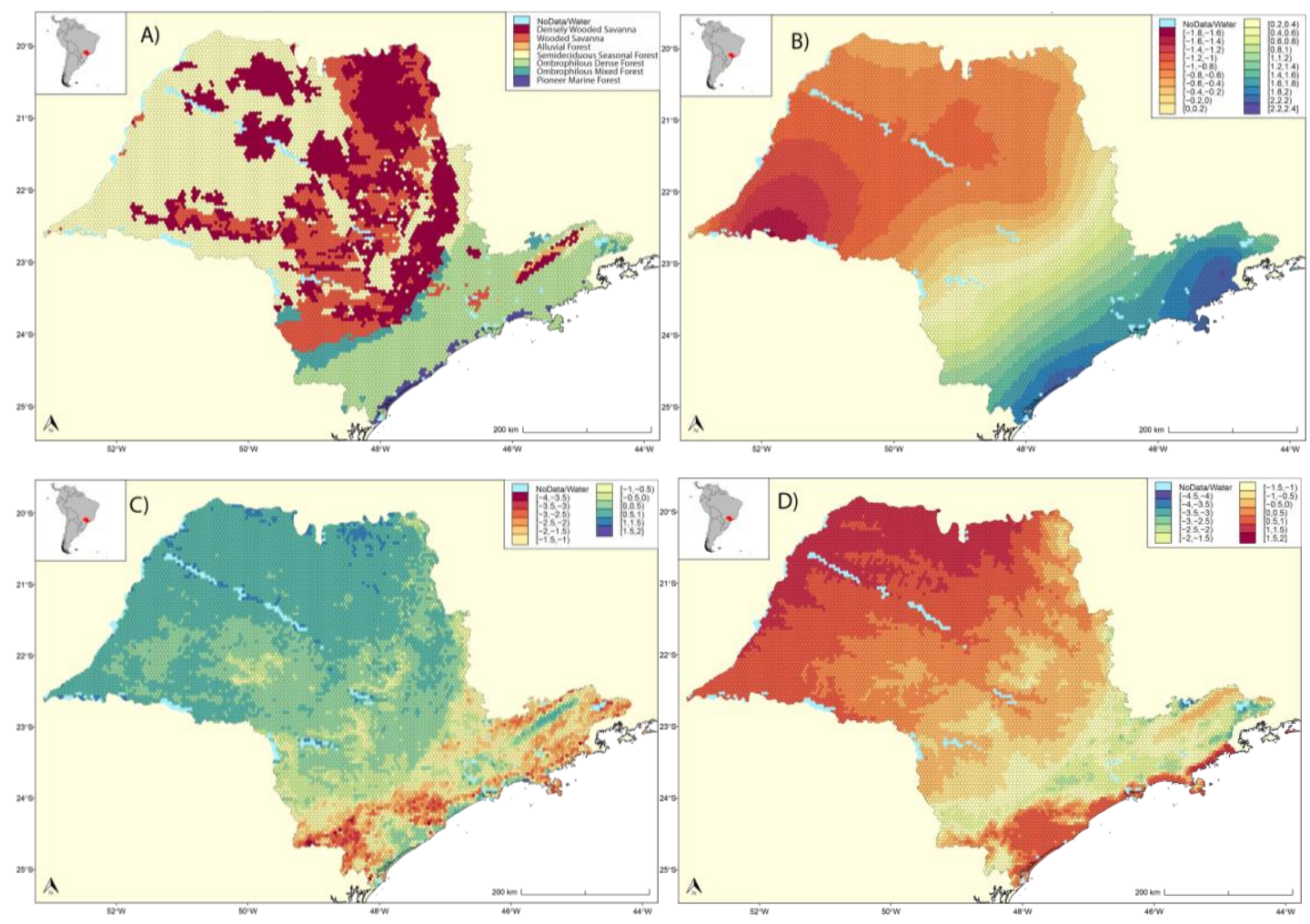

Figure A5.2: Spatial representation of the variable used in the pre-colonial scenario (A) Phytophysiognomies delimitation; (B) Normalized relative humidity; (C) Normalized Direct incident Solar Radiation; (D) Normalized mean annual temperature. Data from ALVARES et al., (2013) and NASA, (2018).

Applying (5) with the co-variables depicted on figure A5.2 along three different methodologies (BATES et al., 2015; HIEMSTRA et al., 2008; GRÄLER et al., 2016; BIVAND \& YU, 2017) to estimate Above Ground Biomass for our pre colonial scenario, results can be seen on Figure A5.3. Mean standard errors on Figure A5.4.

Validation was achieved by applying the same resolution and hexagonal grid to the rasters provided by recent literature (AVITABILE et al., 2015; SANTORO et al., 2015; ENGLUND et al., 2017). 

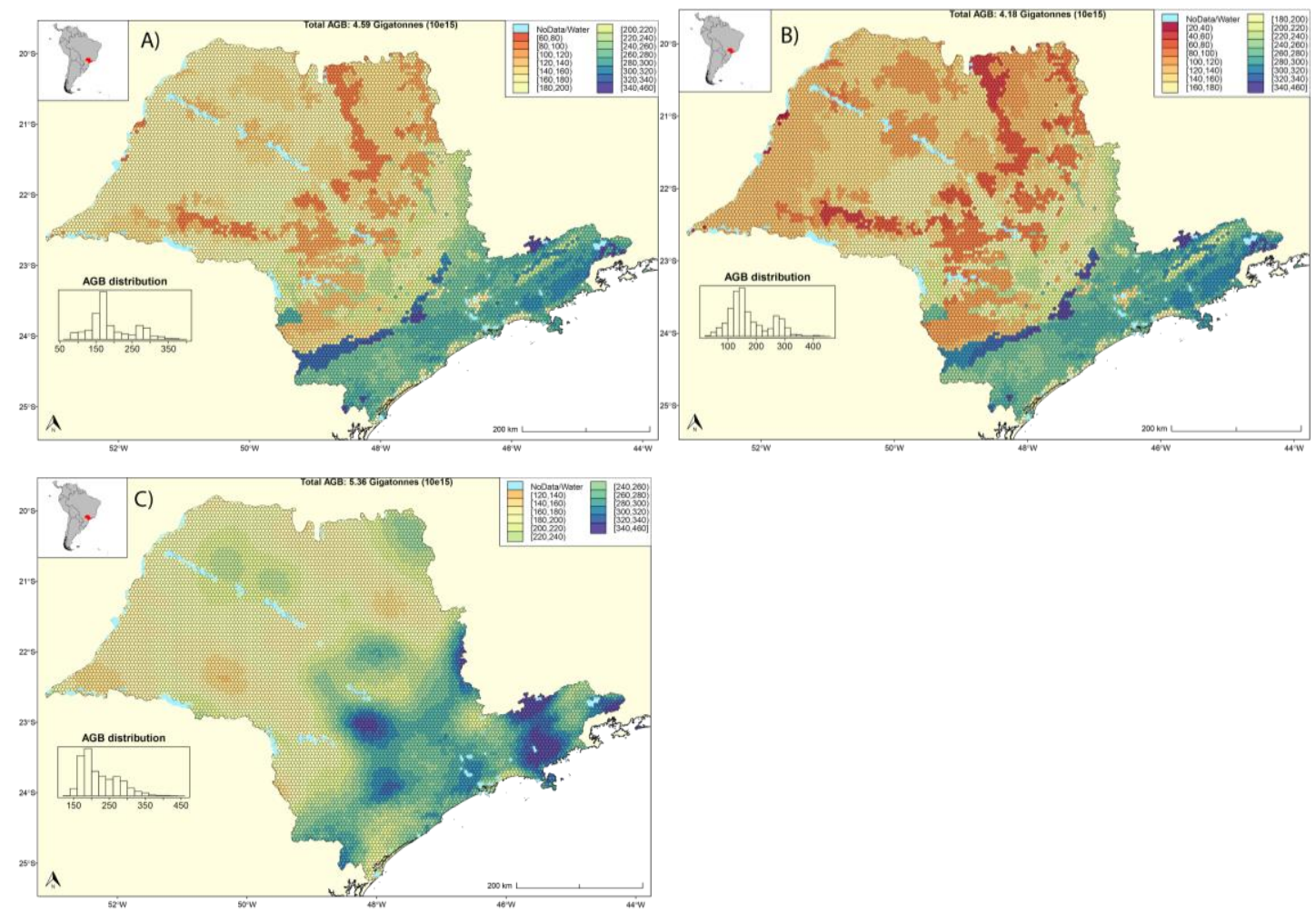

Figure A5.3. AGB distribution prior to heavy human interventions by three methodologies. (A) Linear Mixed Effects Model, with group random effects and spatial correlation; (B) Geographically Weighted Regression Model; and (C) Auto Kriging.

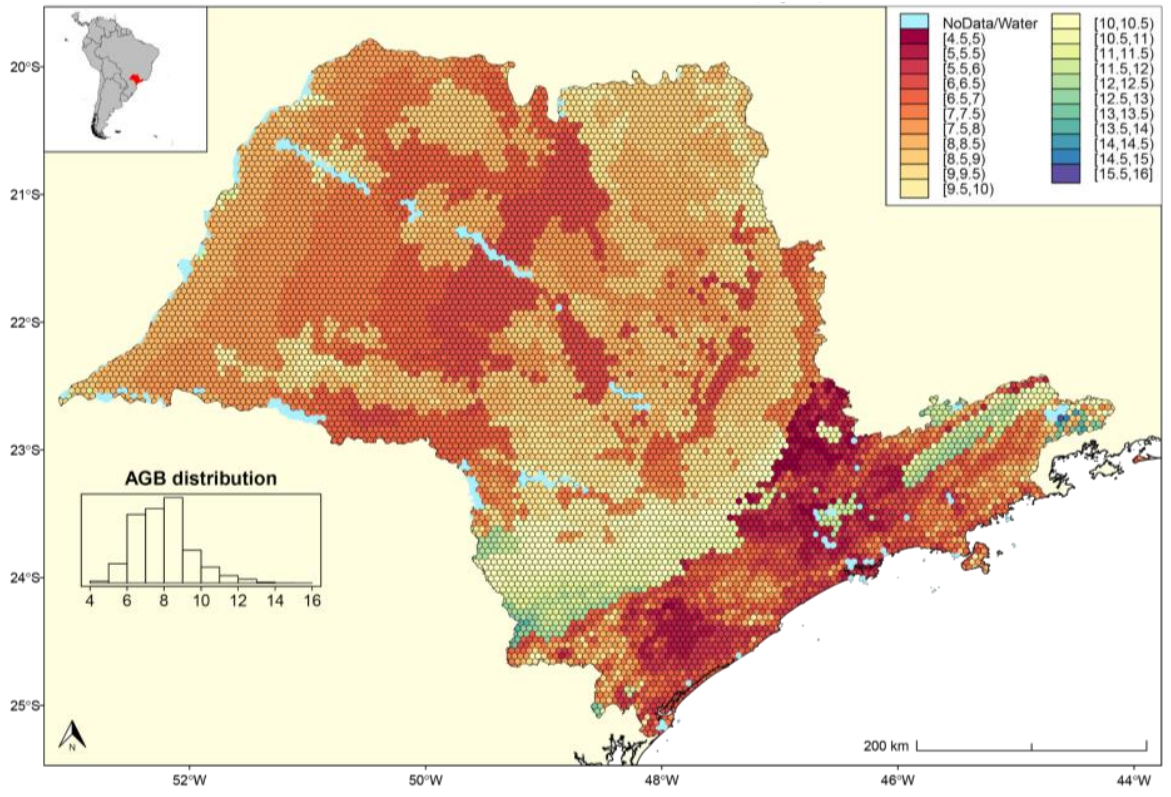

Figure A5.4 Spatial representation of the mean standard errors resulting from the combination of the three methodologies used to obtain the pre-colonial scenario. 

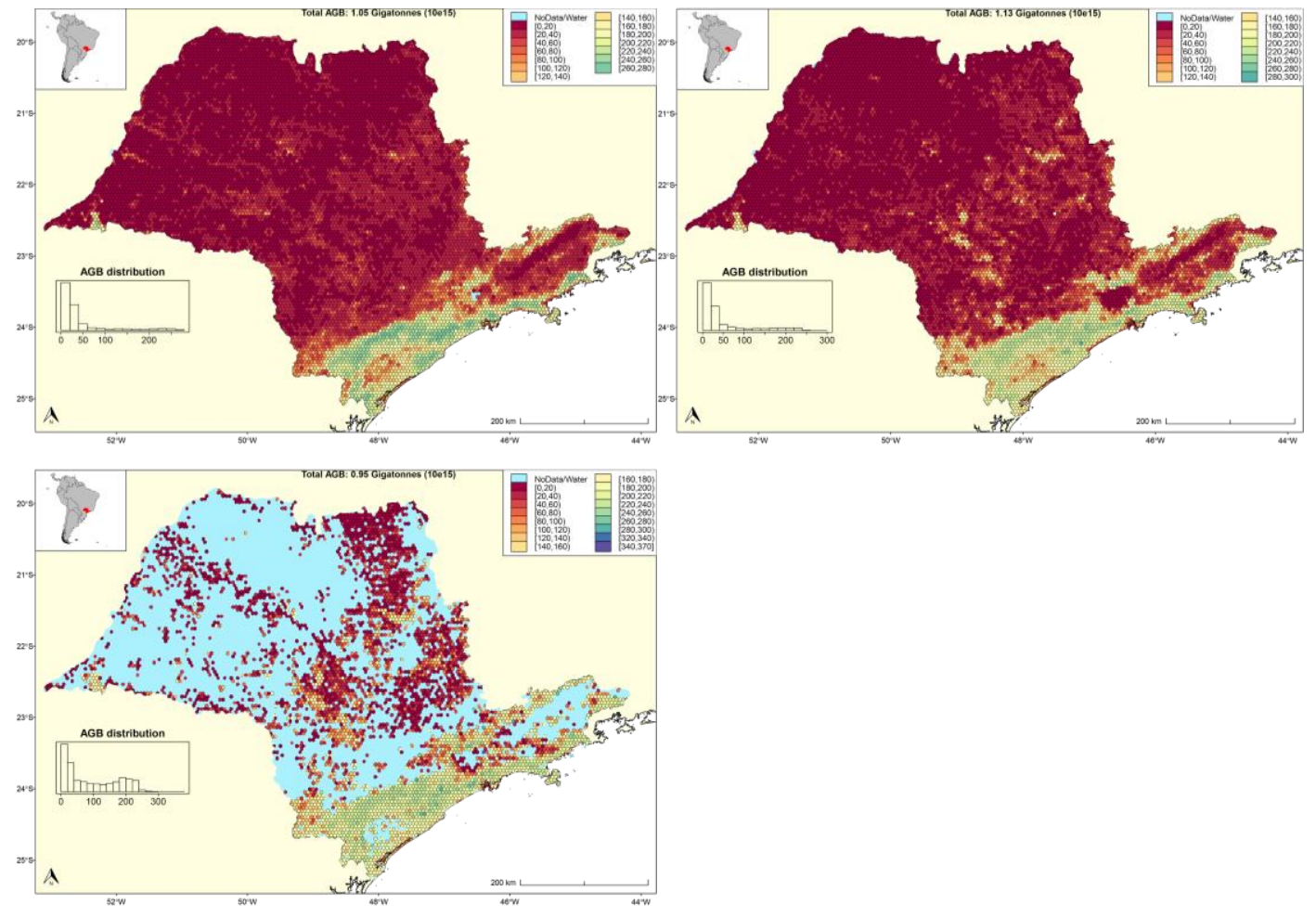

Figure A.5.5 Representation in the same color scale and at 2,500ha scale of the works on carbon estimation from (A) Englund et al. 2017 (B) Avitabile et al. 2015 (C) Saatchi et al. 2011 


\section{References}

Alvares, C. A., Stape, J. L., Sentelhas, P. C., \& de Moraes Gonçalves, J. L. (2013). Modeling monthly mean air temperature for Brazil. Theoretical and Applied Climatology, 113(3-4), 407-427.

Avitabile, V., Herold, M., Heuvelink, G. B. M., Lewis, S. L., Phillips, O. L., Asner, G. P., Armston, J., Ashton, P. S., Banin, L. et al., (2015). An integrated pantropical biomass map using multiple reference datasets. Global Change Biology, 22, pp. 1406-1420.

Bates, D., Maechler M., Bolker, Ben., Walker, S. (2015). Fitting Linear MixedEffects Models Using lme4. Journal of Statistical Software, 67(1), 1-48 doi:10.18637/jss.v067.i01.

Birch, J. C., Newton, A. C., Aquino, C. A., Cantarello, E., Echeverría, C., Kitzberger, T., ... \& Garavito, N. T. (2010). Cost-effectiveness of dryland forest restoration evaluated by spatial analysis of ecosystem services. Proceedings of the National Academy of Sciences, 201003369.

Bivand R. \& Danlin Yu (2017). spgwr: Geographically Weighted Regression. R package version 0.6-32. Available at : https://CRAN.Rproject.org/package $=$ spgwr

Englund, O., Sparovek, G., Berndes, G., Freitas, F., Ometto, J. P., Oliveira, P. V. D. C. E., ... \& Lapola, D. (2017). A new high-resolution nationwide aboveground carbon map for Brazil. Geo: Geography and Environment, 4(2), e00045.

Gräler, B., Pebesma, E., and Heuvelink, G. (2016). Spatio-Temporal Interpolation using gstat. The R Journal 8(1), 204-218

Hiemstra, P.H., Pebesma, E.J., Twenhofel, C.J.W. and G.B.M. Heuvelink, (2008). Real-time automatic interpolation of ambient gamma dose rates from the Dutch Radioactivity Monitoring Network. Computers \& Geosciences, accepted for publication.

NASA. (2019, January 14). Shuttle Radar Topography Mission. Retrieved January 14, 2019, from https://www2.jpl.nasa.gov/srtm/cbanddataproducts.html

Saatchi, S. S., Harris, N. L., Brown, S., Lefsky, M., Mitchard, E. T., Salas, W., ... \& Petrova, S. (2011). Benchmark map of forest carbon stocks in tropical regions across three continents. Proceedings of the National Academy of Sciences, 108(24), 9899-9904. 
Appendix 5: Municipal data table

\begin{tabular}{|c|c|c|c|c|c|}
\hline Municipality & $\begin{array}{r}\text { AGB } \\
\text { Mean } \\
(\mathrm{Mg} / \mathrm{ha}) \\
\end{array}$ & $\begin{array}{r}\text { Legal } \\
\text { egetation } \\
\text { Area } \\
\text { deficit } \\
\text { (ha) } \\
\end{array}$ & $\begin{array}{r}\text { AGB Pre- } \\
\text { Colonial } \\
(\mathbf{M g}) \\
\end{array}$ & $\begin{array}{r}\text { AGB } \\
\text { Remaining } \\
2017 \\
(\mathbf{M g}) \\
\end{array}$ & $\begin{array}{r}\text { AGB } \\
\text { Potential } \\
\text { Recovery } \\
\text { Legal } \\
\text { compliance } \\
(\mathrm{Mg}) \\
\end{array}$ \\
\hline Águas da Prata & 255.49 & 607.08 & 3658159.04 & 511106.97 & 102332.22 \\
\hline Águas de Lindóia & 266.73 & 230.1 & 1600580.69 & 92824.72 & 40390.44 \\
\hline Águas de Santa Bárbara & 147.64 & 1169.88 & 6025949.8 & 382938.95 & 114698.49 \\
\hline Águas de São Pedro & 150.12 & 8.3 & 48013.86 & 2800.28 & 884.74 \\
\hline Adamantina & 163.11 & 3077.41 & 6731839.21 & 84115.34 & 330077.17 \\
\hline Adolfo & 148.71 & 819.45 & 3140792.18 & 58152.97 & 120727.47 \\
\hline Aguai & 191.25 & 2311.92 & 9051474.23 & 403220.1 & 285585.13 \\
\hline Agudos & 138.23 & 4949.13 & 13361834.04 & 1169107.39 & 448365.52 \\
\hline Alambari & 222.04 & 405.88 & 3529850.71 & 175268.39 & 59392.73 \\
\hline Alfredo Marconde & 161.2 & 689.27 & 1919915.53 & 10153.13 & 73279.98 \\
\hline Altair & 145.96 & 1334.76 & 4613898.59 & 194758.23 & 128947.31 \\
\hline Altinópolis & 136.8 & 3011.34 & 12729993.62 & 1424587.26 & 283183.08 \\
\hline Alto Alegre & 173.24 & 1047.32 & 5512446.44 & 139753.21 & 119333.07 \\
\hline Alumínio & 266.71 & 215 & 2249829.79 & 332776.14 & 37602.26 \\
\hline Alvinlândia & 168.31 & 415.1 & 1437403.1 & 238485.16 & 45989.48 \\
\hline Álvares Florence & 150.32 & 1068.33 & 5432018.78 & 148081.65 & 107122.57 \\
\hline Álvares Machado & 158.12 & 1569.99 & 5467313.59 & 47670.85 & 162892.32 \\
\hline Álvaro de Carvalho & 180.34 & 936.27 & 2760016.72 & 199465.2 & 111132.95 \\
\hline Americana & 203 & 210.06 & 2717475.13 & 73666.06 & 28146.61 \\
\hline Américo Brasiliense & 139.77 & 387.47 & 1723453.06 & 102008.55 & 36489.86 \\
\hline Américo de Campos & 255.79 & 2413.39 & 9710864.88 & 559805.68 & 403619.93 \\
\hline Amparo & 168.08 & 1084.56 & 5410651.8 & 194258.64 & 136638.1 \\
\hline Analandia & 150.47 & 1456.61 & 4918748.74 & 568501.99 & 143072.82 \\
\hline Andradina & 162.27 & 7227.09 & 15584375.66 & 329510.75 & 773476.54 \\
\hline Angatuba & 174.17 & 3712.15 & 17908836.77 & 1336089.48 & 418602.9 \\
\hline Anhembi & 208.35 & 1887.72 & 15333126.97 & 1003773.89 & 262073.67 \\
\hline Anhumas & 144.14 & 1964.32 & 4620728.01 & 138668.87 & 180214.92 \\
\hline Aparecida & 299.52 & 741.91 & 3593114.55 & 404637 & 146074.58 \\
\hline Aparecida d'oeste & 166.03 & 1248.51 & 2981938.93 & 66120.04 & 136224.4 \\
\hline Apiaí & 284.21 & 1804.99 & 27579026.59 & 15308723.82 & 354534.94 \\
\hline Araçariguama & 239.92 & 292.97 & 3522599.32 & 772927.03 & 45110.49 \\
\hline Araçatuba & 170.66 & 4743.97 & 19913169.82 & 358427.33 & 535783.59 \\
\hline Araçoiaba da Serra & 225.85 & 497 & 5798752.92 & 379018.3 & 73992.38 \\
\hline Aramina & 158.84 & 420.48 & 3233827.03 & 90175.14 & 43878.92 \\
\hline Arandu & 144.11 & 311.88 & 4110387.85 & 183990.59 & 37469.04 \\
\hline Arapeí & 304.12 & 928.25 & 4734125.11 & 1374834.21 & 185784.38 \\
\hline Araraquara & 147.26 & 3140.8 & 14831266.32 & 745791.01 & 316622.65 \\
\hline Araras & 204.83 & 2996.73 & 13154347.14 & 379247.12 & 400115.7 \\
\hline Arco-íris & 169.86 & 1318.21 & 4478599.64 & 121796.75 & 147463.59 \\
\hline Arealva & 131.26 & 2582.52 & 6651355.46 & 269524.68 & 225002.75 \\
\hline Areias & 284.53 & 1133.02 & 8725974.78 & 1375403.76 & 261818.25 \\
\hline Areiópolis & 154.98 & 153.55 & 1330330.17 & 16048.1 & 15799.74 \\
\hline Ariranha & 173.92 & 381.82 & 2310039.76 & 35609.8 & 43630.16 \\
\hline Artur Nogueira & 202.62 & 252.48 & 3586966.81 & 71454.34 & 33699.58 \\
\hline
\end{tabular}




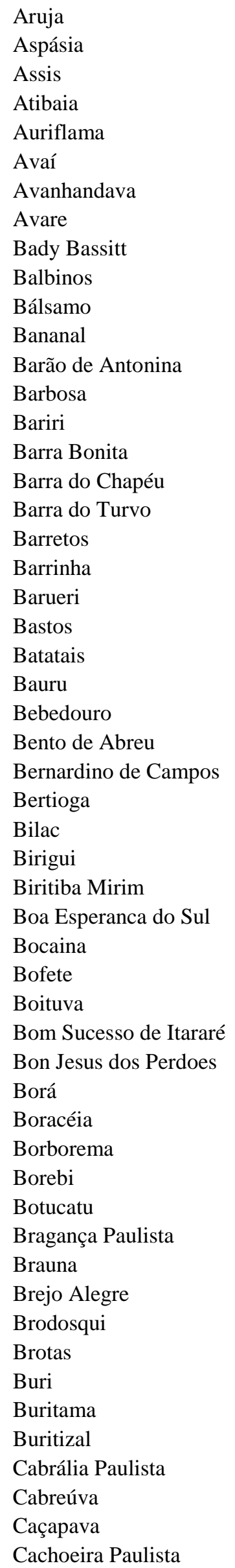

\begin{tabular}{|c|c|c|c|c|}
\hline 265.55 & 55.32 & 2582493.02 & 408549.94 & 9993.93 \\
\hline 167.98 & 218.73 & 1155810.62 & 19988.13 & 24179.14 \\
\hline 1.53 & 1624.94 & 6526369.05 & 464955.64 & 148404.01 \\
\hline 261.39 & 537.05 & 12474357.64 & 1691862.19 & 91380.4 \\
\hline 158.87 & 3097.48 & 6880323.28 & 156597.68 & 328636.86 \\
\hline 148.19 & 1874.11 & 8020476.41 & 505764.6 & 178891.03 \\
\hline 48.88 & 1624.23 & 5074903.73 & 113515.03 & 158032.76 \\
\hline 150.73 & 3866.9 & 18360722.88 & 1055545.59 & 371088.17 \\
\hline 177.66 & 215.63 & 1947967.36 & 22534.48 & 25210.75 \\
\hline 173.74 & 761.4 & 1570779.29 & 36216.99 & 87084.12 \\
\hline 167.29 & 222.77 & 2521836.91 & 95492.58 & 24371.18 \\
\hline 314.69 & 3353.24 & 19372151.91 & 8480919.57 & 653330.76 \\
\hline 191.33 & 522.15 & 2951098.16 & 73071.35 & 66757.05 \\
\hline 147.42 & 772.35 & 3024994.38 & 74937.17 & 74923.61 \\
\hline 177.34 & 2404.15 & 7824265.39 & 153715.24 & 283983.68 \\
\hline 200.03 & 473.67 & 3000918.64 & 25594.72 & 62437.23 \\
\hline 286.32 & 643.42 & 11659386.53 & 3448473.06 & 121914.54 \\
\hline 288.17 & 814.31 & 28942072.61 & 21429208.3 & 149997.79 \\
\hline 126.34 & 3082.11 & 19758812.81 & 793445.02 & 274205.79 \\
\hline 137 & 261.07 & 2006569.47 & 49627.12 & 24081.1 \\
\hline 273.21 & 8.55 & 1729126.55 & 131496.33 & 1532.67 \\
\hline 158.41 & 452.22 & 2670693.71 & 81653.99 & 46377.76 \\
\hline 160.08 & 2241.46 & 13603513.42 & 777793.15 & 236211.42 \\
\hline 153.05 & 1879.43 & 10295842.2 & 683450.35 & 182138.41 \\
\hline 133.8 & 1305.51 & 9106160.26 & 275164.35 & 114706.37 \\
\hline 166.51 & 2285.7 & 5045177.66 & 111307.69 & 250738.18 \\
\hline 184.35 & 1244.87 & 4484545.77 & 123490.61 & 150950.84 \\
\hline 219.21 & 301.65 & 10640814.04 & 8656695.81 & 61878.58 \\
\hline 172.18 & 659.35 & 2706534.26 & 40769.24 & 74621.82 \\
\hline 172.7 & 2536.31 & 9150336.27 & 130010.87 & 288724.9 \\
\hline 276.56 & 859.91 & 8775435.67 & 3964764.43 & 159679.12 \\
\hline 144.91 & 3422.21 & 10009776.42 & 586193.74 & 325640.79 \\
\hline 162.57 & 1990.75 & 5917155.86 & 343717.32 & 212283.43 \\
\hline 205 & 2116.52 & 13399662.54 & 1296775.21 & 298504.89 \\
\hline 224.62 & 618.02 & 5558339.15 & 143299.4 & 90505.41 \\
\hline 301.16 & 352.09 & 3988352.94 & 1246097.56 & 70021.79 \\
\hline 275.43 & 59.23 & 3013537.69 & 1019514.67 & 10658.46 \\
\hline 147.4 & 590.19 & 1742443.04 & 60793.38 & 56328.88 \\
\hline 189.13 & 833.78 & 2285145.85 & 36183.35 & 103646.18 \\
\hline 148.61 & 2626.33 & 8203419.95 & 156197.55 & 250224.05 \\
\hline 130.43 & 2905.37 & 4522648.67 & 326988.73 & 244409.95 \\
\hline 181.23 & 3888.09 & 26895679.23 & 2067884.43 & 476037.31 \\
\hline 240.95 & 1601.59 & 12367045.7 & 772091.67 & 253838.65 \\
\hline 171.79 & 1028.25 & 3363182.68 & 74094.33 & 116287.09 \\
\hline 168.41 & 754.23 & 1756036.71 & 18400.11 & 83771.26 \\
\hline 136.36 & 1202.31 & 3813063.42 & 127986.02 & 102467.67 \\
\hline 158.14 & 3109.18 & 17397851.38 & 1209495.29 & 332811.6 \\
\hline 175.89 & 3456.84 & 21036462.99 & 2010671.53 & 413279.05 \\
\hline 172.48 & 1253.2 & 5660842.93 & 147638.86 & 173087.5 \\
\hline 148.27 & 711.63 & 3950157.84 & 244427.25 & 69731.08 \\
\hline 140.54 & 1147.74 & 3365397.28 & 240523.15 & 108678.97 \\
\hline 245.42 & 734.62 & 6384304.78 & 2202707.87 & 117826.04 \\
\hline 274.96 & 1731.01 & 10180615.35 & 674186.88 & 318530.89 \\
\hline 261.05 & 2008.85 & 7517692.47 & 377823.5 & 345107.25 \\
\hline
\end{tabular}




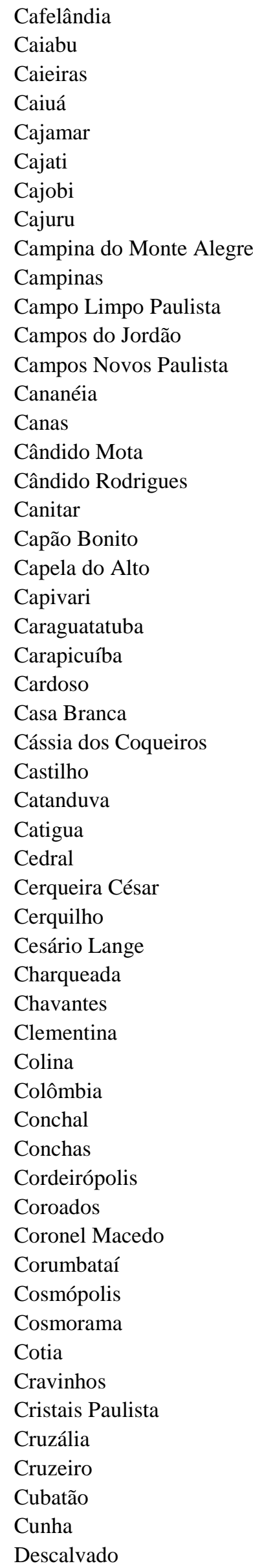

\begin{tabular}{|c|c|c|c|c|}
\hline 171.65 & 4528.28 & 15803719.41 & 886518.99 & .03 \\
\hline 161.32 & 1269.8 & 4047117.19 & 58371.01 & 134864.57 \\
\hline 6.88 & 111.64 & 2661357.72 & 764919.97 & 20284.99 \\
\hline 156.04 & 2778.87 & 8385047.63 & 212227.45 & 284746.93 \\
\hline 274.16 & 170.17 & 3512117.31 & 801862.2 & 30645.04 \\
\hline 274.36 & 762.47 & 12465256.56 & 8286154.91 & 130925.14 \\
\hline 164.74 & 781.6 & 2894182.96 & 49799.44 & 84804.54 \\
\hline 165.16 & 2140.99 & 10888274.64 & 871977.46 & 234797.81 \\
\hline 175 & 723.11 & 3222158.39 & 177441.96 & 86448.65 \\
\hline 247.77 & 2480.22 & 19735394.9 & 545078.84 & 408789.05 \\
\hline 363.7 & 172.81 & 10879367.02 & 4193825.96 & 44291.25 \\
\hline 273.01 & 56.53 & 1929538.7 & 209104.14 & 10187.89 \\
\hline 126.51 & 1881.91 & 6126411.26 & 283567.6 & 158785.67 \\
\hline 224.3 & 333.67 & 29677759.69 & 25960128.16 & 56312.64 \\
\hline 250.32 & 379.94 & 1315996.99 & 41168.92 & 63798.6 \\
\hline 178.97 & 2009.16 & 10688460.04 & 126913.39 & 236522.87 \\
\hline 156.45 & 88.02 & 1094895.77 & 11933.61 & 8955.35 \\
\hline 189.68 & 201.83 & 1093 & 0.43 & 8.28 \\
\hline 240.12 & 3882.31 & 39412 & 129605 & 4.38 \\
\hline 227.89 & 361.33 & 3867 & 1.04 & 54667.92 \\
\hline 206.92 & 1962.72 & 6714890.41 & 114123.1 & 268457.87 \\
\hline 281.78 & 1543.14 & 13764402.86 & 9667949.51 & 274064.11 \\
\hline 275.35 & 0.11 & 3.29 & 6.81 & 19.59 \\
\hline 163.66 & 3160.55 & 10423 & 6.37 & 342450.5 \\
\hline 175.62 & 3878.45 & 15198 & 9019 & 451393.69 \\
\hline 161.54 & 363.68 & 3107 & 5.76 & 37814.6 \\
\hline 146.85 & 6583.96 & 15585448.64 & 9.79 & 688505.43 \\
\hline 170.29 & 1021.25 & 8.05 & 2.14 & 114627.3 \\
\hline 170.44 & 561.16 & 9.28 & 8.39 & 9.85 \\
\hline 174.4 & 581.36 & & & \\
\hline 140.59 & 961.46 & 95.1 & 5.07 & 9.36 \\
\hline 220 & 322.9 & 7.51 & 3.71 & 0.01 \\
\hline 245.19 & 396.48 & 30.43 & 8.33 & 63889.85 \\
\hline 172.71 & 1167.1 & 3045083.68 & 6.34 & 130641.07 \\
\hline 191.98 & 667.19 & & 0.85 & 88522.47 \\
\hline 169.92 & 748.12 & 3.09 & 9.22 & 83621.88 \\
\hline 124.54 & 1256.85 & 528 & 1712 & 111592.13 \\
\hline 97.8 & 2468.53 & 7141997.69 & 574900.64 & 133567.19 \\
\hline 196.15 & 381.53 & 3594113.4 & 1194 & 49244.9 \\
\hline 236.89 & 1659.38 & 11096414.44 & 349129.58 & 261389.06 \\
\hline 199.93 & 537.75 & 2752556.65 & 34739.92 & 70774.8 \\
\hline 171.96 & 1045.76 & 4240 & 80945.35 & 118449.51 \\
\hline 208.36 & 1463.07 & 6349 & 183525.98 & 196514.14 \\
\hline 190.5 & 1116.19 & 5290616.74 & 374364.1 & 139789.06 \\
\hline 203.76 & 460.95 & 3148345.96 & 102943.52 & 61773.74 \\
\hline 144.63 & 1075.89 & 6386908.16 & 223630.28 & 102283.15 \\
\hline 278.34 & 49.12 & 9039752.64 & 3419990.4 & 9031.76 \\
\hline 148.16 & 1371.97 & 4613006.46 & 119076.13 & 133113.56 \\
\hline 150.16 & 1009.44 & 5794019.97 & 469792.75 & 99612.88 \\
\hline 175.24 & 337.97 & 2616245.33 & 10819.22 & 38452.32 \\
\hline 256.44 & 1795.47 & 7824827.39 & 1806282.13 & 295624.56 \\
\hline 259.22 & 0.78 & 3588611.35 & 2700967.92 & 156.84 \\
\hline 299.62 & 3823.38 & 42159986.14 & 8539968.5 & 743175.57 \\
\hline 175.37 & 2339.48 & 13237298.94 & 1046501.63 & 269624.33 \\
\hline
\end{tabular}




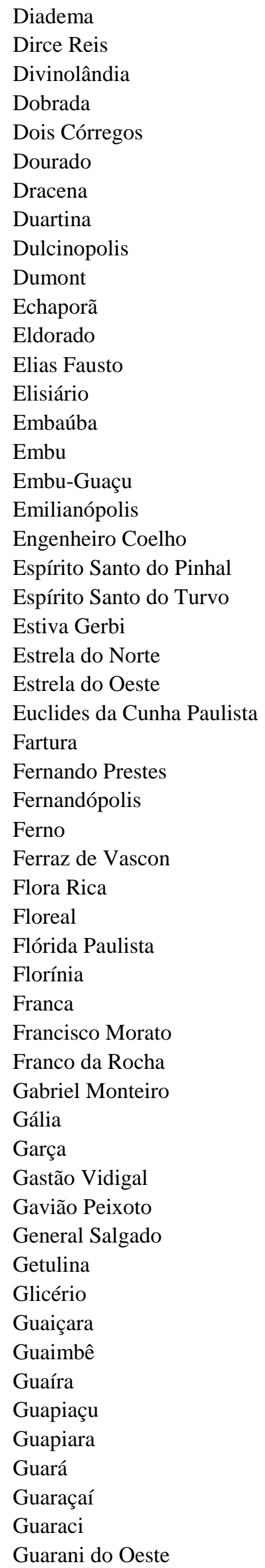

\begin{tabular}{|c|c|c|c|c|}
\hline 285.61 & 0.01 & 893721.94 & 34398.47 & 4.14 \\
\hline 170.5 & 520.35 & 1517661.21 & 69908.92 & 58431.4 \\
\hline 244.48 & 580.45 & 5452497.99 & 240169.34 & 91843.71 \\
\hline 143.79 & 595.06 & 2164347.99 & 27984.99 & 58774.85 \\
\hline 165.47 & 1739.69 & 10445870.13 & 413560.69 & 193109.96 \\
\hline 178.61 & 745.01 & 3687047.62 & 304207.97 & 89870.98 \\
\hline 157.74 & 2739.3 & 7698732.62 & 190213.78 & 284028.96 \\
\hline 147.96 & 1177.2 & 3904762.41 & 218794.58 & 118781.28 \\
\hline 168.64 & 344.53 & 1312665.08 & 16844.22 & 38199.71 \\
\hline 141.77 & 280.97 & 1575719.89 & 22889.08 & 26246.86 \\
\hline 117.8 & 2444.94 & 6081543.17 & 333158.67 & 199922.15 \\
\hline 263.47 & 3498.31 & 43653312.18 & 36752217.82 & 595674.37 \\
\hline 222.73 & 825.46 & 4471526.09 & 85510.98 & 121002.73 \\
\hline 171.16 & 482.29 & 1586662.78 & 30027.4 & 54338 \\
\hline 166.4 & 275.97 & 1383840.5 & 28782.13 & 30186.74 \\
\hline 280.74 & 6.22 & 1948652.15 & 256552.03 & 1146.94 \\
\hline 285.02 & 112.23 & 4387712.93 & 1529542.24 & 21195.24 \\
\hline 159.17 & 1095.42 & $3546 c$ & 19742.8 & 114891.99 \\
\hline 198.49 & 233.35 & 21827 & 54993.02 & 30462.09 \\
\hline 238.12 & 2120.87 & 9303133.52 & 591833.21 & 332477.46 \\
\hline 160.44 & 1457.15 & 3050641.21 & 100199.36 & 154423.39 \\
\hline 201.8 & 295.8 & 1487568.75 & 42081.95 & 39219.49 \\
\hline 151.82 & 2360.81 & 525 & 78487.69 & 236841.36 \\
\hline 172.31 & 1525.19 & 5103526.74 & 155814.79 & 172987.03 \\
\hline 152.66 & 6527.18 & 8794097.58 & 537521.33 & 665710.86 \\
\hline 196.64 & 1569.04 & 8444654.8 & 316450.65 & 206227.05 \\
\hline 158.28 & 273.08 & 2698018.82 & 43321.88 & 27897.54 \\
\hline 172.54 & 3079.59 & 9505846.33 & 266727.45 & 349175.6 \\
\hline 172.41 & 503.76 & 1736710.12 & 3.75 & 58125.4 \\
\hline 287.14 & 19.97 & & 832 & 3810.01 \\
\hline 158.84 & 1331.78 & 3578 & 22556.98 & 139255.45 \\
\hline 176.16 & 771.67 & 35862 & 94077.91 & 89642.3 \\
\hline 162.2 & 3555.2 & 8514827.38 & 109134.65 & 379185.02 \\
\hline 181.12 & 661.36 & 4102021.3 & 59983.81 & 78977.62 \\
\hline 153.3 & 1337.33 & 9300825.02 & 878940.47 & 134403.39 \\
\hline 268.41 & 11.97 & 13213 & 157356.52 & 2100.8 \\
\hline 260.13 & 67.74 & 3483 & 639278.69 & 11585.64 \\
\hline 169.9 & 790.3 & 2346705.78 & 39365.5 & 88414.61 \\
\hline 178.92 & 1948.4 & 6385421.1 & 718248.58 & 229338.94 \\
\hline 183.69 & 3190.89 & 10221421.31 & 745417.51 & 386509.27 \\
\hline 177.05 & 620.78 & 3192121.41 & 72377.36 & 72349.3 \\
\hline 134.63 & 462.11 & 3284660.68 & 124938.86 & 40672.2 \\
\hline 175.14 & 2671.2 & 8630779.98 & 259627.43 & 306764.06 \\
\hline 173.78 & 3632.13 & 11734597.78 & 400524.69 & 415334.53 \\
\hline 161.63 & 1685.36 & 4431444.9 & 57813.54 & 181786.43 \\
\hline 158.93 & 779.77 & 4285776.54 & 84293.1 & 83689.08 \\
\hline 175.58 & 1125.77 & 3817977.21 & 157065.75 & 130212.27 \\
\hline 128.55 & 6340.91 & 16152945.97 & 418810.21 & 552338.76 \\
\hline 295.33 & 403.12 & 12028605.29 & 3950248.7 & 79562.04 \\
\hline 164.47 & 1419.06 & 5353342.59 & 163013.24 & 151717.19 \\
\hline 150.82 & 1583.51 & 5462311.18 & 134704.06 & 158255.42 \\
\hline 162.25 & 4690.94 & 9212440.44 & 383220.28 & 498039.52 \\
\hline 159.97 & 1511.83 & 10201740.98 & 176418.03 & 161114.64 \\
\hline 168.48 & 608.6 & 1429163.65 & 27949.7 & 67540.97 \\
\hline
\end{tabular}




Guarantã
Guararapes
Guararema
Guaratinguetá
Guareí
Guariba
Guarujá
Guarulhos
Guatapará
Guzolandia
Herculândia
Holambra
Hortolândia
Iacanga
Iacri
Iaras
Ibaté
Ibirá
Ibirarema
Ibitinga
Ibiúna
Icém
Iepê
Igaraçu do Tietê
Igarapava
Igaratá
Iguape
Ilha Solteira
Ilhabela
Indaiatuba
Indiana
Indiaporã
Inúbia Paulista
Ipaucu
Iperó
Ipeúna
Ipiguá
Iporanga
Ipuã
Iracemápolis
Irapuã
Irapuru
Itaberá
Itaí
Itajobi
Itaju
Itanhaém
Itaóca
Itapecerica da Serra
Itapetininga
Itapevai
Itapira
Itapirapuã Paulista

\begin{tabular}{|c|c|c|c|c|}
\hline & & & & \\
\hline 3.53 & 90.65 & 34935760.58 & 4258963.79 & 823 \\
\hline 9.97 & 696.28 & 2501335.48 & 45626.3 & \\
\hline 1.15 & 188.32 & 7612072.08 & 105379.14 & 276048.61 \\
\hline 4.96 & 38.12 & 11621988.23 & 853486.55 & 297325.88 \\
\hline 04.84 & 596.76 & 2826286.15 & 1.24 & 60.27 \\
\hline 8.08 & 12.93 & 418.3 & 17258 & 36.19 \\
\hline 222.2 & 70.82 & 7080327.35 & 2113623.39 & 9845.03 \\
\hline 123.42 & 917.51 & 5107648.38 & 207613.56 & 52392.57 \\
\hline 3.61 & 32.97 & 389 & 110 & 0.71 \\
\hline 165.14 & 307.81 & 602 & & \\
\hline 4.32 & 39.5 & 139 & & \\
\hline 4.26 & .45 & 13 & & \\
\hline 156.1 & 04.51 & & 348 & 3.64 \\
\hline 166.2 & 472.3 & 538 & & \\
\hline 128.63 & 361.99 & $51^{7}$ & & \\
\hline 172.62 & 026.35 & 495 & 373 & 12.1 \\
\hline 73.11 & 776.94 & & & \\
\hline 77.71 & & & & 4.37 \\
\hline 48.88 & 811.84 & 1022 & & \\
\hline 8.96 & 24.35 & & $1245^{\circ}$ & 5.18 \\
\hline 55.58 & 338.23 & & & 7.67 \\
\hline 163 & 7 & & & \\
\hline 1539 & 8 & & & \\
\hline 504 & 7.44 & & & \\
\hline 59.62 & 1228 & & & 2.42 \\
\hline 0.5 & 44.73 & 4676 & .06 & 6.98 \\
\hline 0.5 & 64.56 & & & 4.98 \\
\hline 13 & & & & 13.25 \\
\hline 5. & 5.98 & & & 7.02 \\
\hline 3.79 & 11 & & & \\
\hline 7. & 8 & & & .37 \\
\hline & & & & \\
\hline 5.4 & & & & \\
\hline 2 & & & & \\
\hline 9.42 & 29 & & & \\
\hline 5.46 & & & & \\
\hline 8.62 & & 3113 & & 8.65 \\
\hline 19.83 & 233.79 & & & 92.23 \\
\hline 0.85 & & & & 93.05 \\
\hline & & & & 33.39 \\
\hline & & 34 & & 8.89 \\
\hline & 46 & & .34 & 6.84 \\
\hline 0.2 & & 1782 & & 6.44 \\
\hline 0.17 & & & & 8.74 \\
\hline 1 & & & & 3.24 \\
\hline & & 148 & 12 & 73.21 \\
\hline & 5 & & & 4.76 \\
\hline & & & & \\
\hline & & 3582 & & 37177.25 \\
\hline & & 2889 & & 473327.35 \\
\hline & & & & 2947.9 \\
\hline & 92.83 & 1251 & 56.12 & 77466.99 \\
\hline - & 270.51 & 10920927.84 & 3450082.77 & 228742.9 \\
\hline
\end{tabular}




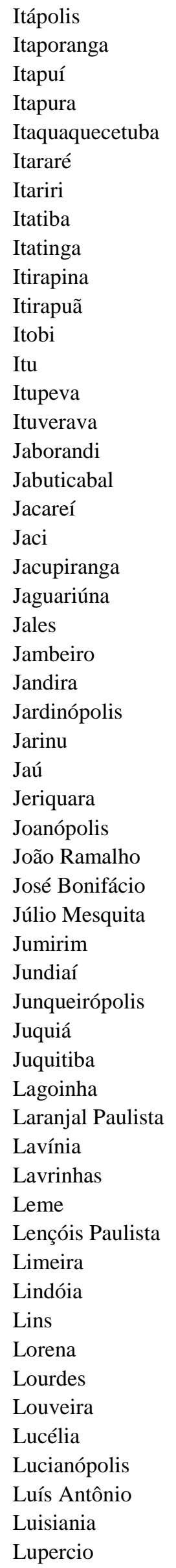

\begin{tabular}{|c|c|c|c|c|}
\hline 147.18 & 3100.53 & 14673556.13 & 436526.73 & 300371.12 \\
\hline 236.89 & 2090.86 & 12053672.9 & 417535.31 & 323873.21 \\
\hline 194.34 & 666.64 & 2706059.37 & 19976.14 & 85257.47 \\
\hline 160.18 & 3120.6 & 4913637.74 & 132955.59 & 341144.54 \\
\hline 246.65 & 9.11 & 2028469.12 & 73591.48 & 1527.56 \\
\hline 160.89 & 2279.11 & 16157013.01 & 2140634.55 & 232482.55 \\
\hline 285.52 & 335.05 & 7814424.42 & 5799342.35 & 62095.31 \\
\hline 259.98 & 1356.98 & 8366646.71 & 550634.2 & 232563.51 \\
\hline 161.01 & 2736.89 & 15754727.48 & 1120859.11 & 286364.1 \\
\hline 168.56 & 2640.19 & 9515933.7 & 912540.49 & 303740.08 \\
\hline 172.12 & 460.07 & 2768561.91 & 331179.34 & 51282.89 \\
\hline 189.98 & 965.36 & 2629308.24 & 52598.37 & 122053.49 \\
\hline 236.47 & 1894.8 & 15136954.29 & 1389734.53 & 286610.65 \\
\hline 291.9 & 564.44 & 5868143.59 & 392489.55 & 112269.14 \\
\hline 158.3 & 3055.99 & 11033427.73 & 332374.12 & 316674.09 \\
\hline 103.15 & 1037.74 & 2835979.53 & 69294.69 & 72507.21 \\
\hline 112.91 & 1544.26 & 7993506.93 & 110279.72 & 120064.54 \\
\hline 276.19 & 2760.82 & 12697630.93 & 845860.45 & 505549.8 \\
\hline 174.41 & 455.33 & 2524190.47 & 81285.23 & 52171.01 \\
\hline 256.02 & 1516.63 & 18115422.09 & 13471400.47 & 253852.9 \\
\hline 236.85 & 409.51 & 3371591.11 & 79201.48 & 64212.41 \\
\hline 170.91 & 1037.07 & 6308339.62 & 184162.89 & 116806.49 \\
\hline 299.24 & 1306.59 & 5484852.01 & 445371.88 & 256850.15 \\
\hline 275.93 & 0.16 & 484075.4 & 20734.77 & 29.92 \\
\hline 141.39 & 1543.62 & 7114266.73 & 255281.66 & 145786.08 \\
\hline 262.43 & 294.55 & 5456419.86 & 569139.13 & 50619.28 \\
\hline 195.42 & 2743.39 & 13463967.34 & 143856.83 & 352252.36 \\
\hline 156.46 & 431.82 & 2205743.61 & 164106.5 & 45104.32 \\
\hline 272.7 & 569.47 & 10185339.62 & 2271082.74 & 100384.18 \\
\hline 138.4 & 2012.33 & 5752713.94 & 166649.63 & 185022.01 \\
\hline 160.01 & 4285.78 & 13742846.12 & 293146.82 & 440760.03 \\
\hline 177.57 & 671.29 & 2271175.95 & 199136.79 & 78381.42 \\
\hline 222.48 & 213.03 & 1256148.65 & 26136.62 & 31208.18 \\
\hline 270.58 & 534.54 & 11686748.84 & 2668880.33 & 94844.89 \\
\hline 159.71 & 4692.9 & 9323254.49 & 105542.79 & 492682.99 \\
\hline 262.32 & 1712.87 & 21538514.25 & 16776855.3 & 292332.21 \\
\hline 283.29 & 87.08 & 14770541.41 & 9795788.09 & 16117.35 \\
\hline 297.13 & 988.65 & 7623081.01 & 855449.61 & 192991.39 \\
\hline 233.85 & 1786.76 & 9050173.4 & 120313.16 & 271976.84 \\
\hline 164.32 & 4015.78 & 8848832.74 & 228989.94 & 431710.5 \\
\hline 263.01 & 1176.58 & 4385572.46 & 1154168.51 & 201111.95 \\
\hline 206.94 & 2368.69 & 8364823.99 & 210603.86 & 325740.85 \\
\hline 136.49 & 2606.38 & 10991150.54 & 369973.1 & 230635.78 \\
\hline 194.19 & 1674.46 & 11265359.15 & 294860.63 & 213368.65 \\
\hline 272.7 & 233.77 & 1330782.37 & 55013.13 & 41730.73 \\
\hline 170.73 & 2027.86 & 9743600.06 & 429189.81 & 229069.56 \\
\hline 269.05 & 3163.09 & 11166075.7 & 944145.78 & 565381.67 \\
\hline 175.63 & 604.86 & 2013772.3 & 99592.44 & 69877.73 \\
\hline 257.72 & 89.8 & 1426812.96 & 109007.75 & 15275.6 \\
\hline 163.63 & 1734.95 & 5144674.71 & 147853.04 & 186925.54 \\
\hline 164.25 & 1168.96 & 3131014.28 & 165289.07 & 126131.5 \\
\hline 152.16 & 2510.12 & 9093486.46 & 1912944.45 & 246897.03 \\
\hline 170.45 & 963.96 & 2847727.51 & 84050.03 & 108051.42 \\
\hline 172.75 & 852.98 & 2663744.02 & 213327.57 & 98252.36 \\
\hline
\end{tabular}




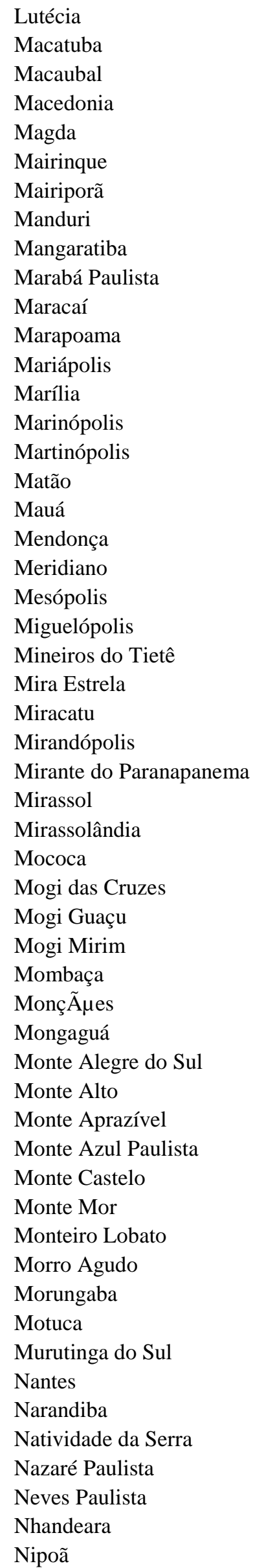

\begin{tabular}{|c|c|c|c|c|}
\hline 136.98 & 2530.09 & 6504079.99 & 250507.38 & .04 \\
\hline 154.98 & 940.54 & 3498765.89 & 52206.55 & 97484.15 \\
\hline 74.28 & 640.28 & 4345523.26 & 155146.14 & 72604.91 \\
\hline 170.49 & 1991.98 & 5605586.49 & 123591.13 & 223479.45 \\
\hline 162.48 & 1267.19 & 5070593.38 & 347400.87 & 135734.85 \\
\hline 248.27 & 284 & 5187494.63 & 728196.45 & 44999.84 \\
\hline 79.91 & 52.72 & 8977446.21 & 3252566.42 & 9723.26 \\
\hline 181.61 & 697.99 & 4155056 & 163906.85 & 83771.89 \\
\hline 265.33 & 0 & 1320191.18 & 760503.58 & 0 \\
\hline 153.97 & 6250.73 & 14101941.6 & 371592.25 & 634146.98 \\
\hline 170.94 & 1651.75 & 9105210.26 & 143100.51 & 181732.52 \\
\hline 171.13 & 310.06 & 1951769.92 & 4118 & 0.52 \\
\hline 161.32 & 905.42 & 2985945.54 & 5.04 & 6.43 \\
\hline 172.11 & 5575.69 & 20116433.09 & 949298.81 & 630828.17 \\
\hline 167.56 & 457.64 & 1302452.82 & 24819.63 & 50528.23 \\
\hline 144.42 & 6609.91 & 18138154.38 & 680936.21 & 634696.39 \\
\hline 145.36 & 2009.88 & 7640800.71 & 5094 & 187792.31 \\
\hline 288.77 & 4.47 & 182 & 228 & 855.05 \\
\hline 150.79 & 539 & 295 & 109 & 53425.95 \\
\hline 155.93 & 1296.05 & 35198 & 179 & 1348 \\
\hline 164.67 & 1270.87 & 2481275.65 & 3.36 & 137648.01 \\
\hline 148.49 & 3773.47 & 12277968.73 & 213516.83 & 367260.15 \\
\hline 184.77 & 705.87 & 3919169.08 & .34 & 3.82 \\
\hline 167.74 & 684.74 & 363 & .47 & 9.23 \\
\hline 271.24 & 990.58 & 271514 & 217893 & 1775 \\
\hline 163.54 & 6084.08 & 15007775.81 & 458244.22 & 652144.2 \\
\hline 148.71 & 6439.3 & 18413890.3 & 3534 & 629649.32 \\
\hline 172.73 & 401.98 & 4220341.66 & 1134 & 46045.47 \\
\hline 145 & 647.47 & 240 & .69 & 9.56 \\
\hline 180.97 & 3997.87 & 1546 & 9078 & 4786 \\
\hline 280.85 & 2133.02 & 2001 & 51646 & 393 \\
\hline 201.57 & 4486.34 & 1635480 & 9777 & 583681.43 \\
\hline 205.33 & 1203.3 & 10304780.74 & 2096 & 162787.54 \\
\hline 206.18 & 1050.53 & 2737815.92 & 6.28 & 142620.33 \\
\hline & & & & 69942.96 \\
\hline 249.02 & 26.95 & 3.68 & 2909781.91 & 4650.25 \\
\hline 261.81 & 376.78 & 2913 & $286 C$ & 0.88 \\
\hline 160.91 & 820.22 & 5584 & 1209 & 87730.89 \\
\hline 169.91 & 882.85 & 8194043.47 & 00.7 & 1.93 \\
\hline 167.1 & & 4421099.49 & 80466.32 & 127853.81 \\
\hline 158.95 & 911.78 & 3718169.2 & 124006.54 & 95395.11 \\
\hline 210.17 & 1275.85 & 5071 & 6.51 & 176707.61 \\
\hline 301.09 & 1036.8 & 9997150.3 & 31025 & 204522.64 \\
\hline 141.41 & 7814.48 & 19618000.6 & 587616.33 & 729432.41 \\
\hline 258.19 & 699.04 & 3793891.26 & 350756.21 & 118754.58 \\
\hline 117.16 & 596.3 & 2669401.27 & 131311.54 & 44851.76 \\
\hline 162.19 & 1540.51 & 4035263.54 & 86843.52 & 164038.43 \\
\hline 153.87 & 1248.01 & 4396906.42 & 158563.62 & 175150.04 \\
\hline 150.66 & 2522.58 & 5393286.24 & 339460.62 & 251901.16 \\
\hline 312.08 & 2245.02 & 25994531.67 & 7287070.77 & 452644.08 \\
\hline 275.29 & 224.83 & 8983931.03 & 2430994.61 & 39560.89 \\
\hline 180.81 & 523.78 & 4179319.4 & 105875.16 & 62425.64 \\
\hline 172.78 & 1050.26 & 7569493.92 & 283240.89 & 119834.55 \\
\hline 174.86 & 392.85 & 2424271.03 & 52773.55 & 44973.91 \\
\hline
\end{tabular}




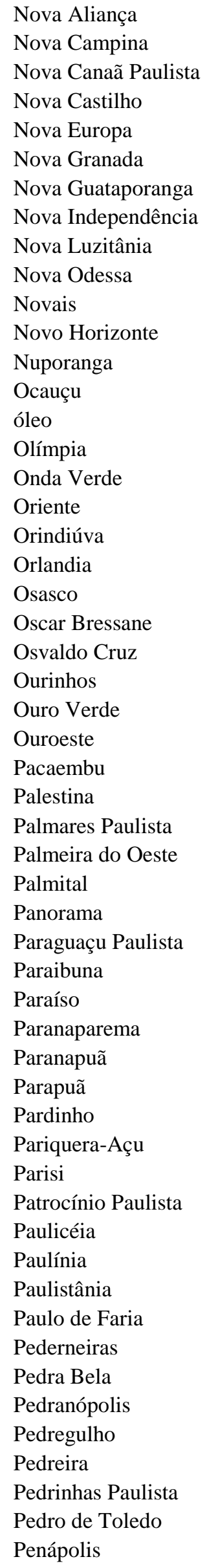

\begin{tabular}{|c|c|c|c|c|}
\hline 157.6 & 362.23 & 3429216.5 & 111647.43 & .24 \\
\hline 239.05 & 873.18 & 9211885.69 & 2325089.5 & 143804.96 \\
\hline 167.31 & 504.04 & 2064241.28 & 41591.81 & 55550.69 \\
\hline 170.35 & 823.12 & 3127627.32 & 109509.81 & 90946.5 \\
\hline 139.23 & 347.31 & 2244823.17 & 87292.35 & 31019.17 \\
\hline 150.93 & 1987.33 & 8033664.57 & 298488.14 & 195752.77 \\
\hline 158.92 & 152.12 & 542181.78 & 3899.38 & 15919.07 \\
\hline 157.76 & 259.68 & 4182891.06 & 109440.15 & 234475.61 \\
\hline 173.32 & 254.4 & 1277305.81 & 42887.49 & 28875 \\
\hline 205.8 & 128.36 & 1492040.34 & 13639.98 & 17412.87 \\
\hline 168.44 & 273.14 & 1977343.34 & 44305.41 & 30360.18 \\
\hline 168.82 & 2102.15 & 15725347.56 & 752002.76 & 229448.57 \\
\hline 159.4 & 1516.39 & 5534274.39 & 91.1 & 159719.48 \\
\hline 138.34 & 1585.42 & 4155048.56 & 263170.93 & 147770.6 \\
\hline 189.45 & 512.75 & 3736460.28 & 139266.99 & 64419.42 \\
\hline 157.45 & 2823.48 & 12668656.54 & 330026.81 & 289527.62 \\
\hline 152.11 & 797.95 & 3691182.89 & 164244.08 & 77844.73 \\
\hline 174.45 & 1113.15 & 776.2 & 1790 & 127929.49 \\
\hline 161.45 & 1168.33 & 4006 & .57 & 124084.22 \\
\hline 151.51 & 1834.16 & 448 & 151 & 182845.72 \\
\hline 274.58 & 8.3 & 1780542.59 & 78296.96 & 1471.6 \\
\hline 159.06 & 1195.92 & 3509979.96 & 1167 & 123925.71 \\
\hline 164.46 & 1353.54 & 4081 & 1571 & 146678.56 \\
\hline 185.79 & 903.28 & 5507 & 84 & 1106 \\
\hline 156.85 & 2045.19 & 4166 & 9.23 & 211178.41 \\
\hline 166.27 & 1940.38 & 4768159.97 & 208280.86 & 212107.65 \\
\hline 161.54 & 2864.39 & 5484040.97 & 59483.3 & 304241.1 \\
\hline 145.93 & 2907.12 & 10130819.02 & 22528 & 283936.49 \\
\hline 171.58 & 379.91 & 9.9 & .98 & 42866.35 \\
\hline 168.18 & 1433.03 & 5371 & & 157967.36 \\
\hline 178.63 & 1866.34 & 9810 & 3.78 & 219225.37 \\
\hline 140.77 & 2695.15 & 4967 & 1629 & 281865.94 \\
\hline 123.69 & 3874.44 & 12385226.98 & 3896 & 321854.11 \\
\hline 308.66 & 3481.99 & 24996204.46 & 50677 & 697763.62 \\
\hline 169.51 & 414.08 & 2635390.15 & & 46229.76 \\
\hline 159.19 & 3666.14 & 16241272.46 & 8813 & 393033.97 \\
\hline 166.67 & 906.88 & 4.79 & .69 & 99474.85 \\
\hline 163.51 & 1734.39 & 59820 & 1257 & 186684.06 \\
\hline 199.04 & 623.83 & 69.5 & 249763.93 & 78772.58 \\
\hline 254.32 & 721.79 & 9187976.27 & 5629562.56 & 120240.09 \\
\hline 166.43 & 385.48 & 1392150.28 & 31977.08 & 42577.91 \\
\hline 147.46 & 1600.21 & 8850271.64 & 1196430.12 & 155754.83 \\
\hline 151.14 & 2519.23 & 5653042.36 & 225731.01 & 279603.53 \\
\hline 217.65 & 258.05 & 3036043.72 & 65502.99 & 37303.35 \\
\hline 142.57 & 1402.78 & 3651757.39 & 273453.7 & 139259.98 \\
\hline 163.56 & 3785.07 & 12119371.98 & 260218.29 & 412129.74 \\
\hline 147.26 & 3710.73 & 10750756.02 & 586334.33 & 351188.22 \\
\hline 263.07 & 253.96 & 4146285.78 & 377190.19 & 43390.28 \\
\hline 170.81 & 1248.02 & 4445785.57 & 108581.2 & 139771.26 \\
\hline 150.22 & 1760.79 & 10563273.48 & 1154654.02 & 170759.52 \\
\hline 254.66 & 754.13 & 2783046.77 & 143370.02 & 126741.02 \\
\hline 176.87 & 384.17 & 2713788.17 & 7818 & 41484.8 \\
\hline 280.59 & 196.3 & 18820559.37 & 16577454.51 & 35969.71 \\
\hline 159.04 & 2938.35 & 11264247.68 & 221045.27 & 304519.73 \\
\hline
\end{tabular}




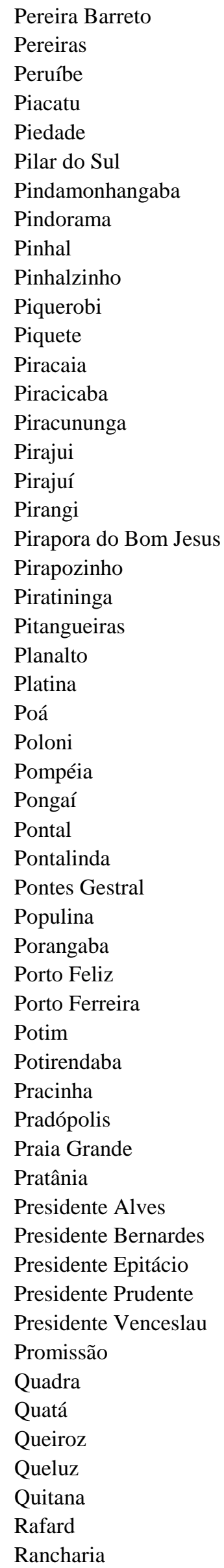

\begin{tabular}{|c|c|c|c|c|}
\hline 160.35 & 6478.32 & 15697375.33 & 358757.13 & .48 \\
\hline 248.4 & 690.94 & 5508849.46 & 78951.7 & 113159.94 \\
\hline 251.52 & 278.67 & 8182459.52 & 6079479.38 & 45646.48 \\
\hline 167.61 & 1485.81 & 3911007.47 & 175081.86 & 163870.27 \\
\hline 305.02 & 448.96 & 22693204.78 & 5056064.43 & 90601.54 \\
\hline 275.01 & 1262.68 & 18802832.69 & 3933135.53 & 232388.03 \\
\hline 288.87 & 5328.55 & 21125478.43 & 4389265.98 & 1019391.15 \\
\hline 154.25 & 673.89 & 2878020.85 & 59103.73 & 69433.15 \\
\hline 261.97 & 492.55 & 2871811.55 & 102952.89 & 84586.56 \\
\hline 250.12 & 320.9 & 3867691.3 & 228565.89 & 52226.33 \\
\hline 157.36 & 3604.03 & 7589523.69 & 120764.61 & 373623.01 \\
\hline 273.27 & 873.27 & 4822418.5 & 1552986.06 & 151483.52 \\
\hline 266.39 & 737.12 & 10247889.49 & 21047 & 127246.8 \\
\hline 178.57 & 6337.35 & 24483527.4 & 586288.92 & 713162.63 \\
\hline 186.33 & 2015.03 & 13550185.92 & 644468.2 & 245151.54 \\
\hline 185.83 & 6075.15 & 20955304.17 & 1086830.38 & 735539.07 \\
\hline 171.59 & 911.69 & 3385857.16 & 88275.1 & 103253.07 \\
\hline 172.86 & 553.22 & 4.63 & 544 & 84.07 \\
\hline 254.46 & 160.19 & 275 & 9216 & 6.18 \\
\hline 150.83 & 3570.01 & $728^{\prime}$ & .62 & 2.62 \\
\hline 141.32 & 1670.09 & 5619012.99 & 344502.46 & 152796.81 \\
\hline 134.26 & 1394.53 & 5760482.04 & 3.49 & 125910.81 \\
\hline 150.82 & 2055.73 & 19.41 & 2220 & 205016.93 \\
\hline 143.6 & 1400.27 & 472 & 133 & 131637.94 \\
\hline 282 & 3.65 & & .85 & 689.69 \\
\hline 175.98 & 262.64 & 2371 & 2.62 & 30476.2 \\
\hline 171.92 & 4680.52 & 194.5 & 472651.85 & 528803.58 \\
\hline 170.93 & 848.19 & 61.66 & .94 & 95500.42 \\
\hline 141.55 & 1822.07 & 503 & 1004 & 169896.37 \\
\hline 169.55 & & 355 & & \\
\hline 150.77 & 417.93 & 1.38 & 1132 & 41821.46 \\
\hline 165.07 & 3167.35 & 5211 & 1500 & 868.7 \\
\hline 247.37 & 836.71 & 32.5 & 2046 & 39.15 \\
\hline 210.27 & 2308.33 & 11698 & 324513.94 & 318925.02 \\
\hline 144.47 & & 3530207.44 & & 96597.22 \\
\hline 302.02 & 506.08 & 1350179.09 & 32843.47 & 100765.87 \\
\hline 163.35 & 451.65 & 21.2 & 123902.65 & 38.11 \\
\hline 161.94 & 376.29 & 1018 & 9965 & 40127.6 \\
\hline 106.03 & 317.86 & 58.72 & 43995.09 & 1.15 \\
\hline 242.31 & 12.28 & 2728399.58 & 2011596.9 & \\
\hline 169.65 & 568.98 & 3037142.92 & 147627.31 & 63509.43 \\
\hline 165.53 & 1441.71 & 476 & 319498.14 & 159397.56 \\
\hline 149.16 & 3998.34 & 11240 & 327836.95 & 391875.87 \\
\hline 153.93 & 4540.84 & 19757843.79 & 567647.84 & 534510.04 \\
\hline 161.04 & 2606.54 & 9056626.82 & 127903.24 & 276280.2 \\
\hline 157.03 & 5620.12 & 11846261.42 & 214051.82 & 580957.95 \\
\hline 159.05 & 2546.4 & 12424566.97 & 325239.89 & 272264.25 \\
\hline 246.91 & 639.49 & 5064241.31 & 127411.6 & 104066.18 \\
\hline 146.45 & 2854.85 & 9558329.44 & 426894.8 & 278540.82 \\
\hline 172.03 & 1310.81 & 4027711.01 & 128435.26 & 148426.57 \\
\hline 261.82 & 1458 & 6549114.26 & 1847560.56 & 253994.03 \\
\hline 155.43 & 2242.33 & 4981830.2 & 213528.88 & 231765.18 \\
\hline 215.99 & 813.53 & 2850742.09 & 49314.78 & 115400.3 \\
\hline 134.32 & 6775.59 & 21299878.02 & 945949.18 & 626505.29 \\
\hline
\end{tabular}




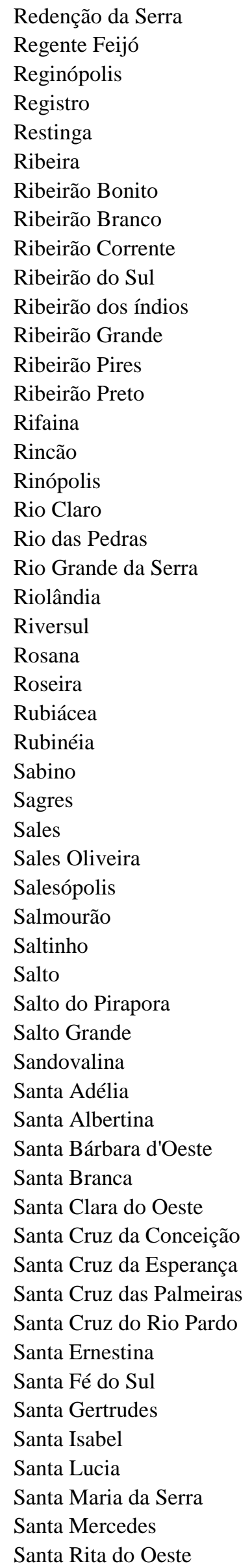

\begin{tabular}{|c|c|c|c|c|}
\hline 309.66 & 1594.92 & 9551138.18 & 1297445.02 & 59.5 \\
\hline 159.97 & 1302.05 & 4205972.3 & 105096.76 & 135249.69 \\
\hline 152.94 & 652.55 & 6281646.42 & 354143.69 & 165720.54 \\
\hline 248.42 & 2489.14 & 17785243.98 & 9096931.29 & 407210.47 \\
\hline 165.17 & 950.82 & 4066709.18 & 369827.61 & 103663.73 \\
\hline 265.94 & 492.39 & 8887089.25 & 4642143.47 & 86817.95 \\
\hline 156.2 & 1040.82 & 7367936.71 & 590459.85 & 113920.6 \\
\hline 301.23 & 2090.26 & 21025934.64 & 6180346.74 & 418453.59 \\
\hline 150.03 & 378.63 & 2236625.11 & 195528.78 & 37019.37 \\
\hline 177.4 & 815.48 & 3609040.2 & 89180.04 & 94155.33 \\
\hline 158.73 & 1213.72 & 3139728.2 & 26199.6 & 126674.5 \\
\hline 287.38 & 452.57 & 9559806.09 & 5414 & 88386.25 \\
\hline 285.53 & 10.33 & 28344 & 6.66 & 3.91 \\
\hline 139.8 & 1834.94 & 9084059.53 & 7.21 & 165568.8 \\
\hline 144.95 & 396.88 & 2482934.56 & 243557.68 & 40352.61 \\
\hline 123.58 & 1194.68 & 3874658.75 & 157766.15 & 99422.85 \\
\hline 166.99 & 1772.45 & 5983646.47 & 238093.37 & 194967.65 \\
\hline 181.29 & 1675.82 & 901 & .12 & 2033 \\
\hline 214.93 & 1101.95 & 4872 & .79 & 1525 \\
\hline 287.01 & 7.99 & 1053 & .76 & 1507.44 \\
\hline 169.2 & 2358.95 & 10672476.75 & 377549.24 & 261996.68 \\
\hline 175.62 & 1999.67 & 6767005.06 & 8.51 & 240046.51 \\
\hline 159.91 & 4777.72 & 11826364.01 & .62 & 5389 \\
\hline 289.41 & 1035.92 & 3744 & 1.85 & 198950.02 \\
\hline 167.73 & 1430.36 & 3941 & 6.74 & 157571.65 \\
\hline 148.48 & 1115.16 & 3490676.65 & 6.74 & 143808.32 \\
\hline 163.57 & 546.33 & 5093942.98 & 98.4 & 60121.15 \\
\hline 161.84 & 1011.19 & 2409407.53 & 0.24 & 107733.78 \\
\hline 156.4 & 389.86 & 482 & .07 & 483 \\
\hline 148.86 & 1158.13 & 4518 & & 113429.46 \\
\hline 291.36 & 1060.6 & 12413 & 55.1 & 205463.76 \\
\hline 164.13 & 883.32 & 2833 & 3.28 & 95510.52 \\
\hline 220.79 & 581.74 & 2222 & 9.17 & 84178.34 \\
\hline 239.78 & 295.09 & 3217639.08 & 1.18 & 46004.5 \\
\hline 264.08 & 653.66 & 7390851.18 & 569479.54 & 111083.68 \\
\hline 181.35 & 560.86 & 3435697.5 & 74208.36 & 66856.22 \\
\hline 146.93 & 2875.74 & 6690 & 9.49 & 286308.32 \\
\hline 154.18 & 935.85 & 5098496.17 & 1070 & 93908.08 \\
\hline 165.87 & 1466.16 & 4544262.68 & 69929.66 & 163637.84 \\
\hline 175.43 & 1177.46 & 4776633.99 & 27853.09 & 137156.81 \\
\hline 293.52 & 2588.02 & 8090587.48 & 895670.36 & 500886.08 \\
\hline 165.52 & 1539.48 & 3016 & 5.69 & 170453.59 \\
\hline 163.33 & 497.26 & 2433373.55 & 1099 & 53744.63 \\
\hline 163.15 & 503.42 & 2427582.26 & 221233.86 & 54036.38 \\
\hline 191.46 & 660.87 & 5663144.28 & 301729.43 & 81165.8 \\
\hline 178.5 & 5679.96 & 19959380.38 & 686519.86 & 642305.97 \\
\hline 141.44 & 499.1 & 1908801.82 & 43702.98 & 49055.42 \\
\hline 153.16 & 809.01 & 3201367.97 & 130428.24 & 82926.2 \\
\hline 207.23 & 474.13 & 2030881.91 & 22475.05 & 64768.89 \\
\hline 273.58 & 1181.82 & 9888388.36 & 1966604.37 & 211244.67 \\
\hline 127.21 & 648.79 & 1937634.86 & 86204.34 & 56333.95 \\
\hline 142.67 & 683.77 & 3675092.38 & 211809.47 & 68482.17 \\
\hline 158.28 & 1318.41 & 2633586.78 & 24614.73 & 137463.6 \\
\hline 166.22 & 1371.82 & 3503394.98 & 58772.55 & 149990.08 \\
\hline
\end{tabular}


Santa Rita do Passa Quatro

Santa Rosa de Viterbo

Santa Salete

Santana da Ponte Pensa

Santana de Parnaíba

Santo Anastácio

Santo André

Santo Antônio da Alegria

Santo Antônio de Posse

Santo Antônio do Aracanguá

Santo Antônio do Pinhal

Santo Expedito

Santópolis do Aguapeí

Santos

São Bento do Sapucaí

São Bernardo do Campo

São Caetano do Sul

São Carlos

São Francisco

São João da Boa Vista

São João das Duas Ponte

São João de Iracema

São João do Pau d'Alho

São Joaquim da Barra

São José da Bela Vista

São José do Barreiro

São José do Rio Pardo

São José do Rio Preto

São José dos Campos

São Lourenço da Serra

São Luiz do Paraitinga

São Manuel

São Miguel Arcanjo

São Paulo

São Pedro

São Pedro do Turvo

São Roque

São Sebastião

São Sebastião da Grama

São Simão

São Vicente

Sarapuí

Sarutaiá

Sebastianópolis do Sul

Serra Azul

Serra Negra

Serrana

Sertãozinho

Sete Barras

Severínia

Silveiras

Socorro

Sorocaba

Sud Mennucci

\begin{tabular}{|c|c|c|c|c|}
\hline 153.86 & 1939.44 & 11582101.56 & 799415.66 & 206116.6 \\
\hline 117.76 & 894.67 & 3403705.84 & 209998.58 & 69337.88 \\
\hline 167.59 & 273.65 & 1332838.93 & 41851.21 & 30172.51 \\
\hline 159.53 & 529.4 & 2069908.71 & 44887.19 & 56325.54 \\
\hline 74.96 & 196.05 & 5051828.97 & 985503.39 & 35509.3 \\
\hline 156.02 & 2675.17 & 8616230.49 & 163448.24 & 273866.46 \\
\hline 269.82 & 39.44 & 4685513.52 & 1998975.4 & 7422.55 \\
\hline 157.42 & 8056.47 & 20563244.14 & 737830.85 & 824891.94 \\
\hline 127.55 & 661.54 & 3943272.52 & 406796.44 & 55932.02 \\
\hline 225.79 & 481.79 & 3482379.13 & 78427.75 & 72484.35 \\
\hline 39.69 & 306.9 & 4487073.89 & 1102262.09 & 67805.73 \\
\hline 160.45 & 601.47 & 1499369.94 & 6171.62 & 63571.18 \\
\hline 167.85 & 820.12 & 2147927.12 & 50289.96 & 90628.14 \\
\hline 265.79 & 128.09 & 6972631.98 & 4872911.67 & 30256.18 \\
\hline 380.68 & 608.85 & 9563191.29 & 1905889.68 & 151898.2 \\
\hline 286.99 & 36.14 & 11674370.17 & 5501810.81 & 7797.21 \\
\hline 271.71 & 0 & 416538.51 & 1245.82 & 0 \\
\hline 168.03 & 3039.57 & 19166306.47 & 1790864.84 & 344155.16 \\
\hline 169.55 & 506.61 & 1269714.21 & 22317.09 & 56620.73 \\
\hline 228.63 & 2952.79 & 11804049.96 & 538936.03 & 455262.84 \\
\hline 172.87 & 772.47 & 2224679.29 & 60959.61 & 87980.75 \\
\hline 168.06 & 1012.09 & 3002080.15 & 161027.1 & 113641.91 \\
\hline 159.24 & 852.86 & 1872046.66 & 25545.62 & 89362.24 \\
\hline 153.95 & 2500.73 & 6356222.76 & 184473.69 & 251519.13 \\
\hline 162.81 & 1528.73 & 4512376.25 & 245111.57 & 163491.58 \\
\hline 325.58 & 1210.61 & 18606107.07 & 8790737.94 & 227049.67 \\
\hline 209.45 & 2193.93 & 8763704.83 & 237434.99 & 304942.1 \\
\hline 163.36 & 504.56 & 7031597.92 & 94090.13 & 55495.14 \\
\hline 276.74 & 5240.44 & 30437837.62 & 5367431.7 & 959620.49 \\
\hline 285.19 & 42.87 & 5342336.05 & 3050743.94 & 8069.28 \\
\hline 310.92 & 2755.11 & 19189710.18 & 4756621.37 & 563711.27 \\
\hline 168.64 & 2391.5 & 10950522.7 & 364012.9 & 265882.28 \\
\hline 254.57 & 2941.97 & 23663099.31 & 4193483.83 & 487821.88 \\
\hline 264.93 & 350.71 & 40383005.46 & 8935360.72 & 67678.82 \\
\hline 150.25 & 3062.08 & 9283748.81 & 633735.17 & 303142.57 \\
\hline 162.41 & 2497.84 & 11874993.71 & 815904.29 & 267432.88 \\
\hline 263.78 & 250.73 & 8113633.49 & 1711179.18 & 40357.8 \\
\hline 268.35 & 11.49 & 11279069.18 & 9120151.63 & 2269.82 \\
\hline 245.03 & 1301.01 & 6174769.5 & 344731.21 & 209858.22 \\
\hline 129.91 & 2502.79 & 8016563.28 & 601695.37 & 222825.14 \\
\hline 263.2 & 5.05 & 4599959.71 & 2729052.99 & 907.56 \\
\hline 221.68 & 1106.92 & 7842539.16 & 495200.72 & 163948.83 \\
\hline 210.17 & 455.54 & 2962640.3 & 171076.31 & 62941.28 \\
\hline 167.06 & 284.45 & 2824821.8 & 125359.41 & 30440.49 \\
\hline 151.14 & 1285.36 & 4272734.57 & 303087.55 & 127923.42 \\
\hline 267.17 & 1232.62 & 5399239.91 & 314724.77 & 216646.64 \\
\hline 145.54 & 752.42 & 1844046.56 & 52205.17 & 70935.3 \\
\hline 143.12 & 911.02 & 5772593.84 & 126115.87 & 85585.03 \\
\hline 254.6 & 1849.67 & 26809891.59 & 21430239.4 & 302065.29 \\
\hline 165.14 & 975.93 & 2317117.54 & 24331.05 & 106171.96 \\
\hline 281.19 & 1549.07 & 11636227.86 & 1830685.4 & 280698.3 \\
\hline 266.52 & 2280.41 & 11935523.8 & 526690.71 & 399715.03 \\
\hline 256.35 & 422.51 & 11499614.84 & 544330.25 & 68852.06 \\
\hline 156.69 & 5402.1 & 9271102.73 & 245895.74 & 564171.22 \\
\hline
\end{tabular}




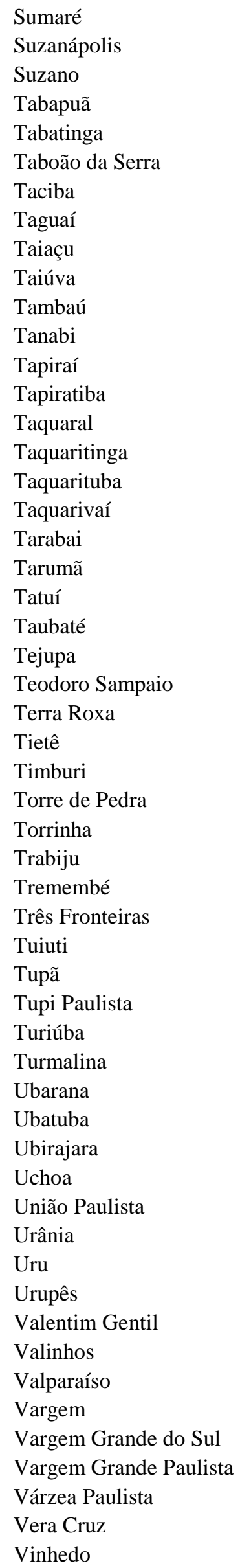

\begin{tabular}{|c|c|c|c|c|}
\hline 210.13 & 298.34 & 3196685.26 & 10495.95 & 41184.67 \\
\hline 271.51 & 6.04 & 591427.59 & 30622.3 & 1076.28 \\
\hline 7.81 & 3059.58 & 10663954.84 & 1193755.59 & 344993.09 \\
\hline 168.27 & 815.05 & 5811591.73 & 140926.18 & 90529.84 \\
\hline 145.61 & 861.65 & 5347589.64 & 261486.98 & 81524.74 \\
\hline 279.48 & 0.07 & 580091.27 & 26048.75 & 13.6 \\
\hline 3.96 & 3374.08 & 9383475.44 & 387852.06 & 348394.64 \\
\hline 95.59 & 815.13 & 2838616.38 & 63442.26 & 103216.84 \\
\hline 169.17 & 181.39 & 1803958.46 & 29697.79 & 19900.72 \\
\hline 131.56 & 233.67 & 1740790.34 & 20768.31 & 21618.44 \\
\hline 156.96 & 1924.11 & 8821224.06 & 663694.75 & 207411.37 \\
\hline 145.64 & 1716.57 & 10855103.45 & 296280.83 & 163760.57 \\
\hline 80.84 & 207.9 & 21195378.64 & 17053837.37 & 39113.97 \\
\hline 215.07 & 1327.41 & 4727635.16 & 207632.91 & 188440.2 \\
\hline 120.09 & 66.55 & 637899.77 & 10109.18 & 5207.23 \\
\hline 154.94 & 1700.12 & 9214796.37 & 169064.15 & 176643.89 \\
\hline 176.96 & 1441.52 & 7922233.23 & 171519.68 & 172347.41 \\
\hline 151.16 & 379.15 & 3524625.86 & 221555.21 & 37860.85 \\
\hline 146.17 & 1366.13 & 2872863.97 & 58242.83 & 132608.14 \\
\hline 178.46 & 1719.75 & 5403801.75 & 68271.91 & 202820.59 \\
\hline 235.53 & 1344.15 & 12366589.83 & 325347.11 & 207056.12 \\
\hline 292.72 & 3128.13 & 18301561.89 & 1851532 & 621086.36 \\
\hline 200.09 & 1359.31 & 5909 & 352080.19 & 181916.37 \\
\hline 149.7 & 10722.22 & 23332412.26 & 5339065.03 & 1111643.93 \\
\hline 140.57 & 1069.23 & 20.29 & 2.15 & 3.13 \\
\hline 212.65 & 1571.84 & 8359163.85 & 151403.41 & 221829.57 \\
\hline 204.5 & 668.48 & 4031613.2 & 281364.97 & 114431.35 \\
\hline 216.1 & 291.25 & 1537 & 107236.88 & 40024.61 \\
\hline 170.77 & 1172.58 & 5326 & 268051.95 & 130176.47 \\
\hline 183.22 & 345.9 & 114 & & \\
\hline 293.21 & 1508.54 & 5649 & 754807.46 & 297568.83 \\
\hline 152.44 & 561.72 & 71.08 & 37762.77 & 56262.26 \\
\hline 239.76 & 303.78 & 3026970.01 & 124820.65 & 48455.14 \\
\hline 163.35 & 3078.98 & 10263035.68 & 267004.49 & 332311.03 \\
\hline 159.75 & 945.51 & 3891679.18 & 26277.15 & 99228.62 \\
\hline 172.26 & 686.76 & 262 & 74169.52 & 78420.59 \\
\hline 168.27 & 789.99 & $246 C$ & 91339.12 & 87382.07 \\
\hline 149.22 & 1533.61 & 3127672.39 & 64690.75 & 153809.24 \\
\hline 283.47 & 39.14 & 20293763 & 17002701.56 & 7670.61 \\
\hline 138.06 & 1394.76 & 3896578.82 & 247105.65 & 134190.55 \\
\hline 171.1 & 819.2 & 4306838.84 & 98353.15 & 92475.45 \\
\hline 170.85 & 233.09 & 13438 & 45419.14 & 25728.19 \\
\hline 168.53 & 623.2 & 3532233.22 & 73461.97 & 69103.38 \\
\hline 171.71 & 1037.51 & 2548967.65 & 79045.21 & 117504.97 \\
\hline 171.4 & 473.82 & 5572288.08 & 131248.25 & 53530.72 \\
\hline 148.37 & 560.33 & 2234387.75 & 119001.82 & 54824.55 \\
\hline 294.38 & 444.25 & 4352482.66 & 183349.56 & 83661.36 \\
\hline 166.03 & 6150.38 & 14255753.36 & 542220.03 & 667226.48 \\
\hline 254.87 & 306.78 & 3636618.81 & 354779.45 & 54189.23 \\
\hline 201.9 & 1356.43 & 5398036.26 & 184357.81 & 181947.46 \\
\hline 272.54 & 1.44 & 911361.41 & 132920.47 & 256.29 \\
\hline 271.96 & 14.32 & 953519.07 & 98829.61 & 2566.57 \\
\hline 182.25 & 1495.43 & 4517601.75 & 251820.41 & 179325.28 \\
\hline 281.81 & 165.03 & 2300957.31 & 134013.62 & 30335.44 \\
\hline
\end{tabular}


Viradouro

Vista Alegre do Alto

Vitória Brasil

Votorantim

Votuporanga

Zacarias

\begin{tabular}{rrrrr}
140.08 & 560.07 & 3068489.54 & 56786.23 & 51776.24 \\
174.59 & 421.89 & 1665386.53 & 15255.97 & 48450.41 \\
171.59 & 169.82 & 861249.94 & 17347.56 & 19176.75 \\
298.34 & 403.91 & 5489282.25 & 665485.03 & 80918.63 \\
150.01 & 1339.02 & 6313860.03 & 232634.65 & 135316.27 \\
147.18 & 1858.29 & 4698914.33 & 90695.75 & 208826.27 \\
\hline
\end{tabular}




\section{Appendix 6: List of studies containing forest inventories}

Abdo, M.T.V. (2009). Caracterização da vegetação arbórea e atributos do solo da Reserva Biológica de Pindorama, SP. Tese (Doutorado). Universidade Estadual Paulista. Jaboticabal . 64p.

Aguiar, O.T. (2003). Comparação entre os métodos de quadrantes e parcelas na caracterização da composição florística e fitossociológica de um trecho de floresta ombrófila densa no Parque Estadual "Carlos Botelho" - São Miguel Arcanjo, São Paulo. Dissertação (Mestrado). Universidade de São Paulo, Piracicaba, 140p.

Albuquerque, G.B. \& Rodrigues, R.R. (2000). A vegetação do Morro de Araçoiaba, Floresta Nacional de Ipanema, Iperó (SP). Scientia Forestalis 58: 145159."http://www.lcb.esalq.usp.br/publications/articles/2000/2000sfv58p145159.pdf>

Almeida-scabbia, R.J. (2001). Análise da relação vegetação-solo em três cotas altitudinais na floresta estacional semidecidual ocorrente em Cuesta basáltica (।"Parque Rawitsher।", fazenda Pedra Vermelha, município de Analândia SP).Tese (Doutorado). Universidade Estadual Paulista I"Júlio de Mesquita Filhol". Rio Claro. 173p.

Almeida, A.; Padovezi, A. \& Lima, R.A.F. (2011). Informações de Referência: Levantamento e avaliação de informações de referência para o Projeto 'Restauração de 350 ha do entorno do reservatório do Rio Cachoeira - Piracaia - SP'. Brasília, DF: The Nature Conservancy do Brasil (Série Água, Clima e Floresta - v. II).

Arzolla, F.A.R.D.P. (2002). Florística e fitossociologia de trecho da Serra da Cantareira, Núcleo Águas Claras, Parque Estadual da Cantareira, Mairiporã, SP. Dissertação (Mestrado). Universidade Estadual de Campinas. Campinas, SP. 184p.

Assis, M.A.; Prata, E.M.B.; Pedroni, F.; Sanchez, M.; Eisenlohr, P.V.; Martins, F.R.; Santos, F.A.M.; Tamashiro, J.Y.; Alves, L.F.; Vieira, S.A.; Piccolo, M.C.; Martins, S.C.; Camargo, P.B.; Carmo, J.B.; Simões, E.; Martinelli, L.A. \& Joly, C.A. (2011). Florestas de restinga e de terras baixas na planície costeira do sudeste do Brasil: vegetação e heterogeneidade ambiental. Biota Neotropica 11 (2): 83-101.

Athayde, S.F. (1997). Composição florística e estrutura fitossociológica em quatro estágios sucessionais de uma Floresta Ombrófila Densa Submontana como subsídio ao manejo ambiental - Guaraqueçaba - PR. Dissertação (Mestrado). Universidade Federal do Paraná, Curitiba, PR.

Barbosa, T. C. (2015) Quantificação de biomassa e carbono da parte aérea em uma área de Mata Atlântica, na Serra da Cantareira, São Paulo

Bertani, D.F.; Rodrigues, R.R.; Batista, J.L.F. \& Shepherd, G.J. (2001). Análise temporal da heterogeneidade florística e estrutural em uma floresta ribeirinha. Revista Brasileira de Botânica 24 (1): 11-23.

Bertoncini, A.P. 2003. Estrutura e dinâmica de uma área perturbada na terra indígena Araribá, Avaí-SP: implicações para o manejo e a restauração florestal. Tese (Doutorado). Instituto de Biologia, Universidade Estadual de Campinas, Campinas. 162p.

Bertoni, J.E.A.; Martins, F.R.; Moraes, J.L. \& Shepherd, G.J. (1988) Composição florística e estrutura fitossociológica do Parque Estadual de Vaçununga, Santa 
Rita do Passa Quatro, SP - Gleba Praxedes. Boletim Técnico do Instituto Florestal de São Paulo 42: 149-170.

Bicudo, L.R.H. (1995) Florística, fitossociologia e ciclagem de nutrientes em um cerradão no município de Botucatu - SP. Tese (Doutorado). Universidade Estadual Paulista, Instituto de Biociências de Rio Claro. 167p.

Borghi, W.A.; Martins, S.S.; Del Quiqui, E.M. \& Nanni, M.R. (2004) Caracterização e avaliação da mata ciliar à montante da Hidrelétrica de Rosana, na Estação Ecológica do Caiuá, Diamante do Norte, PR. Cadernos de Biodiversidade 4 (2): 9-18.

Borgo, M. (2010) A Floresta Atlântica do litoral norte do Paraná, Brasil: aspectos florísticos, estruturais e estoque de biomassa ao longo do processo sucessional. Tese (Doutorado) - Universidade Federal do Paraná, Setor de Ciências Agrárias, Programa de Pós-Graduação em Engenharia Florestal. 165p.

Camargo, P.F.A. (1999) Composição florística e estrutural fitossociológica de um remanescente de floresta estacional semidecidual submontana na Fazenda Santa Rita, no Município de Agudos - SP. Dissertação (Mestrado) - Instituto de Biociências, UNESP, Botucatu, 1999. 118p.

Campos, J.B. \& Souza, M.C. (2003). Potential for natural Forest regeneration from seed bank in an Upper Paraná River Floodplain, Brazil. Brazilian Archives of Biology and Technology 46 (4): 625-639

Campos, J.B.; Romagnolo, M.B. \& Souza, M.C. (2000) Structure, composition and spatial distribution of tree species in a remnant of the semideciduous seasonal alluvial forest of the upper Paraná River floodplain. Brazilian Archives of Biology and Technology 43 (2): 185-194.

Campos, M.C.R.; Tamashiro, J.Y.; Assis, M.M. \& Joly, C.A. (2011). Florística e fitossociologia do componente arbóreo da transição Floresta Ombrófila Densa das Terras Baixas - Floresta Ombrófila Densa Submontana do Núcleo Picinguaba/PESM, Ubatuba, sudeste do Brasil. Biota Neotropica 11 (2): 301312.

Carboni, M. (2007). Composição, estrutura e diversidade vegetal de uma floresta estacional semidecídua ribeirinha com influência fluvial permanente (mata de brejo) em Bauru - SP. Dissertação (Mestrado). Universidade Estadual Paulista, Botucatu, 116p.

Cardoso-leite, E., Castello, A.C.D., Coelho, S., Coelho, J.C., Schievenin, D.F., Carmo, J.B. (2016) Recovery of richness, biomass and density in Atlantic rainforest areas after clearcutting. Revista Árvore 40(3): 499-508.

Cardoso-leite, E.; Podadera, D.S.; Peres, J.C. \& Castello, A.C.D. (2013). Analysis of floristic composition and structure as an aid to monitoring protected areas of dense rain forest in southeastern Brazil. Acta Botanica Brasilica 27(1): 180194

Carvalhaes, M.A. (1997). Florística e estrutura de mata sobre restinga na Juréia, Iguape, SP. Dissertação (Mestrado). Universidade de São Paulo, USP, SP. $107 \mathrm{p}$.

Carvalho, W.A.C. (2010) Diversidade do estrato arbóreo-arbustivo de sete comunidades de floresta ombrófila altomontanas da APA Fernão Dias, MG, Brasil. Tese (Doutorado). Universidade Federal de Minas Gerais, Belo Horizonte. 72p.

Cassola, H. (2008). Aspectos da estrutura fitossociológica e silvigenética em fragmentos de floresta estacional semidecídua com diferentes histórias de 
perturbação em Botucatu, SP. Dissertação (Mestrado). ESALQ, Piracicaba. $85 \mathrm{p}$.

Castro, A.A.J.F. (1987) Florística e fitossociologia de um cerrado marginal brasileiro, Parque Estadual de Vaçununga, Santa Rita do Passa Quatro - SP. Dissertação (Mestrado). Universidade de Campinas, Campinas. 243p.

Catharino, E.L.M. (1989). Estudo fisionômico-florístico e fitossociológico em matas residuais secundárias no município de Piracicaba, SP. Dissertação (Mestrado). Universidade Estadual de Campinas, Campinas, 189p

Cavalcanti, D.C. (1998). Florística e fitossociologia de um remanescente florestal transicional no município de Guaratinguetá, SP. Dissertação (Mestrado). Universidade Estadual Paulista, Rio Claro, 103p.

Cavassan, O. (1990). Florística e fitossociologia da vegetação lenhosa de um hectare de cerrado no Parque Ecológico Municipal de Bauru - SP. Tese (Doutorado). Universidade Estadual de Campinas, Campinas. 06p

Cesar, O.; Pagano, S.N.; Leitão-filho, H.F.; Monteiro, R.; Silva, O.A.; Marinis, G. \& Shepherd, G.J. (1985) Composição e estrutura da vegetação da Reserva Ecológica de Corumbataí, Estado de São Paulo. In: Anais do V Congresso da Sociedade Botânica de São Paulo. Botucatu, p. 39.

Cielo-filho, R. \& Santin, D.A. (2002) Estudo florístico e fitossociológico de um fragmento florestal urbano - Bosque dos Alemães, Campinas, SP. Revista Brasileira de Botânica 23 (3): 291-301.

Cielo-filho, R; Gneri, M. \& Martins, F. (2011). Sampling precision and variability of tree species abundance ranks in a semideciduous Atlantic forest fragment. Community Ecology 12(2):188-195

Costa, M.P.; Pereira, J.A.A.; Fontes, M.A.L.; Melo, P.H.A.; Pifano, D.S.; Pellicciottii, A.S.; Pompeu, P.V. \& Silva, R.A. (2011) Estrutura e diversidade da comunidade arbórea de uma floresta superomontana, no planalto de Poços de Caldas (MG). Ciência Florestal 21 (4): 711-725.

Couto, H.T.Z. (2005) Métodos de Inventário da Biodiversidade de Espécies Arbóreas. Relatório Final de Projeto Temático FAPESP. ESALQ, Piracicaba.

Custódio-filho, A. (2002). A floresta ombrófila densa em diferentes altitudes no Parque Estadual Carlos Botelho. Tese (Doutorado). Universidade de São Paulo, São Paulo. 165p.

D'orazio, F.D.A.E. \& Catharino, E.L.M. (2013). Structure and floristics of two alluvial forests fragments in the Valley of Paraiba do Sul river, São Paulo State, Brazil. Hoehnea 40(3): 567-582.

Danelli, M.F.D., Fisch, S.T.V., Vieira, S.A. (2016) Analysis of the forest structure and the biomass of harvesting areas of juçara fruits (Euterpe edulis mart.) in the northern coast and in serra do mar, sp state - Brazil [Análise da estrutura e biomassa florestal de áreas de colheita de frutos de juçara (Euterpe edulis mart.) no litoral norte e serra do Mar - SP] Ciencia Florestal 26(3) : 773-786

Demarchi, L.O. (2010) Florística e fitossociologia da comunidade arbustivo-arbórea em um trecho de floresta estacional semidecidual Ribeirinha no município de Indaiatuba, SP. Monografia (Graduação). Universidade Estadual Paulista I"Júlio de Mesquita Filhol", Rio Claro. 66p

Dias, A.C. (2005) Composição florística, fitossociológica, diversidade de espécies arbóreas e comparação de métodos de amostragem na floresta ombrófila densa do Parque Estadual de Carlos Botelho/SP, Brasil. Tese (Doutorado). Universidade de São Paulo, Piracicaba, 203p. 
Dias, G. (2010) Florística e Fitossociologia das espécies arbóreas de ocorrência em mata ciliar no Alto Rio Pardo, na Estância Climática de Caconde, SP.Dissertação (Mestrado). Universidade Estadual Paulista "Júlio de Mesquita Filho", Rio Claro, SP, 71p.

Dislich, R. (2002) Análise da vegetação arbórea e conservação na Reserva Florestal da Cidade Universitária \"Armando de Salles Oliveiral", São Paulo,SP. Tese (Doutorado). Universidade de São Paulo,São Paulo. 258p.

Donadio, N. M. M., de Paula, R. C. S., \& Galbiatti, J. O. A. N. (2009). Estrutura da comunidade arbórea de um remanescente florestal localizado em Taquaritinga, Estado de São Paulo, Brasil. CientíFica, 37(2): 77-88.

Donadio, N.M.M.; Paula, R.C. \& Galbiatti, J.A. (2009). Florística e estrutura da comunidade arbórea de um remanescente florestal ripário no município de Guariba, estado de São Paulo, Brasil. Revista do Instituto Florestal de São Paulo 21 (1): 1-17.

Durigan, G. \& Leitão-filho, H.F. (1995). Florística e fitossociologia de matas ciliares do oeste paulista. Revista do Instituto Florestal 7 (1): 197-239.

Durigan, G.. (1987). Fitossociologia e evolução da densidade da vegetação do cerrado, Assis, SP. Boletim Técnico do Instituto Florestal 41: 59-78.

Durigan, G.; Franco, G.A.D.C.; Pastore, J.A. \& Aguiar, O.T. (1997). Regeneração natural da vegetação de cerrado sob floresta de Eucalyptus citriodora. Revista do Instituto Florestal, São Paulo 9(1): 19-36.

Durigan, G.; Franco, G.A.D.C.; Saito, M. \& Baitello, J.B. (2000) Estrutura e diversidade do componente arbóreo da floresta na Estação Ecológica dos Caetetus, Gália, SP. Revista Brasileira de Botânica 23 (4): 371-383

Faraco, A. G. (2007) Composição florística e estrutura fitossociológica de uma área de cerrado pertencente ao Campus de Bauru da Universidade Estadual Paulista - Unesp, SP. Dissertação (Mestrado). Universidade Estadual Paulista "Júlio de Mesquita Filho". Botucatu, 112p.

Farah, F.T. (2009) Vinte anos de dinâmica em um hectare de Floresta Estacional Semidecidual. Tese (Doutorado). Universidade Estadual de Campinas, Campinas, 130p.

Faria, M.B.B.C. (2008) Diversidade e regeneração natural de árvores em Florestas de Restinga na Ilha do Cardoso, Cananéia, SP, Brasil. Dissertação (Mestrado). Universidade de São Paulo, São Paulo. 130p.

Feliciano, A.L.P. (1999) Caracterização ambiental, florística e fitossociológica de uma Unidade de Conservação. Caso de estudo: Estação Ecológica de São Carlos, Brotas, SP. 160p.

Fernandes, F.A.B. (2003) Estudos de gradientes vegetacionais em uma floresta semidecídua altimontana no planalto de Poços de Caldas, MG. Dissertação (Mestrado). Universidade Federal de Lavras, Lavras, MG. 157p.

Fernandes, M.M.; Caldas, A.J.F.S.; Jimenez, L.O.M.; Crepaldi, M.O.S.; Barboza, R.S. \& Rodrigues, R.M.M. (2012). Composição florística e estrutura do componente arbóreo de uma floresta estacional semidecidual da Fazenda Santa Cecília Do Ingá, Volta Redonda, Rio de Janeiro, Brasil. Revista Científica Eletrônica de Engenharia Florestal 20(1): 29-43.

Ferreira, C.S. (2014) Seletividade de espécies arbóreas à margem do lago da barragem de Marimbondo em Frutal, MG. Dissertação (Mestrado). Universidade Federal de Viçosa, Viçosa. 59p. 
Figueiredo, N. (1993) Estudo fitossociológico em uma floresta mesófila semidecídua secundária na Estação Experimental de Angatuba, município de Angatuba, SP. Dissertação (Mestrado). Universidade Estadual de Campinas, Campinas. 160p.

Filippe, J. (2006) Avaliação da largura ideal de Florestas Ribeirinhas considerando modelagem matemática, estimativa de erosão por ${ }^{123} \mathrm{CS}$ e aspectos ecológicos' 01/05/2006 144 f. Mestrado em Ciência Ambiental Instituição De Ensino: Universidade De São Paulo, São Paulo Biblioteca Depositária: IG-USP

Fina, B.G. \& Monteiro, R. (2009). Estudo da estrutura da comunidade arbustivoarbórea de uma área de cerradão, município de Pirassununga (SP). Neotropical Biology and Conservation 4: 40-48.

Fonseca, R. C. B., Rodrigues, R. R. (2000) Análise estrutural e aspectos do mosaico sucessional de uma floresta semidecídua em Botucatu, SP. Scientia Forestalis 57: 27-43.

Fontes, M.A.L. (2008) Dinâmica de comunidades arbóreas de florestas alti-montanhas de Minas Gerais. Tese (Doutorado). Universidade Federal de Minas Gerais, Belo Horizonte. 85p.

França, F.S. \& Rolim, S.G. (2000) Estrutura de um trecho de floresta de restinga no município de Bertioga (SP). In: Anais do $5^{\circ}$ Simpósio sobre Ecossistemas Brasileiros 3: 84-91.

França, G.S. \& Stehmann, J.R. (2004). Composição florística e estrutura de componente arbóreo de uma floresta altimontana no município de Camanducaia, Minas Gerais, Brasil. Revista Brasileira de Botânica 27 (1): 1930.

Franco, G.A.D.C. (2002) Florística e fitossociologia de duas unidades do mosaico florestal da Estação Ecológica dos Caetetus - Floresta Estacional Semidecidual, Gália - SP. Dissertação (Mestrado). ESALQ/USP, Piracicaba. 95p.

Gabriel, J.L.C. (1997) Florística, fitossociologia de espécies lenhosas e aspectos da ciclagem de nutrientes em Floresta Mesófila Semidecídua nos municípios de Anhembi e Bofete, SP. Tese (Doutorado). Instituto de Biociências, Universidade Estadual Paulista, Rio Claro. 217p.

Galvão, F.; Roderjan, C.V.; Ziller, S.R. \& Kuniyoshi, Y.S. (2002) Composição florística e fitossociologia de caxetais do litoral do estado do Paraná - Brasil. Floresta 32 (1): 17-39.

Gatti, G.A. (2000). Composição florística, fenologia e estrutura da vegetação de uma área de restauração ambiental - Guaraqueçaba - PR. Dissertação (Mestrado). Universidade Federal do Paraná, Curitiba, PR

Godoy, J.R.L. (2001) Estrutura e composição específica da Mata Atlântica secundária de encosta sobre calcário e filito, no Parque Estadual Turístico do Alto Ribeira, Iporanga, SP. Dissertação (Mestrado). Universidade de São Paulo, São Paulo. 57p.

Gomes, E.P.C. (1998) Dinâmica do componente arbóreo de um trecho de mata em São Paulo, SP. Tese (Doutorado). Universidade de São Paulo, São Paulo.

Gomes, E.P.C.; Fisch, S.T.V. \& Mantovani, W. (2005) Estrutura e composição do componente arbóreo na Reserva Ecológica do Trabiju, Pindamonhangaba, SP, Brasil. Acta Botanica Brasilica 19 (3): 451-464.

Gomes, J.A.M.A..; Bernacci, L.C. \& Joly, C.A. (2011) Diferenças florísticas e estruturais entre duas cotas altitudinais da Floresta Ombrófila Densa Submontana Atlântica, do Parque Estadual da Serra do Mar, município de Ubatuba/SP, Brasil. Biota Neotropica 11 (2): 123-137 
Gorenstein, M.R. (2002) Métodos de amostragem no levantamento da comunidade arbórea em floresta estacional semidecidual. Dissertação (Mestrado). ESALQ/USP, Piracicaba. 92p.

Gregorini, R.A. (2015) Análise de áreas para a criação de unidades de conservação no município de Boituva (SP). Dissertação (Mestrado). Universidade Federal de São Carlos, Sorocaba. 93 p.

Grillo, R.M.M. (2016). A floresta ombrófila densa altomontana no Parque Estadual da Serra do Mar-Núcleo Cunha, SP: análise da heterogeneidade estrutural e florística em escala local. Dissertação (Mestrado). Universidade Estadual Paulista, Rio Claro. 11p.

Grombone-guaratini, M.T.; Bernacci, L.C.; Meira Neto, J.A.; Tamashiro, J.Y. \& Leitão-filho, H.F. (1990) Estrutura fitossociológica da floresta semidecídua de altitude do Parque Municipal da Grota Funda (Atibaia - estado de São Paulo). Acta Botanica Brasilica 4 (2): 47-64.

Guedes-bruni, R.R. (1998) Composição, estrutura e similaridade florística de dossel em seis unidades fisionômicas de mata atlântica no Rio de Janeiro. Tese (Doutorado). Universidade de São Paulo, São Paulo, SP. 231p

Guedes, D.; Barbosa, L.M. \& Martins, S.E. (2006). Composição florística e estrutura fitossociológica de dois fragmentos de floresta de restinga no município de Bertioga, SP, Brasil. Acta Botanica Brasilica 20 (2): 299-311.

Guedes, D.c.; Cesar, O.; Monteiro, R. \& Silva-filho, N.L. (2001) Florística e fitossociologia de um remanescente de Mata Atlântica em Cubatão - SP. Naturalia 26: 69-86.

Guilherme, F.A.G.; Morellato, L.P. \& Assis, M.A. (2004) Horizontal and vertical tree community structure in a lowland Atlantic Rain Forest, Southeastern Brazil. Revista Brasileira de Botânica 27 (4): 725-737.

Guimarães, J.C.; Van Den Berg, E.; Castro, G.C.; Machado, E.l. \& Oliveira-filho, A.T. (2008). Dynamics of the shrub-tree component of an alluvial gallery forest on the Poços de Caldas Plateau, MG State, Brazil. Brazilian Journal of Botany 31 (4): 621-632.

Ishara, K.L. (2010). Aspectos florísticos e estruturais de três fisionomias de cerrado no município de Pratânia, São Paulo. Tese (Doutorado). Universidade Estadual Paulista. Instituto de Biociências de Botucatu. 154p.

Ivanauskas, N.M. \& Rodrigues, R.R. (2000). Florística e fitossociologia de remanescentes de Floresta Estacional Decidual em Piracicaba, São Paulo, Brasil. Revista Brasileira de Botânica 23 (3): 291-304.

Ivanauskas, N.M. (1997) Caracterização florística e fisionomia da Floresta Atlântica sobre a formação Pariquera-Açu, na Zona da Morraria Costeira do estado de São Paulo. Dissertação (Mestrado). Universidade Estadual de Campinas, Campinas, 231p

Ivanauskas, N.M.; Rodrigues, R.R. \& Nave, A. G. (1997) Aspectos ecológicos de um trecho de floresta de brejo em Itatinga, SP: florística, fitossociologia e seletividade de espécies. Revista Brasileira de Botânica 20 (2): 139-153.

Ivanauskas, N.M.; Rodrigues, R.R. \& Nave, A.G. (1999). Fitossociologia de um trecho de Floresta Estacional Semidecidual em Itatinga, São Paulo, Brasil. Scientia Forestalis 56: 83-99.

Jandoti, D. (2009) Fitossociologia em um fragmento de floresta estacional semidecidual na Estação Ecológica do Caiuá, Paraná, Brasil. Dissertação (Mestrado). Universidade Estadual Paulista "Júlio de Mesquita Filho". Botucatu. 40p 
Jaster, C.B. (1995). Análise Estrutural de Algumas Comunidades Florestais no Litoral do Estado do Paraná, na Área de Domínio da Floresta Ombrófila Densa Floresta Atlântica. Dissertação (Mestrado) (versão traduzida para a língua portuguesa). Forstwissenschaftlicher Fachbereich, Abt. Tropen-Subtropen. Georg-August-Universität Göttingen. Göttingen, Alemanha. 1995.116p.

Kamimura, V.A. (2011) Aspectos estruturais e ecológicos de uma comunidade arbórea do Parque estadual da Serra do Mar. Trabalho de Conclusão de Curso. UNESP, Rio Claro.45p

Knobel, M.G. (1995) Aspectos da regeneração natural do componente arbóreoarbustivo, de trecho da floresta da Reserva Biológica do Instituto de Botânica de São Paulo, SP. Dissertação (Mestrado). Universidade de São Paulo, USP, SP. 123p.

Konopczyk, R.M.G. 2014. Composição florística, estrutura e heterogeneidade ambiental da comunidade arbórea de uma várzea em Porto Ferreira, SP, Brasil. Dissertação (Mestrado). UNESP Rio Claro, Rio Claro. 75p.

Latansio-aidar, S.R., Oliveira, A.C.P.D., Rocha, H.R.D. \& Aidar, M.P.M. (2010) Fitossociologia de um Cerrado denso em área de influência de torre de fluxo de carbono, Pé-de-Gigante, Parque Estadual de Vassununga, SP. Biota Neotropica 10(1): 195-207.

Leal, T.S. (2015). Florística e fitossociologia de Cerrado Sentido Restrito Em Regeneração Natural No Município De Pirassununga, Estado De São Paulo' 27/03/2015 66 F. Mestrado Em Ciências Biológicas (biologia Vegetal) Instituição De Ensino: Universidade Est.paulista Júlio De Mesquita Filho/rio Claro, Rio Claro Biblioteca Depositária: Ib - Rio Claro/sp

Leite, E.c. \& Rodrigues, R.R. 2008. Fitossociologia e caracterização sucessional de um fragmento de floresta estacional no Sudeste do Brasil. Revista Árvore 32 (3): 583-595.

Lima, M.E.L.; Cordeiro, I. \& Moreno, P.R.H. 2011. Estrutura do componente arbóreo em Floresta Ombrófila Densa Montana no Parque Natural Municipal Nascentes de Paranapiacaba (PNMNP), Santo André, SP, Brasil. Hoehnea 38(1): 73-96.

Lindoso, G.S.; Goldenberg, R., Borgo, M., (2005) Aspectos estruturais de distribuição da comunidade vegetacional em duas áreas de floresta ombrófila densa RPPN Serra do Itaqui - PR.. 47p. Monografia (Graduação). Universidade Federal do Paraná. Setor de Ciências Biológicas. Curso de Graduação em Ciências Biológicas, Curitiba.

Los, M.M. (2004) Florística, estrutura e diversidade em floresta com Araucária em áreas de diferentes tamanhos. Dissertação (Mestrado). Universidade de São Paulo, São Paulo. 79p.

Manão, C.Y.G. 2011 Composição florística e estrutura da comunidade arbustivoarbórea de um trecho de floresta submontana na vertente sudeste do Parque Estadual da Ilha Grande, Angra dos Reis / RJ. Dissertação (Mestrado). Universidade do Estado do Rio de Janeiro. 55p.

Manzatto, A.G. (2005) Dinâmica da comunidade arbustivo-arbórea em um fragmento de floresta estacional semidecidual localizada no município de Rio Claro, SP, durante o período de 1989-2003. Tese (Doutorado). Universidade Estadual Paulista, Rio Claro. 114p.

Manzatto, A.G.; Furlan, A.; Cesar, O. \& Pagano, S.N. (1999). Vegetação lenhosa do SESC Interlagos, São Paulo, SP. Rio Claro : UNESP/Instituto de Biociências, $74 \mathrm{p}$. 
Marchiori, N.M.; Rocha, H.R.; Tamashiro, J.Y. \& Aidar, M.P.M. (2016) Composição da comunidade arbórea e biomassa aérea em uma floresta atlântica secundária, Parque Estadual da Serra do Mar, São Paulo, Brazil. Cerne 22(4): 501-514.

Marçon, S.L. (2009) Composição florística e estrutura do componente arbustivoarbóreo do Parque Natural Municipal da Cratera da Colônia, São Paulo, SP. Dissertação (Mestrado). Universidade de São Paulo, Ribeirão Preto, 120 p.

Mardegan, C.M. \& Cavassan, O. (2009) Considerações sobre as alterações de um fragmento florestal às margens de uma represa no município de Guaiçara, SP, a partir da análise florística e fitossociológica. Revista do Instituto Florestal de São Paulo 21 (2): 139-150.

Marmontel, C.V.F.; Martins, T.M.; Nunes, R.L.; Rodrigues, J.P.; Melo, A.G.C. (2012) Estrutura e florística da comunidade arbórea de um fragmento florestal urbano - Bosque Municipal de Garça, SP. Revista Científica Eletrônica de Engenharia Florestal 19(1): 34-49.

Marmontel, C.v.f.; Rodrigues, V.a.; Martins E Martins, T.; Starzynski, R. \& Carvalho, J.L. (2013). Caracterização da vegetação secundária do bioma Mata Atlântica com base em sua posição na paisagem. Bioscience Journal 29(6): 2042-2052.

Martins, L. A. (2010) Estrutura e dinâmica sucessional de um fragmento de floresta estacional semidecidual com diferentes históricos de perturbação. Dissertação (Mestrado). Universidade Estadual Paulista "Júlio de Mesquita Filho". Botucatu. 121p.

Medeiros, D.A. 2004. Métodos de amostragem no levantamento da diversidade do cerradão da Estação Ecológica de Assis. Dissertação (Mestrado). ESALQ/USP, Piracicaba. 85p.

Medeiros, M.C.M.P. (2009) Caracterização fitofisionômica e estrutural de áreas de Florestas Ombrófila Densa Montana no Parque Estadual da Serra do Mar. Dissertação (Mestrado). Instituto de Botânica, São Paulo. 85p.

Medeiros, M.C.M.P.D. \& Aidar, M.P.M. (2011). Structural variation and content of aboveground living biomass in an area of Atlantic Forest in the State of São Paulo, Brazil. Hoehnea 38(3), 413-428.

Meireles, L.D. (2009). Estudos florísticos, fitossociológicos e fitogeográficos em formações vegetacionais altimontanas da Serra da Mantiqueira meridional, Sudeste do Brasil. Tese (Doutorado). Universidade Estadual de Campinas, Campinas, SP. 262p.

Meireles, L.D.; Shepherd, G.j. \& Kinoshita, L.S. (2008) Variações na composição florística e estrutura fitossociológica de uma floresta ombrófila densa altomontana na Serra da Mantiqueira, Monte Verde, MG. Revista Brasileira de Botânica 31 (4): 559-574.

Mello, C. E. (2008) Estrutura da vegetação arbórea em gradiente altitudinal de um morro testemunho em uma Floresta Estacional Semidecidual na região centro sul do estado de São Paulo, sudeste do Brasil. Dissertação (Mestrado). Universidade Estadual Paulista "Júlio de Mesquita Filho". Botucatu. 61p..

Melo, A.C.G; Durigan, G. (2010) Impacto do fogo e dinâmica da regeneração da comunidade vegetal em borda de Floresta Estacional Semidecidual (Gália, SP, Brasil) Brazilian Journal of Botany 33(1) : 37-50

Melo, M.M.R.F. \& Mantovani, W. (1994) Composição florística e estrutura de trecho de Mata Atlântica de encosta, na Ilha do Cardoso (Cananéia, SP, Brasil). Boletim do Instituto de Botânica de São Paulo 9: 107-158. 
Melo, M.M.R.F.; Oliveira, R.j.; Rossi, L.; Mamede, M.c.h. \& Cordeiro, I. 2000. Estrutura de trecho de floresta atlântica de planície na Estação Ecológica de Juréia-Itatins, Iguape, SP, Brasil. Hoehnea 27(3): 299-322

Mendonca, A. H., Russo, C., Melo, A. C. G., \& Durigan, G. (2015) Edge effects in savanna fragments: a case study in the cerrado. Plant Ecology \& Diversity, 8(4): 493-503.

Miranda, F.T.S.; Gusson, E.; Ferez, A.p.c. \& Kageyama, P.Y. (2010). Fitossociologia de um fragmento de floresta estacional semidecidual em anhembi, São Paulo, Brasil. In: Anais do 61o Congresso Nacional de Botânica. Manaus, p. 1562.

Molina, F. G.; Stranghetti, V.; Ituralde, R. B. \& Arantes, F. D. (2001) Aspectos fitossociológicos das espécies arbóreas/arbustivas de um trecho de mata ciliar do Ribeirão Borá, Potirendaba, Estado de São Paulo, Brasil. Revista del Jardin Botánico Nacional 22 (1): 85-91.

Morais, R.F. (2016) Estrutura, composição e riqueza da comunidade arbórea e relações com variáveis edáficas e topográficas na Floresta Pluvial Atlântica no Parque Estadual da Serra do Mar, São Paulo, Brasil. Tese (Doutorado). Universidade Estadual Paulista, Rio Claro. $125 \mathrm{p}$

Nave, A.G. 1999. Determinação de unidades ecológicas num fragmento de floresta nativa, com auxílio de sensoriamento remoto. Tese (Doutorado). ESALQ, Universidade de São Paulo, Piracicaba. 167p.

Nettesheim, F.C.; Menezes, L.F.T.D.; Carvalho, D.C.D.; Conde, M.M.S.; Sommer, G.V.; Rodrigues, G.D.A. \& Araujo, D.S.D.D. (2012). Tree and shrub species of the Atlantic Forest on the slopes of Marambaia Island, Rio de Janeiro, Brazil. Biota Neotropica, 12(3): 213-225.

Nicolini-gabriel, E.M. (1997) Florística e fitossociologia do estrato arbóreo em áreas de ocorrência de floresta mesófila semidecídua em diferentes estágios sucessionais no município de Bofete, SP. Tese (Doutorado). Universidade Estadual Paulista, Rio Claro, 184p.

Ogata, H. \& Gomes, E.P.C. (2006). Estrutura e composição da vegetação no Parque CEMUCAM, Cotia, SP. Hoehnea 33 (3): 371-384.

Oliveira-filho, A.T.; Curi, N.; Vilela, E.A. \& Carvalho, D.A. (1997) Tree species distribution along soil catenas in a riverside semideciduous forest in Southeastern Brazil. Flora 192 (1): 47-64

Oliveira, A.A.; Vicentini, A.; Chave, J.; Castanho, C.T.; Davies, S.J; Martini, A.M.Z.; Lima, R.A.F.; Ribeiro, R. R.; Iribar, A. \& Souza, V.C. (2014) Habitat specialization and phylogenetic structure of tree species in a coastal Brazilian white-sand forest. Journal of Plant Ecology, doi:10.1093/jpe/rtt073.

Oliveira, R.J.; Mantovani, W. \& Melo, M.M.R.F. 2001. Estrutura do componente arbustivo-arbóreo da floresta atlântica de encosta, Peruíbe, SP. Acta Botanica Brasilica 15 (3): 391-412

Oliveira, R.R. (2002) Ação antrópica e resultantes sobre a estrutura e composição da Mata Atlântica na Ilha Grande, RJ. Rodriguésia 53(82): 33-58

Padgurschi, M.C.G.; Pereira, L.P.; Tamashiro, J.Y. \& Joly, C.A. (2011) Composição e similaridade florística entre duas áreas de Floresta Atlântica Montana, São Paulo, Brasil. Biota Neotropica 11 (2): 139-152.

Pansonato, M. et al. Unpublished data

Paschoal, M.G.S. \& Cavassan, O. (1999) A flora arbórea de mata de brejo do ribeirão do Pelintra, Agudos - SP. Naturalia 24: 171-191

Passos, M.J. (1998) Estrutura da vegetação arbórea e regeneração natural em remanescentes de mata ciliar do Rio Mogi Guaçú-SP. 1998. Dissertação de 
mestrado. Escola Superior de Agricultura Luiz de Queiroz da Universidade de São Paulo. Piracicaba, 66p.

Pellico-netto, S. \& Coraiola, M. (2003) Análise da estrutura horizontal de uma Floresta Estacional Semidecidual localizada no município de Cássia - MG. Revista Acadêmica: Ciências Agrárias e Ambientais 1 (2): 11-20

Phillips, O. \& Miller, J.S. (2002) Global patterns of plant diversity: Alwyn H. Gentry's Forest Transect Data Set. Monographs in systematic botany from the Missouri Botanical Garden.Missouri Botanical Garden Press. St. Louis, MO (89). $319 \mathrm{p}$

Pinheiro, E.S. \& Durigan, G. (2012) Diferenças florísticas e estruturais entre fitofisionomias do cerrado em Assis, SP, Brasil. Revista Árvore 36 (1): 181193

Pinheiro, M.H.O. \& Monteiro, R. (2009). Structural analysis and considerations on the successional dynamic of two semideciduous forest fragments at the Municipal Botanical Garden of Bauru, SP, Brazil. Acta Botanica Brasilica, 23 (4): 968-975.

Pinheiro, M.H.O. (2006). Composição e estrutura de uma comunidade savânica em gradiente topográfico no município de Corumbataí (SP, Brasil). Tese (Doutorado). Universidade Estadual Paulista "Júlio de Mesquita Filho", Rio Claro. 119p.

Pinto, M.M. (1989). Levantamento fitossociológico de uma mata residual: campus de Jaboticabal da UNESP. Dissertação (Mestrado). Universidade Estadual Paulista Júlio de Mesquita Filho, Jaboticabal. 67p.

Pinto, M.M. (1998). Fitossociologia e influência de fatores edáficos na estrutura da vegetação em áreas de Mata Atlântica na Ilha do Cardoso, Cananéia, SP.Tese (Doutorado). Universidade Estadual Paulista, Jaboticabal.113 p.

Pompeu, P. V., Fontes, M. A. L., Dos Santos, R. M., Garcia, P. O., Batista, T. A., Carvalho, W. A. C., \& De Oliveira, A. T. (2014)Floristic composition and structure of an upper montane cloud forest in the Serra da Mantiqueira Mountain Range of Brazil. Acta Botanica Brasilica, 28(3): 456-464.

Pompeu, P.V.(2011) Composição e estrutura de uma floresta ombrófila densa ao longo de um gradiente altitudinal na serra da Mantiqueira, Minas Gerais. Dissertação (Mestrado). Universidade Federal de Lavras, Lavras. 105p.

Prata, E.M.B.; Assis, M.A. \& Joly, C.A. (2011) Composição florística e estrutura da comunidade arbórea na transição da Floresta Ombrófila Densa das Terras Baixas - Floresta Ombrófila Densa Submontana do Núcleo Picinguaba/PESM, Ubatuba, sudeste do Brasil. Biota Neotropica 11 (2): 285-299.

Prata, E.M.B.; Pinto, S.A.F \& Assis, M.A. 2011. Fitossociologia e distribuição de espécies arbóreas em uma floresta ribeirinha secundária no Município de Rio Claro, SP, Brasil. Revista Brasil de Botânica 34 (2): 159-168.

Ramos-neto, M.B. 1993. Análise florística e estrutural de duas florestas sobre a restinga, Iguape, São Paulo. Dissertação (Mestrado). Universidade de São Paulo, São Paulo. 129p.

Ramos, E.; Torres, R.B.; Veiga, R.F.A. \& Joly, C.A. Study of the arboreal component in two areas of the Submontane Rainforest in Ubatuba, São Paulo State. Biota Neotropica 11(2): 313-335.

Ranga, N.T.; Rezende, A.a.; Cavassan, O.; Toniato, M.t.z.; Cielo-filho, R. \& Stranghetti, V. (2011). Caracterização florística de remanescentes de vegetação nativa da região noroeste do estado de São Paulo. In: NECCHI JR., 
O. (ed.) Fauna e flora de fragmentos florestais remanescentes da região noroeste do estado de São Paulo. FAPESP, São Paulo, SP, Brasil. pp. 105-136

Reis-duarte, R.M. (2004) Estrutura da floresta de restinga do Parque Estadual da Ilha Anchieta (SP): bases para promover o enriquecimento com espécies arbóreas nativas em solos alterados. Tese (Doutorado). Universidade Estadual Paulista Júlio de Mesquita Filho. Rio Claro. SP. 257p.

Renó, I.P. (2015) Dinâmica temporal e composição florística da comunidade arbórea de floresta ombrófila densa montana, Parque Estadual da Serra do Mar, SP, Brasil. Dissertação (Mestrado). Universidade Estadual Paulista, Rio Claro. 118 p.

Rissi, M. N. (2011) Regeneração natural de um fragmento de cerrado degradado com a formação de pastagens de braquiária (Urochloa decumbens (Stapf) R. D. Webster).. 164 f. Dissertação (mestrado) - Universidade Estadual Paulista, Instituto de Biociências de Botucatu, 2011. Available at: <http://hdl.handle.net/11449/95078>.

Rocha, F.T. 2003. Levantamento florestal na Estação Ecológica dos Caetetus como subsídio para laudos de desapropriação ambiental. 156f. Dissertação (Mestrado em Ciências Florestais) - Escola Superior de Agricultural" Luiz de Queirozl", Piracicaba.

Rochelle, A.L.C.; Cielo-filho, R.; Martins, F.R. (2011) Tree community structure in an Atlantic forest fragment at Serra do Mar State Park, southeastern Brazil. Biota Neotropica 11 (2): 337-346.

Rodrigues, L.N. (1998) Estudo de três estágios sucessionais em florestas de encosta íngreme, na cuesta de São Pedro. Dissertação (Mestrado). ESALQ/USP, Piracicaba. 87p.

Rodrigues, R.R.; Gandolfi, S. \& Souza, V.C. (2006). Diversidade, dinâmica e conservação em florestas do estado de São Paulo: 40,96ha de parcelas permanentes. Universidade de São Paulo, Piracicaba, Brazil, 68p.

Roizman, L.G. 1993. Fitossociologia e dinâmica do banco de sementes de populações arbóreas de floresta secundária em São Paulo, SP. Dissertação (Mestrado). Universidade de São Paulo, USP, SP. 184p.

Rolim, S.G., Cunha, G.c. \& Barreto, K.D. (2000) Fitossociologia de um trecho de floresta ripária do rio Sarapuí na região de sorocaba (SP). In: Anais do $5 o$ Simpósio de Ecossistemas Brasileiros: Conservação, Vitória, vol.3, pp. 334335.

Romagnolo, M.B. \& Souza, M.C. (2000)Análise florística e estrutural de florestas ripárias do alto rio Paraná, Taquaruçu, MS. Acta Botanica Brasilica 14 (2): 163-174.

Rosa, L.P.G. (2013). Florística e fitossociologia da Floresta Atlântica montana no Parque Estadual da Ilha Grande, RJ. Dissertação (Mestrado). Universidade do Estado do Rio de Janeiro. 76p

Rosa, T.H.O. (2011) Composição florística e Fitossociológica de três Fragmentos de floresta Ribeirinha em Ajapi, Rio claro. SP. Universidade Estadual Paulista Júlio de Mesquita Filho. Rio Claro. SP. 76p

Rozza, A.F. (2003). Manejo e regeneração de trecho degradado de floresta estacional semidecidual: Reserva Municipal de Santa Genebra, Campinas, SP. Tese (Doutorado). Universidade de Campinas, Campinas. 140p.

Sanchez, M. (2001) Composição florística e estrutura da comunidade arbórea num gradiente altitudinal da Mata Atlântica. Tese (Doutorado). Universidade Estadual de Campinas, Campinas. 147p. 
Santana, G.C. (2010) Estrutura de uma floresta ombrófila densa montana com monodominância de dossel por Eremanthus erythropappus (DC.) Macleish (candeia) na serra da Mantiqueira, em Itamonte, Minas Gerais. Dissertação (Mestrado). Universidade Federal de Lavras, Lavras. 58p.

Santos Carvalho, L., Cerqueira, R. M., da Silva, G. V., \& Silva, E. R. M. (2015). Estoque de carbono em um fragmento de floresta estacional semidecídua no município de Ribeirão Grande, São Paulo. Bioikos-ISSN 2318-0900, 28(2).

Sartori, R.A.; Carvalho, D.A.; Van Den Berg, E.; Marques, J.J.G.S.M. \& Santos, R.M. (2015) Variações florísticas e estruturais do componente arbóreo de uma floresta estacional semidecidual montana em Socorro, SP. Rodriguésia 66(1): 33-49.

Scheer, M.B.; Mocochinski, A.Y. \& Roderjan, C.V. (2011). Estrutura arbórea da Floresta Ombrófila Densa Altomontana de serras do sul do Brasil. Acta Botanica Brasilica 25 (4): 735-750.

Scolforo, J.R.; Mello, J.M.; Silva, C.P. de C. (2008) Inventário Florestal de Minas Gerais: Floresta Estacional Semidecidual e Ombrófila - Florística, Estrutura, Diversidade, Similaridade, Distribuição Diamétrica e de Altura, Volumetria, Tendências de Crescimento e Áreas aptas para o Manejo Florestal. Lavras, p. $1-1007$.

Silva, A.A.F. (2004) Caracterização Florística e Fitossociológica dos Remanescentes de Floresta Ribeirinha do Rio Tietê no Município de Mogi das Cruzes, SP. Relatório de Iniciação Científica. Universidade de Mogi das Cruzes, Mogi das Cruzes. 37p.

Silva, A.F. (1989) Composição florística e estrutura fitossociológica do estrato arbóreo da Reserva Florestal Professor Augusto Ruschi, São José dos Campos, SP. Tese (Doutorado). Universidade Estadual de Campinas, Campinas. 148 p

Silva, C.R. (2006)Fitossociologia e avaliação da chuva de sementes em uma área de floresta alta de restinga, em Ilha Comprida SP. Dissertação (Mestrado). Instituto de Botânica, São Paulo. 96p.

Silva, L.Á. \& Soares, J.J. (2002). Levantamento fitossociológico em um fragmento de Floresta Estacional Semidecídua, no município de São Carlos, SP. Acta Botanica Brasilica 16 (2): 205-216.

Soares-Filho, Avaldo de Oliveira.(2012) Fitogeografia e estrutura das Florestas Estacionais Decíduas No Brasil' 01/08/2012 346 F. Doutorado Em Botânica Instituição De Ensino: Universidade Estadual De Feira De Santana, Feira De Santana Biblioteca Depositária: Biblioteca Central Julieta Carteado

Soares, M.S.; Soares, J.J. \& Lima, M.I.S. (2005) Florística e fitossociologia de mata estacional semidecidual denominada I"Serra d'Águál" em Araras - SP. In: Anais do 56o Congresso Nacional de Botânica. Curitiba, p. 247.

Souza, A.C.O. (2013) Fatores abióticos influenciando a vegetação em Floresta Ombrófila Densa Montana, Parque Estadual da Serra do Mar (Ubatuba - SP, Brasil). IAC, Campinas. $92 \mathrm{p}$.

Souza, R.P.M. (2008) Estrutura da comunidade arbórea de trechos de florestas de Araucária no estado de São Paulo, Brasil. Dissertação (Mestrado). ESALQ/USP, Piracicaba. 101p.

Souza, R.P.M.; Souza, V.C.; Polisel, R.T. \& Ivanauskas, N.M. (2012) Estrutura e aspectos da regeneração natural de Floresta Ombrófila Mista no Parque Estadual de Campos do Jordão, SP, Brasil. Hoehnea 39 (3): 387-407

Stefani, E.J.F. (2013) Estrutura, composição florística e similaridade em áreas de floresta ombrófila densa submontana e montana do Parque Estadual da Serra 
do Mar, Litoral Norte/SP. Dissertação (Mestrado). Universidade Estadual de Campinas, Campinas. 93p

Sugiyama, M. (1998) Estudo de florestas da restinga da Ilha do Cardoso, Cananéia, São Paulo, Brasil. Boletim do Instituto de Botânica 11: 119-159

Sugiyama, M. (2003). Estudos florísticos e fitossociológicos em comunidades vegetais de restinga da Ilha do Cardoso, Cananéia, SP. Tese (Doutorado). Universidade Federal de São Carlos, São Carlos. 141p.

Sztutman, M. \& Rodrigues, R.R. (2002) O mosaico vegetacional numa área de floresta contínua da planície litorânea, Parque Estadual da Campina do Encantado, Pariquera-Açu, SP. Revista Brasileira de Botânica 25 (2): 161176.

Tabanez, A.A.J. (2008) Dinâmica da comunidade arbórea em eco-unidades de cinco fragmentos de Floresta Estacional Semidecídua no interior do Estado de São Paulo, Brasil, e conseqüências para a sua conservação. Tese (Doutorado). Instituto de Botânica, São Paulo. 111p.

Teixeira, A.P. \& Assis, M.A. (2005) Caracterização florística e fitossociológica do componente arbustivo-arbóreo de uma floresta paludosa no município de Rio Claro (SP), Brasil. Revista Brasileira de Botânica 28 (3): 467-476.

Teixeira, A.P. \& Assis, M.A. 2009. Relação entre heterogeneidade ambiental e distribuição de espécies em uma floresta paludosa no Município de Cristais Paulista, SP, Brasil. Acta Botanica Brasilica 23 (4): 843-853.

Teixeira, A.P.; Assis, M.A.; Siqueira, F.r. \& Casagrande, J.C. (2008) Tree species composition and environmental relationships in a Neotropical swamp forest in Southeastern Brazil. Wetlands Ecology and Management 16 (6): 451-461.

Tiepolo, G., Calmon, M., Feretti, A.R., 2002. Measuring and Monitoring Carbon Stocks at the Guaraqueçaba Climate Action Project, Paraná, Brazil. In, International Symposium on Forest Carbon Sequestration and Monitoring. Taiwan Forestry Research Institute, Taiwan, pp. 98-115

Toledo-filho, D.V. (1984) Composição florística e estrutura fitossociológica da vegetação do Município de Luis Antônio (SP).. Tese (Doutorado). Tese de doutoramento. Universidade de Campinas, Campinas. 173 pp.

Toledo-filho, D.V.; Bertoni, J.E.A.; Batista, E.A. \& Parente, P.R. (2000) Fitossociologia de um fragmento florestal à margem do Rio do Peixe, município de Lindóia (SP). Revista do Instituto Florestal 12 (1): 37-45.

Toledo-filho, D.V.; Leitão-filho, H.F. \& Shepherd, G.J. (1989) Estrutura fitossociológica da vegetação de cerrado em Mogi-Mirim (SP). Revista do Instituto Florestal 1(2): 1-11.

Toledo Filho, D.V.; Batista, E.a.; Buzatto, O. \& Couto, H.T.Z. (2002) Estudo fitossociológico em uma área de cerrado com transição para mata no município de Casa Branca - SP. Revista do Instituto florestal 14(1): 53-64.

Tomasetto, F. (2003) Composição florística e estrutura do componente arbóreo de um trecho de floresta estacional semidecidual na Estação Ecológica de Paulo de Faria - SP. Dissertação (Mestrado). Universidade Estadual Paulista, Rio Claro. $133 \mathrm{p}$

Toniato, M.T.Z.; Leitão-filho, H.D.F. \& Rodrigues, R.R. (1998) Fitossociologia de um remanescente de floresta higrófila (mata de brejo) em Campinas, SP. Brazilian Journal of Botany, 21 (2): 197-210.

Toppa, R.H. (2004) Estrutura e diversidade florística das diferentes fisionomias de cerrado e suas correlações com o solo na Estação Ecológica de Jataí, Luiz 
Antônio, SP. Tese (Doutorado). Universidade Federal de São Carlos, São Carlos, SP.127p.

Uhlmann A, (2003). Análise estrutural de duas áreas de vegetação savânica (cerrado) sob influência de gradientes ambientais complexos. Tese de Doutorado. Campinas: PPG Biologia Vegetal. Universidade Estadual de Campinas.

Uhlmann, A.; Galvão, F.; Menezes-silva, S. (1998) Análise da estrutura de duas unidades fitofisionômicas de savana (cerrado) no sul do Brasil. Acta Botanica Brasilica 12 (3): 231-247.

Morais, R. F. D. (2016). Estrutura, composição e riqueza da comunidade arbórea e relações com variáveis edáficas e topográficas na Floresta Pluvial Atlântica no Parque Estadual da Serra do Mar, São Paulo, Brasil.

Urbanetz, C. (2010) Fatores abióticos e variação espacial na estrutura da Floresta Ombrófila Densa Atlântica. Tese (Doutorado). Universidade de Campinas, Campinas. 114p.

Vanini, A. (1999) Estudo comparativo de dois métodos de amostragem fitossociológica em Caxetais (floresta ombrófila densa permanentemente alagada). Dissertação (Mestrado). ESALQ, Piracicaba, SP. 120p.

Vieira, M.G.I.; Moraes, J.L.; Bertoni, J.E.A.; Martins, F.R. \& Zandarin, M.A. (1989). Composição florística e estrutura fitossociológica da vegetação arbórea do Parque Estadual de Vaçununga, Santa Rita do Passa Quatro (SP). II-Gleba Capetinga Oeste. Revista do Instituto Florestal 1(1): 135-159.

Vincent, R.C. (1997) Florística, estrutura e sucessão de matas ripárias em Cosmópolis (SP). Dissertação (Mestrado). Universidade de São Paulo, São Paulo. 146p.

Wakabayashi, T.Y. (2015) Composição florística, estrutura fitossociológica e caracterização sucessional de três fragmentos florestais, na Estância Turística de Itu-SP, Brasil. Dissertação (Mestrado). Universidade Federal de São Carlos, Sorocaba. 74 p.

Yamamoto, L. F. (2009) Florística e fitossociologia de espécies arbóreas ao longo de um gradiente altitudinal no extremo sul da Mantiqueira (Serra do Lopo) MG/SP. Tese (Doutorado). Universidade de Campinas, Campinas. 169p.

Zacarias, R.R.; Britez, R.M.; Galvão F.; Boeger, M.R.T. (2012). Phytosociology analysis of two sites in the Dense Alluvial Ombrophilous Forest with hydromorphic soils, Paraná, Brazil. Floresta 42(4):769-782 


\section{Appendix 7: List of $\mathbf{R}$ packages used}

\section{AICcmodavg}

Marc J. Mazerolle (2017) AICcmodavg: Model selection and multimodel inference based on Q)AIC(c). R package version 2.1-1. https://cran.rproject.org/package=AICcmodavg.

automap

Hiemstra, P.H., Pebesma, E.J., Twenhofel, C.J.W. and G.B.M. Heuvelink, 2008. Real-time automatic interpolation of ambient gamma dose rates from the Dutch Radioactivity Monitoring Network. Computers \& Geosciences, accepted for publication.

bbmle

Ben Bolker and R Development Core Team (2017). bbmle: Tools for General Maximum Likelihood Estimation. R package version 1.0.20. https://CRAN.RclassInt project.org/package=bbmle

Roger Bivand (2018). classInt: Choose Univariate Class Intervals. R package version doParallel

0.2-3. https://CRAN.R-project.org/package=classInt

Microsoft Corporation and Steve Weston (2017). doParallel: Foreach Parallel Adaptor for the 'parallel' Package. R package version 1.0.11. https://CRAN.RdoSNOW project.org/package $=$ doParallel

Microsoft Corporation and Stephen Weston (2017). doSNOW: Foreach Parallel Adaptor for the 'snow' Package. R package version 1.0.16.https://CRAN.Rproject.org/package $=$ doSNOW

dplyr

Hadley Wickham, Romain François, Lionel Henry and Kirill Müller (2018). dplyr: A Grammar of Data Manipulation. R package version 0.7.6. https://CRAN.RFNN project.org/package $=$ dplyr

Alina Beygelzimer, Sham Kakadet, John Langford, Sunil Arya, David Mount and Shengqiao Li (2018). FNN: Fast Nearest Neighbor Search Algorithms and Applications. R package version 1.1.2.1. https://CRAN.R-

foreach project.org/package $=\mathrm{FNN}$

Microsoft and Steve Weston (2017). foreach: Provides Foreach Looping Construct for

R. R package version 1.4.4. https://CRAN.R-project.org/package=foreach gdalUtils

Jonathan Asher Greenberg and Matteo Mattiuzzi (2018). gdalUtils: Wrappers for the

Geospatial Data Abstraction Library (GDAL) Utilities. R package version 2.0.1.14. https://CRAN.R-project.org/package=gdalUtils

gdata

Gregory R. Warnes, Ben Bolker, Gregor Gorjanc, Gabor Grothendieck, Ales Korosec, Thomas Lumley, Don MacQueen, Arni Magnusson, Jim Rogers and others (2017). gdata: Various R Programming Tools for Data Manipulation. R package version 2.18.0. https://CRAN.R-project.org/package=gdata 
geosphere

Robert J. Hijmans (2017). geosphere: Spherical Trigonometry. R package version 1.5-

7. https://CRAN.R-project.org/package=geosphere

gstat

Pebesma, E.J., 2004. Multivariable geostatistics in S: the gstat package. Computers \& Geosciences, 30: 683-691.

igraph

Csardi G, Nepusz T: The igraph software package for complex network research, InterJournal, Complex Systems 1695. 2006. http://igraph.org

lme4

Douglas Bates, Martin Maechler, Ben Bolker, Steve Walker (2015). Fitting Linear

Mixed-Effects Models Using lme4. Journal of Statistical Software, 67(1), 1-

lmerTest

48. doi:10.18637/jss.v067.i01.

Kuznetsova A, Brockhoff PB, Christensen RHB (2017). "lmerTest Package: Tests in

Linear Mixed Effects Models.”_Journal of Statistical Software_, *82*(13), 1-

26. doi:10.18637/jss.v082.i13 (URL: http://doi.org/10.18637/jss.v082.i13).

maptools

Roger Bivand and Nicholas Lewin-Koh (2018). maptools: Tools for Reading and

Handling Spatial Objects. R package version 0.9-3. https://CRAN.R-

nlme

project.org/package $=$ maptools

Pinheiro J, Bates D, DebRoy S, Sarkar D, R Core Team (2018)._nlme: Linear and

Nonlinear Mixed Effects Models_. R package version 3.1-137,

<URL:https://CRAN.R-project.org/package=nlme>.

perturb

John Hendrickx (2012). perturb: Tools for evaluating collinearity. R package version

2.05. https://CRAN.R-project.org/package=perturb

piecewiseSEM

Lefcheck, Jonathan S. (2016) piecewiseSEM: Piecewise structural equation modeling in R Ofor ecology, evolution, and systematics. Methods in Ecology and

Evolution. 7(5): 573-579. DOI: 10.1111/2041-210X.12512

plyr

Hadley Wickham (2011). The Split-Apply-Combine Strategy for Data Analysis.

Journal of Statistical Software, 40(1), 1-29. URL

http://www.jstatsoft.org/v40/i01/.

prettymapr

Dewey Dunnington (2017). prettymapr: Scale Bar, North Arrow, and Pretty Margins

in $\mathrm{R}$. $\mathrm{R}$ package version 0.2.2. https://CRAN.R-

r2glmm

project.org/package=prettymapr

Byron Jaeger (2017). r2glmm: Computes R Squared for Mixed (Multilevel) Models. RANN

$\mathrm{R}$ package version 0.1.2. https://CRAN.R-project.org/package $=\mathrm{r} 2 \mathrm{glmm}$

Sunil Arya, David Mount, Samuel E. Kemp and Gregory Jefferis (2018). RANN: Fast Nearest Neighbour Search (Wraps ANN Library) Using L2 Metric. R package version 2.6. https://CRAN.R-project.org/package=RANN

raster

Robert J. Hijmans (2017). raster: Geographic Data Analysis and Modeling. R package version 2.6-7. https://CRAN.R-project.org/package=raster 
RColorBrewer

Erich Neuwirth (2014). RColorBrewer: ColorBrewer Palettes. R package version 1.12. https://CRAN.R-project.org/package=RColorBrewer

rgdal

Roger Bivand, Tim Keitt and Barry Rowlingson (2018). rgdal: Bindings for the

'Geospatial' Data Abstraction Library. R package version 1.3-4.

https://CRAN.R-project.org/package=rgdal

rgeos

Roger Bivand and Colin Rundel (2018). rgeos: Interface to Geometry Engine - Open

Source('GEOS'). R package version 0.3-28. https://CRAN.R-

rlang

project.org/package $=$ rgeos

Lionel Henry and Hadley Wickham (2018). rlang: Functions for Base Types and Core $\mathrm{R}$ and 'Tidyverse' Features. R package version 0.2.2. https://CRAN.R-

soiltexture

project.org/package $=$ rlang

Julien Moeys (2018). soiltexture: Functions for Soil Texture Plot, Classification and Transformation. R package version 1.4.6. https://CRAN.Rproject.org/package $=$ soiltexture

$s p$

Pebesma, E.J., R.S. Bivand, 2005. Classes and methods for spatial data in R. R News 5 (2), https://cran.r-project.org/doc/Rnews/.

spgwr

Roger S. Bivand, Edzer Pebesma, Virgilio Gomez-Rubio, 2013. Applied spatial data analysis with R, Second edition. Springer, NY. http://www.asdar-book.org/

Roger Bivand and Danlin Yu (2017). spgwr: Geographically Weighted Regression. R stringr package version 0.6-32. https://CRAN.R-project.org/package=spgwr

Hadley Wickham (2018). stringr: Simple, Consistent Wrappers for Common String Operations. R package version 1.3.1. https://CRAN.Rproject.org/package=stringr 